$\mathrm{PhD}$ Thesis

\title{
Inhibition of specific histone deacetylases suppresses pathogenesis in a Drosophila model of Huntington's disease
}

\author{
Judit Pallos
}

Supervisor: Prof. J. Lawrence Marsh

Department of Developmental and Cell Biology

University of California, Irvine

Irvine, CA, USA 


\section{CONTENTS}

ABBREVIATIONS 4

$\begin{array}{ll}\text { INTRODUCTION } & 7\end{array}$

The Signs and Symptoms of Huntington's Disease $\quad 7$

The Genetics of Huntington's Disease $\quad 8$

Huntingtin Function $\quad 9$

$\begin{array}{lr}\text { Aggregation in HD } & 12\end{array}$

$\begin{array}{ll}\text { Cleavage and Clearance of Huntingtin } & 13\end{array}$

Transcriptional Dysregulation in HD 15

$\begin{array}{ll}\text { Animal Models of HD } & 18\end{array}$

$\begin{array}{ll}\text { AIMS } & 23\end{array}$

MATERIALS AND METHODS 24

$\begin{array}{ll}\text { Drosophila Stocks and Crosses } & 24\end{array}$

$\begin{array}{ll}\text { Media and Chemicals } & 25\end{array}$

Generation of HDAC Transgenics $\quad 26$

$\begin{array}{ll}\text { Drosophila Assays } & 27\end{array}$

$\begin{array}{ll}\text { Western analysis } & 30\end{array}$

RNA detection using quantitative real time PCR 30

$\begin{array}{ll}\text { Statistical analysis } & 31\end{array}$

RESULTS 
HDAC Inhibitors Reduce Degeneration in Httex 1p Q93 Flies

Histone deacetylase inhibitors reduce the neuronal cell loss of Httex 1p Q93 flies with no effect on eclosion rate 33

Butyrate treatment improves motor function of Httexlp Q93 flies 35

Butyrate reduces pigment cell loss in gmr>Httex1p Q93 flies 37

$\begin{array}{ll}\text { Summary } & 38\end{array}$

Modulating Specific HDACs as a Therapeutic Strategy 39

Generation and characterization of HDAC mutants 39

Selected HDAC mutants have impact on Httex1p Q93 induced pathology 42

Sirtuin inhibitor feeding reproduces the protective effect seen with loss of function $\begin{array}{ll}\text { mutations } & 44\end{array}$

Combinatorial reduction of HDAC activities $\quad 46$

$\begin{array}{ll}\text { Summary } & 48\end{array}$

The Mechanism of Deacetylase Action $\quad 49$

$\begin{array}{ll}\text { Rpd3 does not regulate Sir2 levels } & 49\end{array}$

Effects of deacetylase levels on life span $\quad 50$

Sir2 improves sleep anomalies seen in HD expressing flies 52

Butyrate treatment has no effect on inclusion body formation 56

Butyrate treatment corrects hypoacetylation of H3K27 in Httex1p Q93 flies 58

Transcriptional dysregulation of Httex 1p Q93 flies is corrected by HDAC mutants 59

$\begin{array}{ll}\text { Summary } & 63\end{array}$

$\begin{array}{ll}\text { DISCUSSION } & 64\end{array}$

$\begin{array}{ll}\text { SUMMARY } & 71\end{array}$

$\begin{array}{ll}\text { ACKNOWLEDGEMENTS } & 74\end{array}$

$\begin{array}{ll}\text { REFERENCES } & 75\end{array}$ 


\section{AbBreviations}

3-NP 3-Nitropropionic acid

AMP-kinase Adenosine 5'-monophosphate (AMP) activated protein kinase

ANOVA Analysis of variance

BDNF Brain-derived neurotrophic factor

C. elegans Caenorhabditis elegans

CAG Cytosine, Adenine, Guanine

CBP CREB binding protein

CREB Cyclic AMP-responsive element-binding protein

DAPI 4',6-diamidino-2-phenylindole

Def Defensin

Dpt Diptericin

DMSO Dimethyl sulfoxide

elav Embryonic lethal abnormal vision

ERG Ets (E twenty six) related gene

ERK Extracellular signal regulated kinase

ESET ERG-associated protein with SET domain

GAPDH Glyceraldehyde-3-phosphate dehydrogenase

GFP Green fluorescent protein

GS GeneSwitch

H3K9/14/27 Histone 3, lysine 9/14/27

HAP1 Huntingtin-associated protein 1

HAT Histone acetyltransferase

HD Huntington's disease

HDAC Histone deacetylase

HEAT Huntingtin, Elongation factor 3, and Target of rapamycin

HIP1 Huntingtin interacting protein 1

HIP2 Huntingtin interacting protein 2

HMGCS1 3-hydroxy-3-methylglutaryl coenzyme A synthase 1 (human)

Hmgs $\quad$ HMG Coenzyme A synthase (fly)

HP1 Heterochromatin protein 1 
hPRC1L Human polycomb repressive complex 1-like

HRP Horseradish peroxidase

hsp70Bc Heat shock protein $70 \mathrm{kDa} \mathrm{Bc}$

Htt Huntingtin

Httex1p Q93 Huntingtin exon 1 protein with 93 glutamines

HYPB Huntingtin yeast partner B

IT15 Important transcript 15

IкB Inhibitor of kappa B

LIM Lin11, Isl-1, Mec-3 domain

MAPK Mitogen-activated protein kinase

MSK1 Mitogen and stress activated protein kinase 1

Mtk Metchnikowin

mTOR Mammalian target of rapamycin

N-CoR Nuclear receptor corepressor 1

NF- $\kappa$ B Nuclear factor kappa-light-chain-enhancer of activated B cells

p300 Protein 300 (E1A-associated protein p300)

PACSIN-1 Protein kinase $\mathrm{C}$ and casein kinase substrate in neurons 1

PBS Phosphate buffered saline

PBT PBS with $0.1 \%$ Tween-20

PCAF P300/CBP-associated factor

polyQ polyglutamine

PRC2 Polycomb repressive complex 2

PSD95 Postsynaptic density 95

PVDF Polyvinylidene fluoride

qPCR Quantitative (real time) polymerase chain reaction

RE1 Repressor element-1

Rel Relish

REST/NRSF RE1-silencing transcription factor/ Neural-restrictive silencer factor

RILP REST-interacting LIM domain protein

RNAi RNA interference

ROCK Rho-associated protein kinase

rp49 Ribosomal protein 49 (60S Ribosomal protein L32)

Rpd3 Reduced potassium dependency 3

RT-PCR Reverse transcription polymerase chain reaction 


$\begin{array}{ll}\text { SAGA } & \text { Spt-Ada-Gcn5-acetyltransferase } \\ \text { SAHA } & \text { Suberoylanilide hydroxamic acid } \\ \text { SET } & \text { Suppressor of variegation 3-9, Enhancer of zeste, trithorax } \\ \text { SETDB1 } & \text { SET domain bifurcated 1 } \\ \text { SETD2 } & \text { SET domain containing protein } 2 \\ \text { Sir2 } & \text { Silent information regulator 2 } \\ \text { SIRT } & \text { SIR2-like protein (sirtuin) } \\ \text { Sp1 } & \text { Specificity protein 1 } \\ \text { TAFII130 } & \text { TBP-associated factor TFIID 130 kDa subunit (TAF4) } \\ \text { TBP } & \text { TATA box binding protein } \\ \text { TBST } & \text { Tris-buffered saline with Tween } \\ \text { Tip60 } & \text { Tat-interactive protein } 60 \\ \text { TPR } & \text { Translocated promoter region } \\ \text { trpl } & \text { Transient receptor potential like } \\ \text { UAS } & \text { Upstream activating sequence } \\ \text { UPS } & \text { Ubiquitin proteasome system } \\ \text { UTR } & \text { Untranslated region }\end{array}$




\section{INTRODUCTION}

\section{The Signs and Symptoms of Huntington's Disease}

Huntington's disease (HD) is a dominantly inherited neurodegenerative disease, first described in 1872 by a young physician called George Huntington [Huntington, 1872]. The prevalence of HD is about 4-8 persons in 100,000 [Harper, 1992] - with the lowest frequencies found in China, Japan and Africa, and the highest in Europe (with Finland being a notable exception) and countries of European origin [Kumar et al., 2010]. The pathological process affects primarily the striatum [Vonsattel et al., 1985], extending to the frontal and temporal lobes of the cerebral cortex as the disease progresses [Rosas et al., 2003], resulting in a progressive movement disorder as well as cognitive and psychological impairments. By the time of death, about half of the striatum and up to a quarter of the cortical grey matter may be atrophied [Lange et al., 1976; Halliday et al., 1998].

The movement disorder aspect of the disease is characterized by involuntary movements that can affect any part of the body and are typically (at least initially) disguised by the patient as a part of a purposeful activity. The motor disturbances, which start with clumsiness, slight uncontrolled movements and loss of voluntary movement coordination, progress slowly, until they interfere with the patient's ability to walk, eat or sleep. In late stages of the disease, choreic movements are often replaced by a complete hindrance of voluntary movements (Parkinsonism) [Gil and Rego, 2008].

The major factor in HD patients' functional decline is the loss of cognitive abilities: attention, concentration, executive functioning (e.g. planning, problem solving or the ability to maintain initiated voluntary movements), as well as visuospatial abilities, emotional processing and memory [Montoya et al., 2006]. The disease also often ends in dementia, although language and memory functions are typically better preserved compared to other dementias, such as Alzheimer's [Hodges et al., 1990].

Psychiatric impairments include apathy, anxiety, depression, paranoia and schizophrenia [Shiwach et al., 1994; Caine and Shoulson, 1983; Cummings, 1995], all of which contribute to the high suicide rate of Huntington's patients, making suicide one of 
the leading causes of death in HD (after aspiration pneumonia and heart disease) [Chiu and Alexander, 1982; Farrer, 1986].

Other clinical manifestations of the disease include weight loss, presumably due to hypermetabolic state [Pratley et al., 2000; Mochel et al., 2007], high frequency of diabetes [Farrer, 1985], endocrine abnormalities [Leblhuber et al., 1995; Markianos et al., 2005], and sleep disturbances, including insomnia, altered circadian rhythms and increased activity during sleep [Taylor et al., 1997; Morton et al., 2005].

\section{The Genetics of Huntington's Disease}

Huntington's disease is monogenetic: the IT15 (important transcript 15, or Huntingtin, Htt) gene is located on chromosome arm $4 \mathrm{p} 16.3$, and the mutation that causes the disease is the expansion of a polymorphic CAG repeat in the first exon of the gene [Huntington's Disease Collaborative Research Group, 1993]. While normal versions of the gene contain fewer that 35 CAG repeats (median, 18), a repeat number between 40-121 (median, 44) invariably results in HD (the 35-39 "intermediate alleles" result in very late onset disease with patients often dying before the symptoms manifest) [Kumar et al., 2010]. The length of the pathogenic CAG repeat sequence is inversely correlated with the age of disease onset [Stine et al., 1993; Kremer et al., 1994; Claes et al., 1995]; in most cases, the disease occurs in midlife, between 35-50 years of age, but a CAG expansion over 60 units results in manifestation during the teenage years or earlier [Nance and Myers, 2001]. In patients with very large repeat numbers, where the symptoms begin before age 21 (juvenile or Westphal variant HD) disease progression is particularly fast, while in typical HD, life expectancy after disease onset is 15-20 years; also, in the juvenile form, the chorea is usually entirely absent with the dominant phenotype being rigidity [Nance and Myers, 2001; Gonzalez-Alegre and Afifi, 2006]. The relationship between the rate of clinical decline (disease progression or phenotype severity) and the CAG repeat length is controversial, with some reports showing positive correlation [Illarioshkin et al., 1994; Brandt et al., 1996; Furtado et al., 1996; Penney et al., 1997] while others suggesting that a correlation exists only in the very upper pathological range [Kieburtz et al., 1994; Claes et al., 1995; Foroud et al., 1999; Squitieri et al., 2002]. However, greater CAG repeat lengths are associated with greater degrees of cell death in the striatum [Vonsattel and DiFiglia, 1998]. 
HD is inherited in Mendelian fashion as a dominant trait. An interesting feature of the disease is genetic anticipation: a trend towards earlier disease onset in successive generations due to instability of the expanded repeat during meiosis, especially during spermatogenesis [Duyao et al., 1993; Myers et al., 1993; Zühlke et al., 1993; Ranen et al., 1995]. Interestingly, the rate of disease progression is also faster in paternally transmitted cases, regardless of the CAG repeat length or age of onset [Ashizawa et al., 1994]. Although the disease has long been described as an example of 'complete dominance', more recent studies suggest that although the age of onset does not differ, the disease progresses more rapidly in homozygotes and they show a more extensive brain atrophy [Squitieri et al., 2003]. Therefore, it is possible that the pathogenic mechanism in Huntington's disease has a double nature, i.e. it is a combination of a toxic gain-offunction from the expanded polyglutamine (polyQ) tract and the loss of wild type function [Cattaneo et al., 2001].

\section{Huntingtin Function}

The normal function of Huntingtin is not well understood, despite the identification of the gene almost two decades ago. Htt is widely expressed within the central nervous system and in other, non-neuronal tissues, with the highest expression in the cerebellar cortex, the neocortex, the striatum, and the hippocampal formation [Sayer et al., 2005]. Within the cell, Huntingtin is mostly localized to the cytoplasm, and is associated with various organelles (the mitochondria, the endoplasmatic reticulum, the Golgi, synaptic vesicles and components of the cytoskeleton); it is also present in the nucleus [Velier et al., 1998; Dorsman et al., 1999; Kegel et al., 2002]. Its widespread subcellular localization does not facilitate the definition of its function, but some insights have been gained by studying the phenotypes of loss of function mutant animals, analyzing the domain structure of the protein, and the identification of its interacting partners.

Normal $\mathrm{Htt}$ is essential for embryonic development, as disruption of the homologous mouse gene (called $H d h$ ) results in death shortly after gastrulation [Duyao et al., 1995; Nasir et al., 1995; Zeitlin et al., 1995]. Although mice heterozygous for Hdh are phenotypically normal, reducing the protein level to below $50 \%$ results in smaller body

size, movement abnormalities and a variable increase in ventricle volume, suggesting a role of $\mathrm{Htt}$ in neurogenesis [Auerbach et al., 2001]. In addition to its role in brain 
development, Huntingtin might also be required throughout life, since conditional knockout mice are sterile and develop a progressive degenerative neuronal phenotype [Dragatsis et al., 2000]. In contrast to the mouse, loss of Htt in Drosophila has a minimal impact on survival and development, but it has an essential role in the long-term mobility and survival of adult animals [Zhang et al., 2009].

Human Huntingtin is comprised of 3144 amino acids, resulting in a $348 \mathrm{kDa}$ cytoplasmic protein. Its N-terminal, highly polymorphic polyglutamine region (CAG translates into glutamine) which begins at the eighteenth amino acid, is followed by a polyproline region also of variable length, which mediates interaction with $\mathrm{WW}$ domain proteins [Faber et al., 1998]. The 18 amino acid N-terminus is an amphipathic $\alpha$-helical membrane binding domain, which targets the protein to vesicles and the endoplasmatic reticulum [Atwal et al., 2007]; this N-terminal portion is also subject to a range of posttranslational modifications, including ubiquitination [Kalchman et al., 1996] and sumoylation [Steffan et al., 2004] on K6, K9 and K15, and phosphorylation on T3, S13 and S16 [Aiken et al., 2009; Gu et al., 2009; Thompson et al., 2009]. In addition, Htt is phosphorylated on several more C-terminal serines [Humbert et al., 2002; Luo et al., 2005; Schilling et al., 2006], as well as palmitoylated on C214 [Yanai et al., 2006] and acetylated at K444 [Jeong et al., 2009]. These modifications affect the subcellular localization, stability, activity, cleavage and toxicity of the mutant protein.

Htt contains 10 HEAT repeats in its $\mathrm{N}$ terminal half, and as many as 26 additional HEAT-like repeats extending across the entire protein, suggesting that it may have a rodlike superhelical structure, which is both flexible and exposes a large surface, making the protein suitable to act as a scaffold for guiding protein-protein interactions [Takano and Gusella, 2002; Li et al., 2006; Palidwor et al., 2009]. Additionally, recent analysis revealed a modular organization with two large $\alpha$-helical arms separated by a hinge region, lending a conformational flexibility to the protein which further supports its role as a facilitator of protein-protein interactions; indeed, Huntingtin has been recently shown to stimulate the multi-subunit epigenetic silencer polycomb repressive complex 2 (PRC2) and increase methylation of histone H3 at lysine 27 [Seong et al., 2010].

Huntingtin has over 40 well studied binding partners belonging to diverse functional categories, such as apoptosis, vesicle transport, synaptic activity, morphogenesis, cell signaling and transcriptional regulation. Most of the proteins interact with the N-terminal region of $\mathrm{Htt}$, and several interactions depend on the length of the polyglutamine tract [Li and Li, 2004; Zuccato et al., 2010]. Some notable examples 
include Huntingtin-associated protein 1 (HAP1), which is involved in intracellular transport through dynactin, as well as the anterograde transport in the neuronal processes through the kinesin light chain [Li et al., 1995; Engelender et al., 1997; McGuire et al., 2006]; the clathrin-binding protein Huntingtin-interacting protein 1 (HIP1), which is involved in cytoskeleton assembly and endocytosis, and also has proapoptotic roles by activating caspase-8 [Kalchman et al., 1997; Wanker et al., 1997; Metzler et al., 2001; Gervais et al., 2002]; PSD95 (postsynaptic density 95) and PACSIN-1 (protein kinase C and casein kinase substrate in neurons protein 1), both regulators of synaptic activity [Sun et al., 2001; Modregger et al., 2002]; beta-tubulin and the microtubules [Hoffner et al., 2002]; active caspase-3 [Zhang et al., 2006]; the histone acetyltransferase CREB-binding protein (CBP) [Steffan et al., 2000]; the histone methyltransferase HYPB/SETD2 (Huntingtin yeast partner B/SET domain containing protein 2) [Sun et al., 2005]; the nuclear pore protein translocated promoter region (TPR), which is involved in nuclear export [Cornett et al., 2005]; the ubiquitin-conjugating enzyme HIP2 (Huntingtininteracting protein 2) [Kalchman et al., 1996]; and the glycolytic enzyme glyceraldehyde3-phosphate dehydrogenase (GAPDH) [Burke et al., 1996]. Several transcription factors also interact with Huntingtin, one well studied example being REST/NRSF (repressor element-1 silencing transcription factor/neuron-restrictive silencer factor), which interacts with wild type Huntingtin through REST-interacting LIM domain protein (RILP) and HAP1, keeping the repressor complex in the cytoplasm and thereby promoting the expression of brain-derived neurotrophic factor (BDNF) [Zuccato et al., 2003]. Mutant Huntingtin, however, does not upregulate transcription of the pro-survival factor BDNF, which leads to insufficient neurotrophic support for, and ultimately death of, striatal neurons [Zuccato et al., 2001].

As these examples illustrate, Huntingtin is involved in numerous cellular processes through a range of interacting partners. A recent study identified as many as 234 potential interactors using yeast two-hybrid screening and affinity pull down experiments; many of these interactions were confirmed using a Drosophila model and some by coimmunoprecipitation in mouse brains [Kaltenbach et al., 2007]. The interactors that show increased or decreased affinity for the mutant Huntingtin may explain aspects of the pathology seen in HD; the polyglutamine expansion can result in deregulation of the affected intracellular pathways and ultimately lead to cell loss. 


\section{Aggregation in HD}

Huntington's disease primarily affects the medium spiny neurons of the striatum and the cortical pyramidal neurons, resulting in the death of these neurons [Vonsattel and DiFiglia, 1998; Thu et al., 2010; Rozas et al., 2011]. Aside from the neuronal loss, the neuropathological hallmark of HD is the presence of intranuclear inclusion bodies, the density of which correlates with the number of CAG repeats [Becher et al., 1998]. The role of inclusion bodies in disease pathogenesis remains controversial however. Only pathological length polyglutamine expansions form aggregates [Scherzinger et al., 1997], which are limited to the affected areas in the brain, and cannot be found in unaffected areas such as the cerebellum [Iuchi et al., 2003]. On the other hand, the highest frequency of aggregates can be observed in the interneurons which are spared by the disease, not in the medium spiny neurons [Kuemmerle et al., 1999]. The frequency of nuclear but not cytoplasmic inclusions appears to correlate with the severity of disease [Hoffner et al., 2005], but nuclear aggregates are uncommon in the striatum, the most affected region of the brain, where only $1-4 \%$ of neurons contain nuclear aggregates [Gutekunst et al., 1999]. The inclusion bodies contain a number of other cellular proteins as well, especially other polyglutamine containing proteins, such as transcriptional regulators, as well as motor proteins, suggesting a mechanism that their deleterious effect lies in their titrating out these factors [Li et al., 2001; Cha 2007], and several small molecule screens targeted at decreasing inclusion body formation have resulted in therapeutic hits [Heiser et al., 2002; Pollitt et al., 2003; Zhang et al., 2005; Desai et al., 2006]. On the other hand, inclusion body formation reduces the levels of mutant Huntingtin by trapping it in insoluble aggregates in the cell, and as such actually reduces the level of neuronal death in some models [Arrasate et al., 2004]. A serendipitously established shortstop mouse model of HD shows widespread neuronal inclusions without neuronal dysfunction or degeneration [Slow et al., 2005]. Accordingly, a nitroquinoline compound which promotes inclusion formation and prevents Huntingtin-mediated proteasome dysfunction in cells was suggested to be of therapeutic value [Bodner et al., 2006].

It has been suggested that various forms of Huntingtin monomeric formations and oligomers exist and that toxicity results from some but not all of these forms [Takahashi et al., 2008; Lajoie and Snapp, 2010; Takahashi et al., 2010]. Recent analysis shows that there are multiple different folding pathways for mutant $\mathrm{Htt}$, generating a range of globular, protofibril and amyloid-like intermediate conformations, some of which are 
toxic, before ultimately growing into an inclusion body [Thakur et al., 2009]. The conformational rearrangement of Huntingtin generates toxic forms which interact with selected intracellular targets in a deleterious manner [Schaffar et al., 2004], and amyloid oligomers can permeabilize cellular membranes to induce neurotoxicity [Demuro et al., 2005; Glabe, 2006]. Mathematical modeling of the relationship between $\mathrm{Htt}$ concentration, inclusion body formation and neuronal death revealed that a unimolecular conformation change of polyQ into a nucleus that can seed aggregation is the rate limiting step for both death and aggregation, but the rate of inclusion body formation accelerates faster than the rate of death as Htt levels increase, suggesting that the two events are triggered by different conformations of monomeric mutant Htt [Miller et al., 2010]. The existence of multiple folding pathways seeded by different monomeric conformations has been implied in other studies [Wacker et al., 2004; Legleiter et al., 2009] and might explain some of the discrepancies between observations regarding the role of Huntingtin aggregates in cellular toxicity, namely that one pathway could lead to an elevated risk of death while the other to an adaptive homeostatic response marked by inclusion body formation [Miller et al., 2010].

\section{Cleavage and Clearance of Huntingtin}

Huntingtin is cleaved into smaller N-terminal fragments that accumulate in the neurons prior to onset of symptoms [Wellington et al., 2002]. Caspase-2, -3, -6 and -7, as well as calpains and aspartyl proteases each cleave Huntingtin generating amino terminal fragments up to 600 amino acids long [Goldberg et al., 1996; Wellington et al., 1998; Kim et al., 2001; Lunkes et al., 2002; Hermel et al., 2004]. These fragments accumulate in brain tissue from affected HD patients and not in controls [DiFiglia et al., 1997], although according to one study of human post mortem tissues, mutant HD appears more resistant to proteolysis than normal HD [Dyer and McMurray, 2001]. The N-terminal fragments are more toxic and prone to aggregate, and can diffuse passively into the nucleus [Martindale et al., 1998; Gafni and Ellerby, 2002]. The smallest fragment that accumulates in the cell, corresponding to the first exon of Huntingtin [Landles et al., 2010], has been used to generate one of the most extensively used HD mouse models [Mangiarini et al., 1996], and multiple lines of evidence show that reducing Huntingtin proteolysis diminishes toxicity and delays disease onset [Ona et al., 1999; Chen et al., 
2000; Wellington et al., 2000; Gafni et al., 2004; Graham et al., 2006]. According to the toxic fragment hypothesis, the generation of $\mathrm{N}$-terminal fragments of mutant $\mathrm{Htt}$ leads to alteration of various cellular processes, such as transcription or endocytosis, resulting in excitotoxicity and increased proteolysis, which generates more toxic fragments in a vicious cycle until the neuron is committed to apoptosis [Wellington and Hayden, 1997]. The relationship of these $\mathrm{N}$-terminal Htt fragments to each other or their exact contribution to cell functioning or HD pathology remains unclear.

Several attempts are made by the cell to clear itself of the toxic protein. There are two primary systems that can clear misfolded proteins: the ubiquitin-proteasome system (UPS), which degrades short lived proteins in various compartments of the cell including the nucleus, and autophagy, which rids the cell of long-lived proteins or damaged organelles in the cytoplasm [ $\mathrm{Li}$ and $\mathrm{Li}, 2011]$. Mutant Huntingtin is targeted for degradation by the UPS, but the UPS is deficient in HD, as evidenced by the accumulation of polyubiquitin chains in the brains of trangenic mice and human patients [Bennett et al., 2007], as well as by the accumulation of fluorescent reporter proteins specifically in the synapses of Huntington's disease mice [Wang et al., 2008]. Several components of the proteasome are sequestered into aggregates [Jana et al., 2001], and although the proteasome activity is not affected by soluble expanded polyglutamines [Michalik and Van Broeckhoven, 2004], filamentous forms of Huntingtin (but not the inclusion bodies) purified from patient brains non-competitively inhibit the activity of the $26 \mathrm{~S}$ proteasome [Díaz-Hernández et al., 2006], which leads to the depletion of functional proteasomes and the accumulation of misfolded proteins in the cell. Additionally, only one cytoplasmic protease, the puromycin-sensitive aminopeptidase, is capable of digesting polyglutamine sequences [Bhutani et al., 2007]; the majority of the enzymes can only efficiently degrade the flanking sequences of $\mathrm{Htt}$, generating pure polyglutamine peptides that are even more prone to aggregation and toxicity [Venkatraman et al., 2004].

The autophagic system also attempts to clear the cell of the mutant Huntingtin, first suggested by the increased amount of autophagic vesicles observed in the brain tissue of patients [Kegel et al., 2000; Petersén et al., 2001]. Macroautophagy is an evolutionarily conserved pathway for degradation of aggregated proteins and damaged organelles. Excessive or imbalanced induction of the process however can actively contribute to neuronal atrophy and cell death [Cherra et al., 2010]. In case of Huntingtin, the process is regulated by acetylation of lysine 444, which targets it to the autophagic vesicles, 
improves its clearance and reverses the toxic effects of the mutant protein [Jeong et al., 2009]. The mammalian target of rapamycin (mTOR), a negative regulator of the autophagic pathway, is sequestered into aggregates, which impairs its kinase activity leading to the induction of autophagy and the clearance of Htt fragments [Ravikumar et al., 2004]. According to this, chemical activators of autophagy, such as rapamycin, increase degradation of Huntingtin and reduce toxicity in several model systems [Ravikumar et al., 2004; Berger et al., 2006]. While autophagy may be initially induced as a protective response and activating selective clearance in early phases of disease progression might be protective, due to defects in completing degradation, toxic products and clearance intermediates accumulate, eventually leading to the demise of the cell [Steffan, 2010].

Huntington's disease is a result of the combination of loss of normal Htt function and a toxic gain of function conferred by the expanded polyglutamine region. The mutant protein (either in its soluble monomeric or oligomeric, or insoluble aggregate form) disrupts important intracellular pathways by sequestering or abnormally interacting with key components, leading to disruption of intracellular homeostasis, neuronal dysfunction and death. The mechanism of neurodegeneration is multifaceted; it includes excitotoxicity, dopamine toxicity, BDNF deficit, mitochondrial dysfunctions (including energy metabolism defects, oxidative stress and impairment of calcium signaling), transcriptional dysregulation, apoptosis and autophagy [Gil and Rego, 2008; Zuccato et al., 2010]. Some of these may be primary, while others secondary events, and their sequence, degree of cross-talk, and exact contributions to pathology remains to be elucidated; but each has offered targets for therapeutic intervention.

\section{Transcriptional Dysregulation in HD}

The first lines of evidence demonstrating that transcription is impacted in HD were altered enkephalin, substance $\mathrm{P}$ and dopamine receptor mRNA levels in brain tissues of patients with early stage disease [Augood et al., 1996; Augood et al., 1997]. Subsequently, transcriptional dysregulation has been demonstrated, in both human tissues and animal models, for a large number of genes, encoding neurotransmitters and their receptors, and proteins involved in neuron structure, stress response and axonal transport [Cha, 2007]. 
Following singe gene studies, large scale DNA microarray technology was utilized to map the genes altered in animal or cell culture models of Huntington's disease [Orr, 2002]. These studies identified several new pathways impacted in HD pathology, such as impaired cyclic AMP response element signaling [Wyttenbach et al., 2001], altered expression of molecules regulated by retinoic acid response element and nuclear factor kappaB (NF-кB) [Sugars et al., 2004], the MAP kinase pathway [Apostol et al., 2006], and deficiencies in cholesterol biogenesis [Sipione et al., 2002]. They also showed that the dysregulation is selective (a relatively small percent of genes are changed), that downregulated genes usually outnumber the upregulated ones, as well as manifest at earlier time points [Luthi-Carter et al., 2000], and that nuclear localization or increasing the polyglutamine stretch of Htt worsens the phenotype [Chan et al., 2002; Benn et al., 2005].

Various hypotheses for the mechanism of transcriptional dysregulation have been proposed. Both wild type and mutant Huntingtin interact directly with a number of transcriptional regulators, including the TATA binding protein [Huang et al., 1998], the nuclear co-repressor N-CoR [Boutell et al., 1999], CBP and p53 [Steffan et al., 2000], REST/NRSF [Zuccato et al., 2003], as well as TAFII130 and Sp1 [Dunah et al., 2002]. The strength of these interactions often depends on the length of the polyglutamine stretch in Htt, suggesting a mechanism for the disturbance in gene transcription seen in HD.

The sequestration model proposes that dysregulation is a result of depletion of transcription-related factors by trapping them in neuronal intranuclear inclusions. Although several proteins involved in transcription (many of which themselves contain polyglutamine repeats) localize to Huntingtin aggregates [Kazantsev et al., 1999; Suhr et al., 2001], these inclusions do not seem to deplete factors such as TBP, CBP or Sp1 [Yu et al., 2002], and microdissection of mouse brains reveals that striatal neurons with or without inclusions show similar degree of mRNA dysregulation [Sadri-Vakili et al., 2006]. Lastly, recent evidence suggests that $\mathrm{Htt}$ itself is a transcriptional regulator and it binds DNA directly in a polyglutamine length dependent manner [Benn et al., 2008].

Transcriptional activity is regulated by the posttranslational modification of histones, such as acetylation, methylation, ubiquitination and phosphorylation, and evidence is accumulating that these processes are affected in Huntington's disease. Mitogen and stress activated protein kinase 1 (MSK1), which is involved in histone H3 phosphorylation, is deficient in the striatum of Huntington's disease patients and mice, and correcting its expression improves disease phenotypes and reduces neuronal death [Roze 
et al., 2008]. Mutant Huntingtin binds weaker than wild type Htt to Bmi-1, a member of the hPRC1L E3 ubiquitin ligase complex, resulting in increased monoubiquityl histone $\mathrm{H} 2 \mathrm{~A}$ levels and gene repression, while levels of monoubiquitylated histone $\mathrm{H} 2 \mathrm{~B}$, which corresponds to actively transcribed chromatin, are decreased [Kim et al., 2008]. Both of these ubiquitination events regulate subsequent methylation of histone $\mathrm{H} 3$ at different lysines, but Htt also affects histone methylation more directly. One of the first described interacting partners of Huntingtin, HYPB, [Rega et al., 2001] was later identified as a histone methyltransferase [Sun et al., 2005]. Another methyltransferase, SETDB1/ESET (ERG-associated protein with SET domain), which has a central role in the epigenetic repression of euchromatic genes by recruiting HP1, is highly upregulated in Huntington's disease patients and in transgenic mice, and suppressing basal ESET promoter activity with the antitumor antibiotic mithramycin ameliorates neuropathology [Ferrante et al., 2004; Ryu et al., 2006]. Recently, full length Huntingtin has been shown to stimulate H3K27 trimethylation by the PRC2 (polycomb repressive complex 2) in a polyglutamine dependent manner [Seong et al., 2010].

The most studied histone modification is acetylation, which corresponds to gene activation. As described earlier, Htt binds to and inhibits the enzymatic activity of several histone acetyltransferases, including CBP and PCAF (p300/CBP-associated factor) [Steffan et al., 2001]. Levels of acetylated histones are reduced in HD, but while some have shown global histone hypoacetylation in brains of transgenic mice expressing mutant Huntingtin [Stack et al., 2007], others find that hypoacetylation is restricted to the promoters of dysregulated genes [Sadri-Vakili et al., 2007]. Regardless of these discrepancies, multiple lines of evidence demonstrate that counteracting the acetylation defect by inhibiting the enzymes responsible for removing the acetyl moiety (the histone deacetylases or HDACs) improves neuropathology in models of Huntington's disease [Steffan et al., 2001; Hockly et al., 2003; Ferrante et al., 2003; Gardian et al., 2005; Thomas et al., 2008]. In a small study of human patients, one HDAC inhibitor, phenyl butyrate, decreased the expression of some abnormally increased genes in peripheral tissues [Borovecki et al., 2005].

Regulation of gene transcription appears to be impacted in several levels in Huntington's disease. Transcriptional changes often precede the onset of symptoms [Augood et al., 1997; Cha et al., 1999], suggesting that they are not a result of non-specific degradation of mRNAs in degenerating neurons, but instead an early step in the disease pathology, thereby showing potential for timely therapeutic intervention. As discussed 
above, several classes of pharmacological agents that affect transcription reduce toxicity in cellular and animal models. Importantly, various animal models of HD have shown a remarkably similar pattern of dysregulated genes, recapitulating the gene expression signature of the human disorder [Kuhn et al., 2007], making them invaluable tools for studying this aspect of pathology.

\section{Animal Models of HD}

Before the discovery of the gene responsible for Huntington's disease, HD mouse and non-human primate models were generated by injecting neurotoxins, most commonly quinolinic acid or kainate in the striatum [Beal et al., 1986]. Subsequently, pharmacologic inhibitors of mitochondrial complex II, such as 3-NP and malonate, which induce striatal damage and result in motor phenotypes that resemble symptoms of HD, have also been used [Brouillet et al., 1999; Ayala et al., 2007]. Although these models proved useful for studying selective neuronal death, they could not fully recapitulate the pathophysiological mechanisms induced by the mutant gene.

The first genetic mouse model was generated by inserting a $1.9 \mathrm{~kb}$ DNA fragment containing the promoter and the first exon of the human Huntingtin gene with $144 \mathrm{CAG}$ repeats into mouse embryonic stem cells [Mangiarini et al., 1996]. These mice, known as the R6/2 model, exhibit early and severe phenotypes, including problems with movement, learning and memory disabilities, and weight loss, and they die around 12 weeks of age with severely atrophied brains [Carter et al., 1999; Lione et al., 1999; Mangiarini et al., 1996]. This model remains one of the most studied ones in HD, since the fast progression of the disease makes this mouse line well suited for therapy screening [Gil and Rego, 2009], but to study early pathological events, additional models have been generated. There exist other N-terminal fragment models with shorter CAG repeats, such as the N171-82Q [Schilling et al., 1999], or the tetracycline-regulatable HD94 line [Yamamoto

et al., 2000], as well as full length models, both transgenic [Hodgson et al., 1999; Reddy et al., 1998] and knock-in, in which extra CAG repeats are inserted into the endogenous mouse locus [Menalled et al., 2002; Shelbourne et al., 1999]. In addition to mice, transgenic models have also been generated in other species, such as rat [De Almeida et al., 2002; Von Horsten et al., 2003], fish [Miller et al., 2005], sheep [Jacobsen et al., 2010], pig [Yang et al., 2010] and rhesus monkey [Yang et al., 2008]; and models using 
simpler organisms, such as the fruit fly [Jackson et al., 1998; Steffan et al., 2001] or the worm Caenorhabditis elegans [Faber et al., 1999; Parker et al., 2001] have also been created. Each of these systems has its own strength, such as availability of behavioral tests or genetic tools, easy analysis of organs and tissues, similarity to human, speed of development, size, price, etc., and each model has yielded valuable insights into understanding the pathological mechanisms of Huntington's disease.

The fruit fly Drosophila melanogaster is well suited for studying genetic diseases because of its fast reproductive cycle and small size, which allows for the study of large populations in a relatively short time. Also, a large array of genetic tools and behavioral

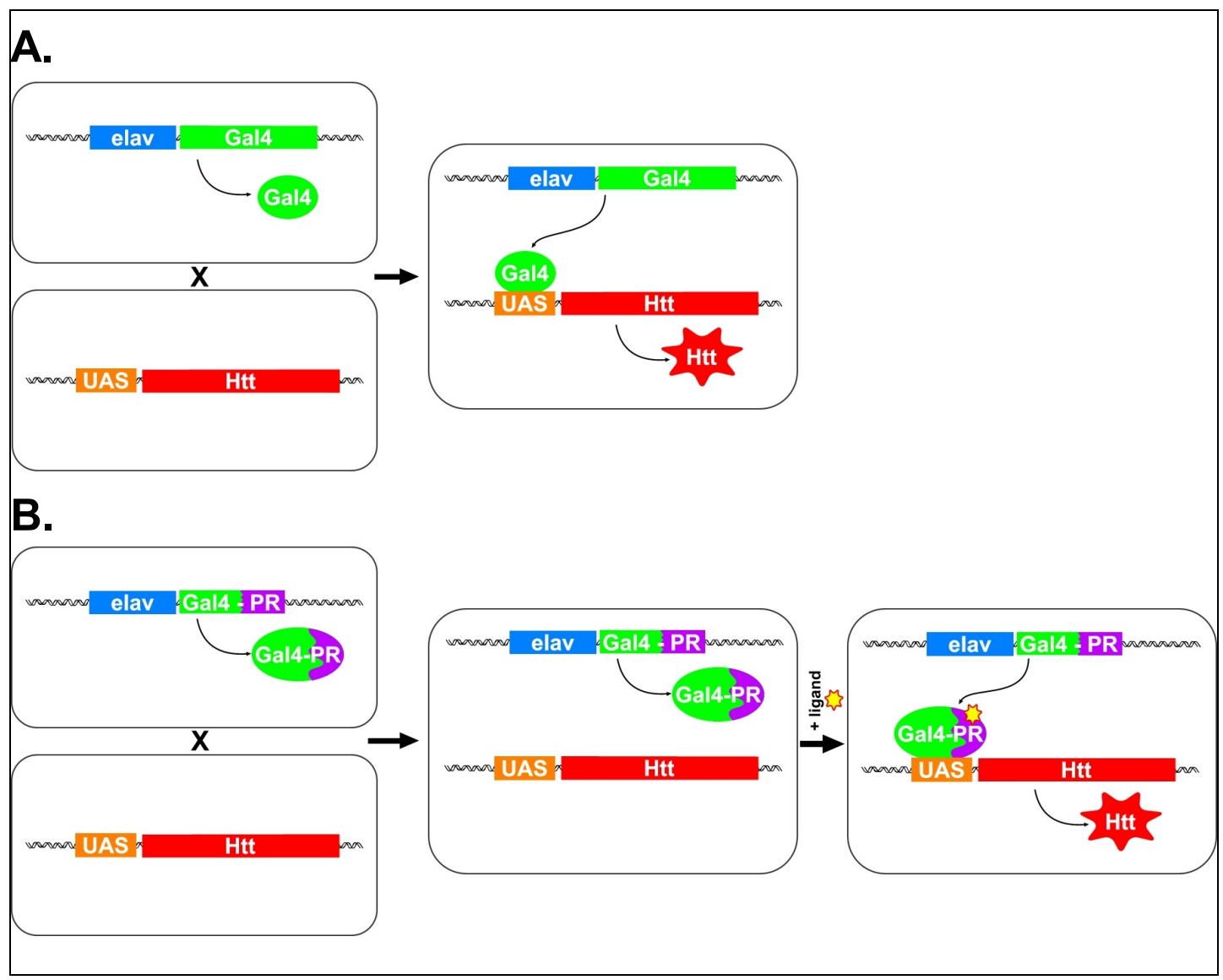

Figure 1. Overview of the UAS/Gal4 system.

In the classical setup (A), flies carrying the elav-Gal4 transgene, which produces the GAL4 protein throughout their nervous system, are crossed to flies carrying a UAS-Htt transgene. In the offspring, GAL4 binds to the upstream activating sequence (UAS) and drives the expression of the downstream transgene, Htt. In the mifepristone-inducible version (B) the driver is a Gal4-progesterone receptor (PR) chimera, and the transgene downstream of the UAS remains silent even following the cross of Gal4 and UAS carrying flies, until the ligand mifepristone, which is a progesterone receptor antagonist, is added to the medium. 
assays are available to investigate the disease phenotypes. Importantly, it can be easily engineered to express foreign genes in a spatially and temporally specific manner, using the bipartite UAS/Gal4 system (Fig. 1) [Duffy, 2002]. In this expression system, the gene of interest is introduced into the fly genome fused to the upstream activation sequence (UAS) of yeast, resulting in a transgene that is transcriptionally not active. To drive the expression of the transgene and investigate the resulting phenotypes, the flies are crossed to Drosophila carrying activator transgenes ('drivers') that express the yeast Gal4 transcription factor in a variety of tissue specific patterns. Some of these drivers are also inducible, which allows for additional control of the system: the Gal4 can be activated by heat shock, UV light, or by addition of a hormone ligand or tetracycline [Duffy, 2002].

Polyglutamine diseases were one of the first human disorders modeled in the fly [Warrick et al., 1998]. The early models used pure polyglutamine constructs [Marsh et al., 2000], as well as N-terminal Htt fragments [Jackson et al., 1998], and recently, full length Drosophila models have also been generated [Romero et al., 2008].

Our laboratory has created transgenic animals that carry the first exon of the Htt gene (Httexlp), with either 20 (normal length) or 93 (expanded) CAG repeats [Steffan et al., 2001]. When the expanded polyglutamine construct is expressed in the nervous system, the flies show many characteristics of the human disease, including reduced viability, motor deficits and accumulation of intracellular inclusions [Steffan et al., 2001, Agrawal et al., 2005; Slepko et al., 2006; Pallos et al., 2008]. The progressive, widespread neuronal loss can be detected as a reduction of the size of the mushroom body or as loss of individual cell bodies throughout the brain lobes and the ventral nerve cord [Agrawal et al., 2005]. A most convenient and popular assay of degeneration in the fly, however, involves the photoreceptor neurons.

In a wild type fly, each ommatidium of the compound eye contains 8 photoreceptors, which have light gathering membrane structures called rhabdomeres. When light is shined through the head of the fly using the pseudopupil technique, seven of these rhabdomeres become visible in each ommatidium, and appear as shining dots under the light microscope (two photoreceptor neurons are stacked exactly on top of each other, resulting in a trapezoidal arrangement of seven dots instead of eight). As the photoreceptor neurons die, their rhabdomeres disintegrate, becoming faint then invisible, which allows for an easy quantification of the degeneration. Wild type flies preserve the 7 visible rhabdomeres per ommatidium throughout their lives, while Httexlp Q93 
expressing flies have only an average of $\sim 6.5$ upon eclosion, and this number drops further as the flies age (Fig. 2) [Marsh et al., 2003].

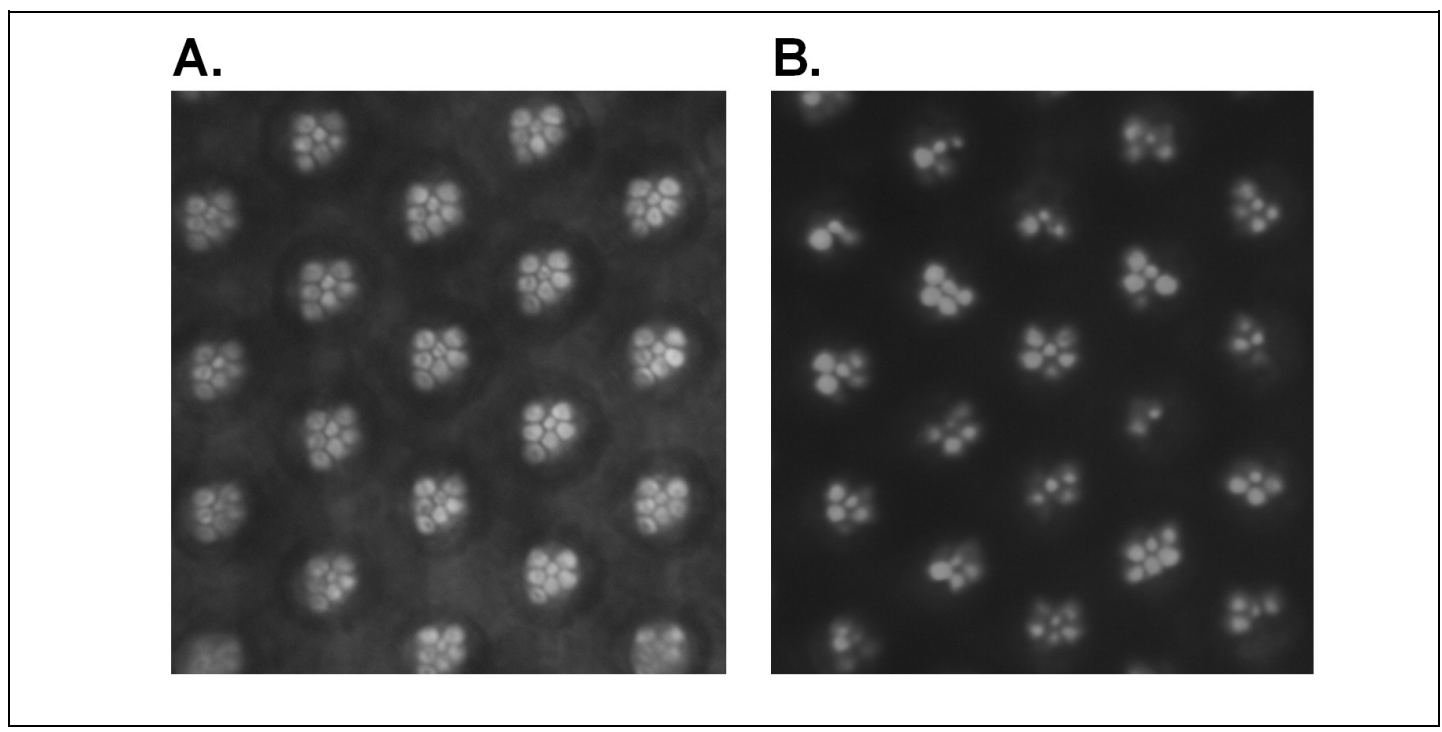

Figure 2. Pseudopupil images of the Drosophila eye.

(A) Each ommatidium of wild type flies contains seven visible rhabdomeres arranged in a regular trapezoidal pattern. (B) Httexlp Q93 expressing flies show a progressive loss of rhabdomeres, which can be readily quantified and used as a measure of neurodegeneration.

We have used the sensitive, quantifiable phenotypes of our Drosophila model to find, or verify the in vivo importance of, chemical agents that can alter the disease progression. By examining the protein targets of these drugs and taking advantage of the genetic versatility of the fly, these results enabled us to identify pathways that play an important role in the pathogenesis of Huntington's disease. One example of this work, in collaboration with Marc Diamond's laboratory at the University of California, San Francisco (currently at Washington University in St. Louis), was the identification of the role of the Rho/ROCK pathway in HD [Pollitt et al., 2003]. Another example is described in this dissertation in detail, where, following the finding that broad spectrum histone deacetylase inhibitors arrest neurodegeneration in the fly [Steffan et al., 2001], we have examined the contribution of each of the 10 HDACs to pathology. We found that only one of the 5 classic deacetylases is responsible for the improvement seen earlier with pharmacological agents, a result that can aid future drug development efforts. We have also demonstrated that reduction of the sirtuins is beneficial in HD [Pallos et al., 2008], an 
entirely novel finding that opened up opportunities for new therapies for treating this devastating disorder. 


\begin{abstract}
AIMS
1. Validate the finding that broad spectrum histone deacetylase inhibitors reduce mutant Htt induced pathology using different assays, in addition to the pseudopupil analysis which evaluates photoreceptor neuron degeneration of elav>Httex 1p Q93 flies

- Explore the motor degeneration phenotype of Httex 1p Q93 flies

- Set up a quantitative assay using a different driver (gmr-Gal4) and validate it using an HDAC inhibitor

2. Determine the specificity of histone deacetylase inhibitor treatment

- Establish and characterize new HDAC mutant lines

- Determine the effect on viability and photoreceptor neuron degeneration of genetically reducing each of the 10 Drosophila deacetylases, alone and in combination
\end{abstract}

- Validate the genetic results using pharmacological agents

3. Investigate the cellular mechanism by which reducing deacetylase activity reduces neurodegeneration

- Test the effect of deacetylase mutants on longevity and determine if treatments that extend the life span also reduce neurodegeneration of Httex1p Q93 flies

- Determine if mutant $\mathrm{Htt}$ expressing flies display abnormalities in their sleep pattern and if it can be manipulated by altering deacetylase levels

- Evaluate the effect of HDAC inhibitor treatment on inclusion body formation

- Examine the acetylation state of histones in Httex 1p Q93 flies

- Identify a set of candidate genes that are dysregulated in mutant Htt expressing flies and test if reducing HDAC mutations can correct the transcriptional output of these genes 


\section{Materials ANd Methods}

\section{Drosophila Stocks and Crosses}

The Drosophila Htt lines carrying the UAS transgenes were generated in our laboratory previously [Steffan et al., 2001]. They contain a single insert of the Htt transgene with either normal length (20) or expanded (93) CAG repeats. For most of our experiments, the third chromosomal line $w ; P\{w[+m C]=U A S$-Httexon1Q93 4 F1 (P463, "Httex1p Q93") was used; in addition, a second chromosomal line (P468) was used in the microarray experiment. The UAS-exon1-Q96-GFP line, which carries a construct comprised of the first exon of $\mathrm{Htt}$ with $96 \mathrm{CAG}$ repeats tagged with GFP and was used to measure aggregate formation, was a kind gift from the laboratory of Troy Littleton (Massachusetts Institute of Technology).

The Gal4 drivers were obtained from the Bloomington Drosophila Stock Center at Indiana University, and included the X chromosomal $P\{w[+m W \cdot h s]=G a w B\}$ elav [C155] ("elav-Gal4"), which provides pan-neuronal expression, and the second chromosomal eye specific driver $P\{w[+m C]=G A L 4-n i n a E . G M R\} 12$ ("gmr-Gal4"). The mifepristoneinducible GeneSwitch version of the elav driver ("elav-GS-Gal4") was a gift from Thomas Osterwalder of Yale University, New Haven, Connecticut.

Most of the histone deacetylase mutations used in this study were obtained from the Bloomington Drosophila Stock Center, and their full genotypes are as follows: $\underline{\mathrm{Rpd} 3}$ : $P\{r y[+t 7.2]=P Z\} R p d 3[04556] \quad r y[506] / T M 3, \quad r y[R K] \quad S b[1]$ Ser[1], HDAC4: $y[1]$ $P\{y[+m D i n t 2] \quad w[B R . E . B R]=S U P o r-P\} H D A C 4[K G 09091] / F M 7 c, \quad \underline{\text { HDAC6: }}$ Df(1)ED7294, w[1118] P\{w[+mW.Scer|FRT.hs3]=3'.RS5+3.3'\}ED7294/FM7j, B[1], Sir2: $P\{r y[+t 7.2]=P Z\}$ Sir2[05327a] cn[1], l(2)05327b[05327b]/CyO; ry[506], Sirt2: $D f(3 R) H-B 79, e[*] / T M 2$ and w[1118]; Sirt2[5B-2-35], Sirt4: w[1118] Sirt4[white+1]; sna[Sco]/CyO, S[2] and w[67c23] $P\{y[+m 8]=$ Mae-UAS.6.11\}Sirt4[GG01208], Sirt6: $w[1118] ; \quad D f(3 R) E D 5472, P\left\{w[+m W . S c e r \mid F R T . h s 3]=3^{\prime} \cdot R S 5+3.3^{\prime}\right\} E D 5472 / T M 6 C, \quad c u[1]$ $S b[1]$ and $w[1118] ; D f(3 R)$ Exel6156, $P\{w[+m C]=X P-U\}$ Exel6156/TM6B, Tb [1], Sirt7: $w[1118] ; D f(3 R) 3450 / T M 6 B, T b[1]$ and $w[1118] ; D f(3 R)$ Exel6211, $P\{w[+m C]=X P-$ U\}Exel6211/TM6B, Tb[1]. The Sir2 overexpressing w[1118]; $P\{w[+m C]=E P\} \operatorname{Sir} 2[E P 2300] D n a J-H[E P 2300] / C y O$ stock was obtained from the Szeged Drosophila Stock Centre. The null allele $R p d 3$ [m5-5] and the hypomorphic alleles 
of $H D A C 3[I]$ and $H D A C 3[J]$ were a gift from Douglas Bornemann (University of California, Irvine), the $H D A C 3$ [N] a gift from Jeffrey Simon (University of Minnesota, Minneapolis), and the Sir2 [17] allele was kindly provided by Stefan Aström (Wennergren Institute, Stockholm University).

To generate animals that express the mutant $H t t$ transgene in their nervous system, $w P\{w[+m W \cdot h s]=G a w B\} \operatorname{elav}[C 155]$ females were crossed to $w ; P\{w[+m C]=U A S$ Httexon1Q93 $4 F 1$ males, and the resulting F1 offspring was used for drug feeding or motor perfomance experiments. For the pigment measurement essay, $w$; $P\{w[+m C]=G A L 4$-ninaE.GMR $\} 12$ females were used with the same males as above. For the experiments analyzing the viability of the newly generated UAS-RNAi transgenes, actin-Gal4 (w; P\{Act5C-GAL4\}17bFO3/TM6) or elav-Gal4 females were crossed to $w$; $P\{w[+m C]=U A S-H D A C-R N A i\}$ males; the viability with the actin driver was determined as the number of eclosed animals expressing the RNAi construct compared to the nonexpressing siblings (that carry the TM6 balancer), while for the elav-Gal4 experiment, we crossed the flies in cages on grape juice plates and counted out 100 eggs per vial for each of the 8-10 vials per RNAi line, and scored the total eclosing progeny to assess viability.

To test the eclosion rate and pseudopupil phenotypes of mutant $\mathrm{Htt}$ expressing flies also carrying an HDAC mutation, homozygous Httexlp Q93 females were crossed to elavGal4; $H D A C^{-} / \mathrm{CyO}$ or elav-Gal4; $H D A C^{-} / \mathrm{Sb}$ males (these males were generated in a previous cross using either elav-Gal4; Sco/CyO or elav-Gal4; Sb/TM6). For X chromosomal HDACs, elav-Gal4/Y; Httexlp Q93/Sb males were first generated at $18{ }^{\circ} \mathrm{C}$ (at this temperature they are fully viable), then crossed to HDAC ${ }^{-} /$balancer stock. Similar crosses were carried out for experiments involving combinatorial or homozygous reduction of HDAC activities, except recombinant lines were used, as appropriate: Sir2/(CyO); Rpd3/TM3 or Sir2; Httex1p Q93 or Httex1p Q93 Sirt2.

All crosses were carried out at $25^{\circ} \mathrm{C}$ unless noted otherwise.

\section{Media and Chemicals}

Drosophila stocks were maintained and the crosses carried out in vials containing standard fly medium, the main ingredients of which are cornmeal, sucrose, dextrose and yeast, which was prepared at the Drosophila media facility at UCI based on a recipe of the 
Bloomington Drosophila Stock Center at Indiana University (http://flystocks.bio.indiana.edu).

The medium used for drug feeding experiments was prepared by mixing $0.93 \mathrm{~g}$ agar, $6.12 \mathrm{~g}$ cornmeal, $12.94 \mathrm{~g}$ dextrose, $3.24 \mathrm{~g}$ dry yeast with $90 \mathrm{ml}$ water, and cooking the mixture in the microwave oven. The medium was cooled to approximately $45{ }^{\circ} \mathrm{C}$

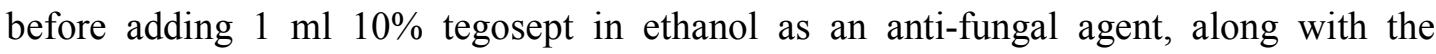
compounds in desired concentrations and a drop of food coloring to aid the visualization of the mixing process. The prepared food was then poured into vials and stored at $4{ }^{\circ} \mathrm{C}$ for up to a week.

For dietary restriction experiments we used a sugar-yeast medium with $150 \mathrm{~g}$ each of dextrose and yeast in 11 water and $2 \%$ agar as the control condition; and $65 \mathrm{~g}$ each of dextrose and yeast as the diluted medium, as described [Partridge et al., 2005].

The plates for collecting eggs were made of grape juice containing 1.5\% agar; a small drop of yeast paste was placed in the middle of each plate as a protein supplement.

The sources of drugs were as follows: butyric acid, niacin, nicotinamide, mifepristone, 2-hydroxypropyl- $\beta$-cyclodextrin and tegosept (methyl 4-hydroxybenzoate) from Sigma-Aldrich; SAHA and sirtinol from Calbiochem; HDACi \#4 was a gift from Joel Gottesfeld, The Scripps Research Institute, La Jolla, California; AK-1, AGK2 and Sirt2 inhibitor "4" were provided by Aleksey Kazantsev, Harvard Medical School, Boston. Butyric acid was used as a free acid, while niacin, nicotinamide and 2-hydroxypropyl- $\beta$ cyclodextrin were dissolved in water, mifepristone and tegosept in ethanol; all of the other chemicals were solubilized in DMSO.

\section{Generation of HDAC Transgenics}

The UAS-RNAi lines were generated by cloning a 511-697 bp long fragment of the gene in question in both reverse and forward orientation on either side of an intron of the $w g$ gene into a modified pWIZ cloning vector, using the TOPO TA cloning kit (Invitrogen). (The cloning was performed by Tamas Lukacsovich.) Approximately $0.2 \mu \mathrm{g} / \mu \mathrm{l}$ of the purified UAS construct, along with $0.1 \mu \mathrm{g} / \mu 1 \Delta 2-3$ helper plasmid, was injected using borosilicated micropipettes with omega dot filaments (Sutter Instrument Co.) in a buffer containing 5 $\mathrm{mM} \mathrm{KCl}, 0.1 \mathrm{mM} \mathrm{NaH} 2 \mathrm{PO} 4$ and green dye to facilitate visualization, into up to 30 minutes old $w$ embryos, which were lined up on microscope slides coated with grape juice 
(as the egg laying plates). The emerging flies were individually crossed to $w$ stock and the transgenic offspring was identified based on eye color. The affected chromosome was determined in parallel to the establishing of the RNAi stocks using two subsequent crosses to double balanced $w ; S c o / C y O ; M K R S / T M 6$ animals.

\section{Drosophila Assays}

\section{Feeding experiments}

We allowed a large population of elav-Gal4 females to mate with Httexlp Q93 males in a vial for 1-2 days and then transferred them into grape juice plate cages for egg laying. After up to 20 hours, we harvested the eggs, and transferred approximately 200 each in control food vials prepared as described above. We incubated the vials at $25^{\circ} \mathrm{C}$ for 9 days, then the freshly eclosed elav>Httex1p Q93 virgin females were collected and distributed among vials containing various concentrations of the drug to be tested; the adults were transferred into fresh vials daily until sacrificing them for the assay, typically 7 days later. For experiments involving niacin or nicotinamide, the animals were reared in vials containing appropriate concentrations of the drugs starting from the larval stages, as opposed to feeding them the drug only as adults.

In case of the viability tests with SAHA, we counted out exactly 100 eggs and placed them in the vials already containing the drug. The effect of the HDAC inhibitor on the viability of the Httexlp Q93 flies was determined as the number of eclosed animals per vial, at least 7 vials were used for each concentration. For the butyrate viability test, Httex 1p Q93 females were used and elav-Gal4 males, and the eclosion rate determined as the ratio of elav>Httexlp Q93 females to Httex1p Q93 (non-expressing) males.

For the pigment measurement assay, we used males of the genotype gmr-Gal4/+; Httex1p Q93/+, which were either reared on standard food or on food containing $100 \mathrm{mM}$ butyric acid. Half of the animals reared on standard food as larvae were fed butyrate as adults, starting immediately following eclosion.

For measuring the effect of butyrate on incusion body formation, we raised the elav-GS $>$ Httex1pQ96-GFP larvae on plates containing fly food prepared as described above (with or without $100 \mathrm{mM}$ butyric acid). Third instar male larvae were collected and induced at various time points by transferring them onto plates supplemented with 200 
$\mu \mathrm{g} / \mathrm{ml}$ mifepristone in ethanol [Osterwalder et al., 2001] (in addition to butyric acid, as appropriate), then dissected at the wandering stage.

\section{$\underline{\text { Pigment measurement }}$}

The heads of gmr>Httexlp Q93 males were collected by freezing the animals on dry ice and shaking the tubes vigorously. 30 heads per tube were homogenized in 1:1 mixture of chloroform and $0.1 \%$ ammonium hydroxide using a motorized pestle, then centrifuged at maximum speed for 3 minutes. The absorbance of the supernatant was read at $485 \mathrm{~nm}$ in a spectrophotometer. The samples were prepared in triplicates.

\section{Climbing assay}

To assess the motor behavior of elav>Httex1p Q93 females, individual flies were placed without anesthesia in a vertical tube made from a $25 \mathrm{ml}$ plastic pipette glued to a petri dish. They were allowed to acclimatize for 1 minute, after which the tube was tapped down and the distance that the flies climbed in 10 seconds was recorded. At least 10 flies were measured for each condition.

For the experiments with the nine-choice geotaxis maze, a light source was placed at the end tube side of the vertical maze to attract the flies in the otherwise dimmed room. For each experiment, 70-80 flies (a mixture of the control and experimental groups) were placed in the entrance tube of the maze, and were allowed to walk the maze for 20 minutes before the trial was ended; the flies collected from the end tubes and sorted based on their genotype (or age). The geotaxis score was calculated as $\sum \mathrm{i} \cdot \mathrm{x}_{\mathrm{i}} / \mathrm{N}$, where $\mathrm{N}=\sum \mathrm{x}_{\mathrm{i}}$ and $\mathrm{x}_{\mathrm{i}}$ is number of flies in each end tube $(1 \leq i \leq 9,1=$ the lowest, $9=$ the highest tube).

Both types of climbing experiments were performed in quiet rooms absent of external disturbances or noise.

\section{Pseudopupil assay}

Adult flies were decapitated using a needle and the head mounted on a microscopic slide by dipping one eye in a drop of nail polish. The head was positioned at a slight angle so that the head tissue would not obstruct the light shining from below onto the upper eye. The head was then covered in immersion oil and analyzed with a Nikon EFD-3/Optiphot-2 microscope using a 50x objective. The rhabdomeres in at least 30 ommatidia were counted and an average calculated for each fly; 7-18 flies were scored for each condition. Relative rescue was calculated by $100 *(\exp -\mathrm{ctrl}) /($ wt-ctrl $)$, where "ctrl" and "exp" are the 
average rhabdomeres per ommatidium in control and experimental flies, respectively, and "wt" is the average rhabdomeres per ommatidium of wild type flies (i.e. the maximum attainable average, 7 ).

\section{Measurement of longevity}

For longevity analysis, freshly eclosed adult flies were collected and placed in vials at a density of 20-30 flies per vial. The number of dead animals was recorded daily and the animals were passed into fresh vials every 2-3 days (or every day, in case of drug feeding experiments), until the last animal died.

\section{$\underline{\text { TriKinetics activity assay }}$}

Locomotor activity-rest rhythms were assayed by placing individual virgin females in 0.6 $\mathrm{ml}$ glass tubes supplied with food at one end and a sponge stopper at the other. 24 animals were used for each of the four genotypes measured ("Htt": elav/w; Httexlp Q93/+ or "Htt+Sir2": elav/w; Sir2[17]/+; Httex1p Q93/+ or "wt": elav/w or "Sir2": elav/w; Sir2[17]/+). The movement of the flies across the tube causes breaks in an infra-red beam when these tubes are placed in an automatic Drosophila Activity Monitor (DAM 2, TriKinetics, Waltham, MA). Flies were subjected to light:dark cycles of 12:12 h for their entire life (the experiment was terminated after 12 days when all the mutant $H t t$ expressing flies were dead); light intensity was between 1000 to 2500 lux during the light phase and below 0.001 lux during the dark phase. All assays and rearing of flies were done at $25{ }^{\circ} \mathrm{C}$. Raw time series data were obtained from DAM System 3 Data collection software, the activity was recorded in 5 min binning intervals, as five minutes of continuous inactivity is considered sleep and similarly, each 5 minute window with greater than one beam crossing is defined as 5 min of activity [Shaw, 2003]. The data were analyzed using Microsoft Excel; the macros for sleep analysis were written by Ezequias Simon (Interactive Data Corporation).

\section{Brain imaging}

The brains of third instar elav-GS>GFP or elav-GS>Httex1pQ96-GFP larvae were dissected in PBS on ice, and then fixed in 4\% paraformaldehyde in PBT for 30 minutes. After several washes in PBT, the brains were mounted onto microscopic slides using VECTASHIELD mounting medium with DAPI (Vector Labs), and analyzed using a 40x objective of an Olympus Fluoview FV1000 Laser Scanning Confocal Microscope. 


\section{Western analysis}

The heads of elav>Httexlp Q93 females were separated from the bodies by freezing them on dry ice and then shaking the tubes. For each sample, we homogenized 10 heads in Tris lysis buffer containing complete mini protease inhibitor tablet (Roche) using a motorized pestle, pelleted the insoluble material with centrifugation for 5 minutes at $4{ }^{\circ} \mathrm{C}$ at $13000 \mathrm{~g}$, denatured the supernatants by boiling for 5 minutes, and loaded the samples containing 10 $\mu \mathrm{g}$ total protein (as measured by Bradford assay) in Laemmli buffer on 15\% acrylamide gels. Following the run, the gels were transferred onto a PVDF membrane at $200 \mathrm{~mA}$ for $\sim 75$ minutes at room temperature. After several washing steps, we blocked the membranes with 5\% BSA in TBST for $1 \mathrm{~h}$ at room temperature. The primary antibodies were used in 1:1000 dilution, total H3 (Abcam ab10799, mouse), H3K27ac (Abcam ab4729, rabbit); the secondary antibodies were HRP-labeled, used in 1:3000 dilution. For detection, SuperSignal West Pico chemiluminescent substrate was used (Pierce Protein Research Products).

\section{RNA detection using quantitative real time PCR}

Heads of flies of the appropriate genotype were separated from the bodies using the freeze-shake method, except for the Rpd3-Sir2 cross regulation experiment, where whole flies were used. We collected samples in at least triplicates for every genotype and experiment. We isolated total RNA using the TRIzol reagent (Invitrogen) following the manufacturer's recommendations. The RNA pellets were resuspended in water and $1 \mu \mathrm{g}$ of total RNA was used in the reverse transcription reaction, which was performed using random hexamer primers and the SuperScript III First-Strand Synthesis System (Invitrogen). The quantitative PCR was performed in a DNA engine opticon real time PCR machine (MJ Research/Bio-Rad) using the SYBR Green PCR Master Mix (Applied Biosystems), typically $250 \mathrm{nM}$ forward and reverse primers (or up to $750 \mathrm{nM}$, depending on the results of the primer optimization experiment), and $1 \mu \mathrm{l}$ of the RT reaction mix as template. The primer sequences were as follows: HDAC3 forward: ACA GCC TGG TAA TGA ACT ACG GAC, HDAC3 reverse: ATA GGC CAC GGA ATT GCA CTG, HDAC4 forward: AGC CAT ACA GCA AAC GCA TTG, HDAC4 reverse: GTT GAT CGT CTC GGA CTC GTC, HDAC6 forward: TCA CTC CAG TTG CTC CAC TTC C, HDAC6 
reverse: CTG AAT CTT TGC CTG CTG CG, HDAC11 forward: CAA GCA CAT TCA CAA GCT CCT G, HDAC11 reverse: CTC CAG CGC AGT GAC TTT AGG, Sir2 forward: CTT TTT CGG CGA GGG ACT, Sir2 reverse: GGA GCC GAT CAC GAT CAG TA, rp49 forward: GCT AAG CTG TCG CAC AAA TGG, rp49 reverse: CTT GTT CGA TCC GTA ACC GAT G, SV40 forward: TGA TGA ATG GGA GCA GTG GTG, SV40 reverse: AGA ATG TTG AGA GTC AGC AGT AGC C, msta forward: CAC CCG GAA TAT CTT CCT CA, msta reverse: CGA CAA GTA GGT GCC GTT TT, trpl forward: AGA AGT TCC TGC TGG CTG TC, trpl reverse: AAT GGG TCC ATG CAG TTG AT, Rel forward: GGC CAT TCG ACA GAA CAA GT, Rel reverse: TGC CAT GTG GAG TGC ATT AT, $h s p 70 B c$ forward: AGG GTC AGA TCC ACG ACA TC, $h s p 70 B c$ reverse: CGT CTG GGT TGA TGG ATA GG, Hmgs forward: GCC TGA GCT TCA ACG ATT TC, Hmgs reverse: TCC ACA TCG CGA TCA AAG TA, Mtk forward: CCA CCG AGC TAA GAT GCA A, $M t k$ reverse: GGC CTC GTA TCG AAA ATG G, Def forward: TTC TCG TGG CTA TCG CTT TT, Def reverse: ATC CTC ATG CAC CAG GAC AT, $D p t$ forward: ACC GCA GTA CCC ACT CAA TC, $D p t$ reverse: CCC AAG TGC TGT CCA TAT CC, CG11426 forward: AGA GCG TCG TAG TGG CAA TAA, CG11426 reverse: CGT TTG CGG GGA TGT AAT, CG5966 forward: TGC AGA CCA TGT TGT ATT TGG, CG5966 reverse: GCC ATA CAC TCC GAA GCA TT, CG11489 forward: CAG GAC TTC CTC TCG CTG TC, CG11489 reverse: AGA CTG CTG TCG GAC GAA TC.

\section{Statistical analysis}

The drug feeding results, the pigment measurement experiment and the transcriptional dysregulation data were analyzed using one-way ANOVA followed by Dunnett's post hoc analysis or Tukey's honest significance test, as appropriate, on the VassarStats website for statistical computation (maintained by Richard Lowry, http://faculty.vassar.edu/lowry/VassarStats.html). The sleep fragmentation data from the TriKinetics activity monitors were analyzed by two-way ANOVA using the programming language and software environment GNU R. The longevity results were analyzed by logrank test, with hand written formulae in Excel. The eclosion data on various HDAC mutant backgrounds were compared by paired t-test, while all the other data sets were analyzed using Student's unpaired t-test in Microsoft Excel. 
Error bars on the graphs represent SEM, except for Fig. 7B, where the error bars are standard deviation calculated as $\mathrm{S}(\mathrm{p}) * \operatorname{sqrt}((1 / \mathrm{n})+(1 / \mathrm{m}))$, where $\mathrm{S}(\mathrm{p})=$ $\operatorname{sqrt}\left(\left((\mathrm{n}-1) * \operatorname{stdev}^{2}+(\mathrm{m}-1) * \operatorname{stdev}^{2}\right) /(\mathrm{n}+\mathrm{m}+2)\right) ; \mathrm{n}$ and $\mathrm{m}$ are the two sample sizes $($ Httex $1 p$ Q93 with and without the HDAC mutation) and $\mathrm{stdev}^{2}$ is their respective variance. 


\section{RESULTS}

\section{HDAC Inhibitors Reduce Degeneration in Httex1p Q93 Flies}

Histone deacetylase inhibitors reduce the neuronal cell loss of Httex lp Q93 flies with no effect on eclosion rate

Over the years, several investigators have shown that histone acetylation is impaired in Huntington's disease. Histone acetyltransferases (HATs) and various transcription factors are trapped in inclusions [Kazantsev et al., 1999; Suhr et al., 2001], and mutant Htt protein also binds to and directly inhibits the activity of various HATs [Steffan et al., 2001], as well as affects the methylation, phosphorylation or ubiquitination of histones [Stack et al., 2007; Kim et al., 2008]; thus resulting in reduced levels of the acetylated histones in the brain of mice [Stack et al., 2007], most specifically at the promoters of dysregulated genes [Sadri-Vakili et al., 2007].

The histone deacetylases (HDACs) are the opposing enzyme group, which removes the acetyl residue from the histone tails. We theorized that inhibiting their activity could counteract the impaired acetylation state seen in HD and reduce pathology. Flies that express the Httexlp Q20 transgene show no sign of toxicity; they are fully viable, and show no degeneration even at an advanced age (data not shown). On the other hand, when UAS-Httexlp Q93 flies are crossed to the elav-Gal4 driver at $25{ }^{\circ} \mathrm{C}$, only $30 \%$ of the resulting elav>Httex $1 p$ Q93 females eclose, and practically no males. The females appear externally normal, but they are short lived: compared to wild type flies, of which very few die in the first month of life, the median life span of mutant Htt expressing females is $\sim 10$, and the maximum 20 days. The absence of the males is likely due to dosage compensation: elav is an $\mathrm{X}$ chromosomal gene that is expressed higher in males than in females, and this property is retained by the elav-Gal4 driver, resulting in a higher expression of Gal4 and thus higher expression of any UAS trangene used in these crosses (in this case, $H t t$ ) in males.

To test if HDAC inhibitor administration is beneficial in vivo, we fed Httex1p Q93 expressing adult flies the drugs suberoylanilide hydroxamic acid (SAHA) and butyrate [Steffan et al., 2001; Agrawal et al., 2005]. The short chain fatty acid butyrate is a noncompetitive inhibitor of most HDACs except the sirtuins and the class II HDAC6 and -10 [Davie, 2003], while SAHA, a hydroxamate-based HDAC inhibitor, acts on most class I 
and II enzymes [Glaser, 2007]; although one study showed that the Drosophila HDAC4 is insensitive to either of these two drugs [Cho et al., 2005]. We found that SAHA administration is not toxic to elav>Httexlp Q93 females up to $100 \mu \mathrm{M}$ concentration, as it does not alter the eclosion rate (Fig. 3A). We observed a decrease in viability from $30 \%$ to $13 \%$ at the highest administered dose due to the toxicity of the solvent DMSO; therefore we repeated the experiment using 2-hydroxypropyl- $\beta$-cyclodextrin as an inclusion compound, which greatly increases the aqueous solubility of the drug [Hockly et al., 2003]

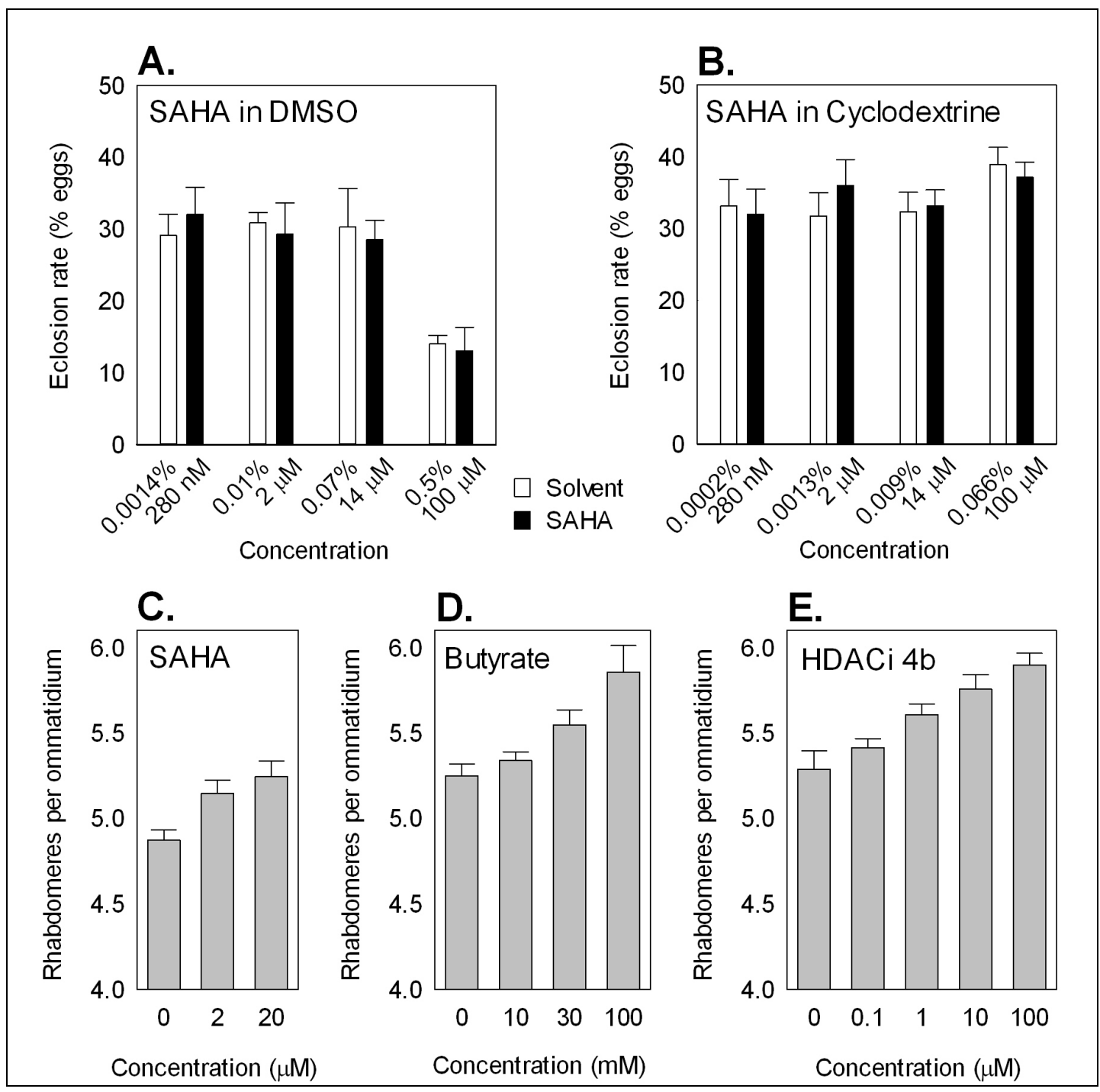

Figure 3. Broad spectrum pharmacological inhibitors are neuroprotective.

SAHA is not toxic to flies when it is administered in either DMSO (A) or Cyclodextrine (B), as it does not reduce the eclosion rate of elav>Httexlp Q93 females. Feeding elav>Httexlp Q93 flies SAHA (C), butyrate (D) or a pimelic diphenylamide HDAC inhibitor dubbed $4 \mathrm{~b}(\mathbf{E})$ reduces the photoreceptor neuron degeneration, as assessed by the pseudopupil technique. 
and found that SAHA indeed does not alter the eclosion rate of expanded polyglutamine expressing flies (Fig. 3B). However, $20 \mu \mathrm{M}$ SAHA appears to moderately improve the viability of these flies, since about $85 \%$ of the SAHA fed animals were still alive at seven days post-eclosion (the timepoint when they were sacrificed for the pseudopupil assay) as opposed to less than $60 \%$ of controls. We also did not observe any toxicity from administering up to $100 \mathrm{mM}$ butyric acid (data not shown).

Using the pseudopupil technique, we observed that both HDAC inhibitors reduce neurodegeneration in a concentration dependent manner when fed to adults expressing the Httex1p Q93 peptide in their nervous system: $20 \mu \mathrm{M}$ SAHA improves from 4.87 to 5.24, $(\mathrm{P}<0.01)$ (Fig. 3C), while $100 \mathrm{mM}$ butyrate increases the average rhabdomeres per ommatidium in 7-day-old flies from 5.25 to 5.85 , ( $\mathrm{P}<0.001$ ) (Fig. 3D). In addition, a third broad spectrum HDAC inhibitor compound, a pimelic diphenylamide dubbed HDACi 4b, which ameliorates the phenotypes of Huntington's disease transgenic mice [Thomas et al., 2008], also reduces neurodegeneration in the fly, improving the eye phenotype from 5.28 rhabdomeres per ommatidium in flies fed the solvent DMSO to 5.89 with $100 \mu \mathrm{M}$ compound $(\mathrm{P}<0.001)$ (Fig. 3E).

\section{Butyrate treatment improves motor function of Httexlp Q93 flies}

Httex1p Q93 expressing flies display a progressive loss of motor function, which can be measured by exploiting the negative geotactic behavior of Drosophila. In a nine-choice geotaxis maze (Fig. 4A) [Toma et al., 2002], young wild type flies choose to move upwards at the majority of bifurcation points, and therefore most of the flies exit the maze into the highest collection tubes; the agility of the flies, however, diminishes as they age, resulting in a different distribution pattern if older flies are used (Fig. 4B). The climbing ability of a fly population can be represented with a "geotaxis score", by numbering the tubes from 1 (lowest) to 9 (highest tube) and calculating a weighted average of the number of flies found in each collection tube. We found that in the case of 3-day-old wild type flies, this score is 6.8, while 12-day-old flies scored at 2. In contrast, flies expressing the Httexlp Q93 construct in their nervous system score at 2.9, showing an early loss of climbing ability (Fig. 4B).

Although the nine-choice geotaxis maze is an attractive tool for assessing the motor behavior of flies, we found that there is a large variation between repeated runs, and therefore the method is most suitable for running a mixed population of experimental and control flies, which can be measured together and separated at the end of the run based on 


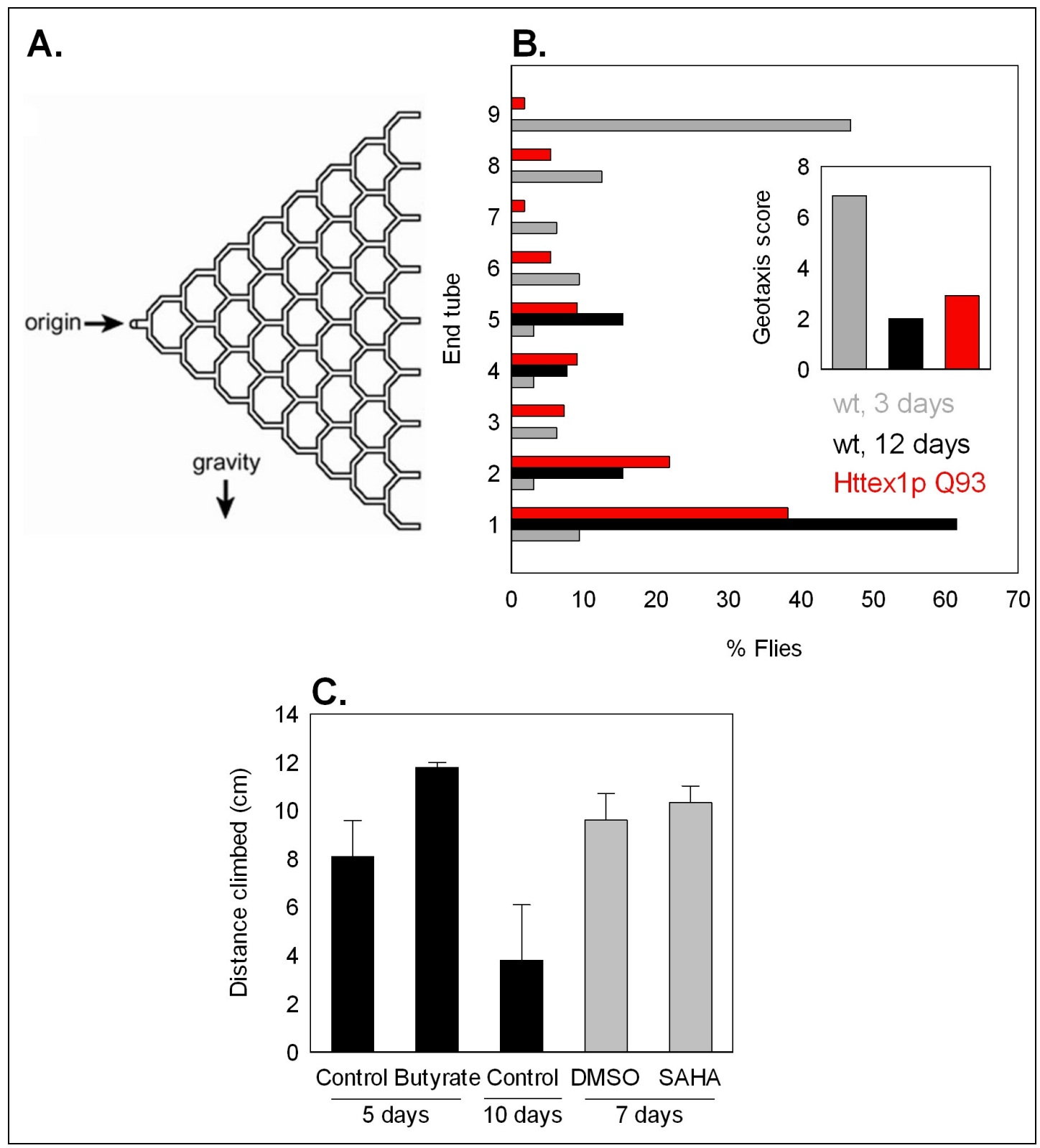

Figure 4. Htt challenged flies display a progressive loss of motor function.

(A) Schematic representation of the nine-choice geotaxis maze, a vertical maze where the flies choose between going up or down at every bifurcation point. Once they exit into one of the collection tubes on the right, they cannot reenter the maze. (B) The distribution of young and old flies carrying but not expressing the Htt transgene ("wt"), as well as mutant Httex $1 p$ expressing flies, is shown from a representative experiment. The geotaxis scores are calculated as a weighted average of the number of flies in each exit tube. (C) Feeding elav>Httexlp Q93 flies $100 \mathrm{mM}$ butyrate improves their motor function.

a distinguishing phenotype (such as age, eye color, etc.). For this reason, we chose a different approach for measuring the effect of HDAC inhibitors on the motor behavior of Httex1p Q93 flies: we used a vertical tube and monitored the distance the flies can climb 
in a fixed amount of time. We found that elav>Httex1p Q93 females progressively lose their climbing ability as they age: while at day 5 they cover an average of $8.1 \mathrm{~cm}$, at 10 days old this number drops to $3.8 \mathrm{~cm}$. In contrast, 5-day-old elav>Httex1p Q93 flies fed $100 \mathrm{mM}$ butyrate cover $11.8 \mathrm{~cm}(\mathrm{P}<0.05)$ (Fig. 4C). Feeding flies the drug SAHA resulted in a mild improvement which we observed in three repeated experiments, however the change remained statistically not significant. The average distance climbed increased from $9.6 \mathrm{~cm}$ with the solvent DMSO to 10.3 with $2 \mu \mathrm{M}$ SAHA at 7 days posteclosion (Fig. 4C).

\section{$\underline{\text { Butyrate reduces pigment cell loss in } g m r>H t t e x 1 p Q 93 \text { flies }}$}

Several Drosophila models of polyglutamine disorders are based on the eye specific expression of the polyglutamine transgene using the $g m r$ promoter, which results in a polyQ-length and protein context dependent rough or glassy eye phenotype and loss of pigmentation [Kazemi-Esfarjani and Benzer, 2000; Chan and Bonini, 2000]. Expressing our Httex1p Q93 transgene in the eye results in a very mild rough eye phenotype (the ommatidial lattice only being irregular on the edges), and a progressively increasing pigment loss, which can be readily quantified with a spectrophotometer. We found that while normally the eyes of Drosophila darken as they age, in Httexlp Q93 expressing animals the amount of red eye pigments drops about $25 \%$ over a course of three weeks $(\mathrm{P}<0.001)$ (Fig. 5A), suggesting a progressive loss of pigment cells in response to the expression of the mutant polyglutamine containing peptide.

We tested the effect of HDAC inhibitor administration using the pigment assay by feeding gmr $>$ Httexlp $Q 93$ animals $100 \mathrm{mM}$ butyrate. We found that 15 days post eclosion, the flies raised on butyrate containing food lost less pigment than their siblings kept in control vials (Fig. 5B). We also noticed that when butyrate is administered throughout development, it significantly reduces the size of the animals: the length of the pupae is $14 \%$ smaller, while the average wing area, another measure of the size of the animal, is $9 \%$ less. This presumably also affects the overall size of the eye, and therefore the amount of pigments in each, thereby potentially diminishing the measured effect the drug has on reducing the Htt-induced pigment cell loss.

To circumvent this problem, we repeated the experiment and fed butyrate only to adults. We generated flies that express the expanded polyglutamine containing peptide in their eyes (gmr>Httexlp Q93) and aged half of them on $100 \mathrm{mM}$ butyrate containing food while we kept the other half as controls. We found that 15 days post eclosion the butyrate 
treated animals show significantly less pigment loss than controls fed regular food (absorbance at $485 \mathrm{~nm}$ drops from 0.150 to 0.135 , versus in controls it falls from 0.155 to 0.120; $\mathrm{P}<0.05$ ) (Fig. 5B). This assay confirmed our earlier finding that histone deacetylase inhibitor treatment reduces cell death in Httexlp Q93 flies.

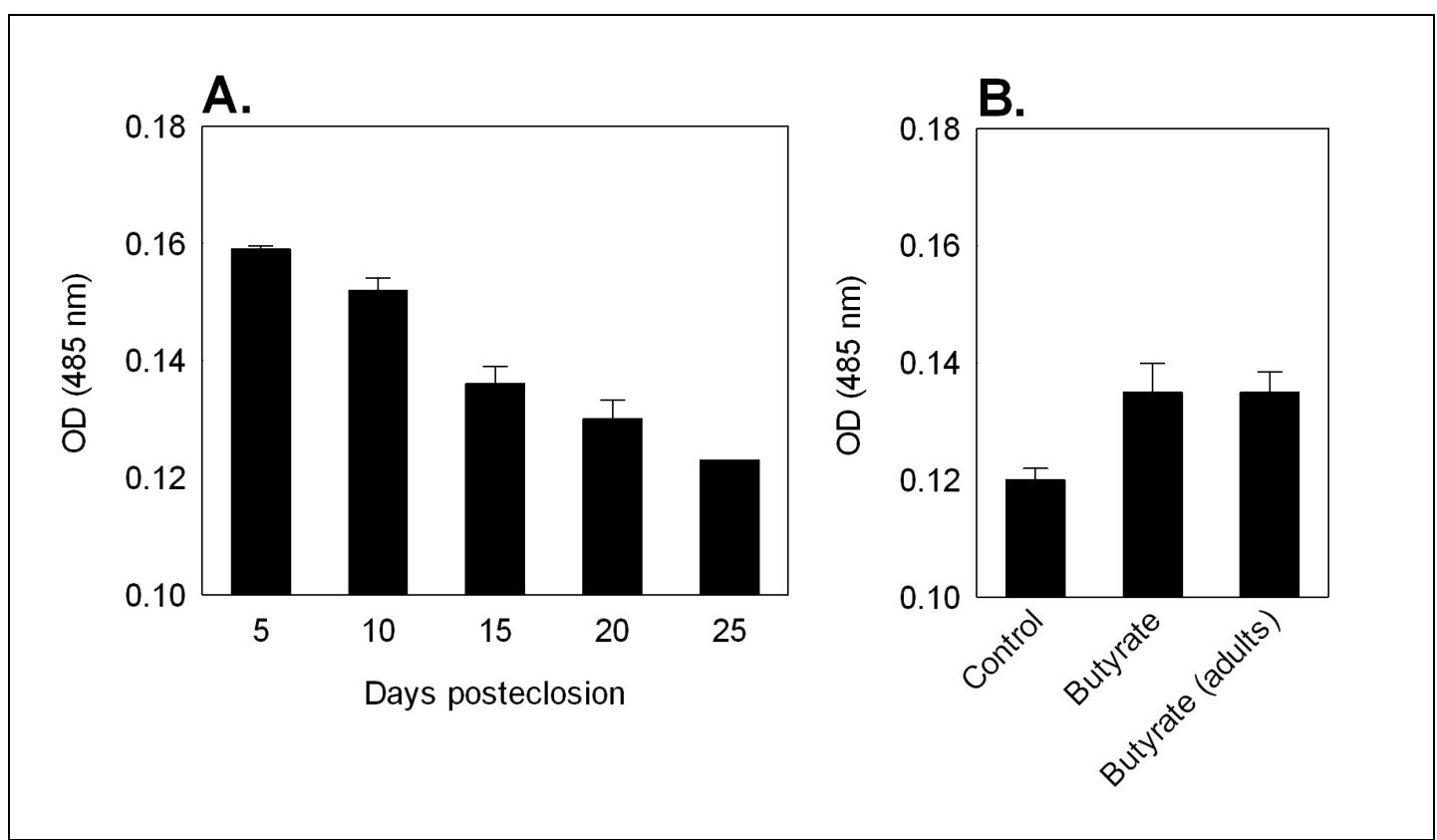

Figure 5. Butyrate treatment reduces pigment cell loss in $\mathrm{gmr}>$ Httexlp Q93 flies.

(A) Flies expressing the mutant $H t t$ transgene progressively lose their eye pigments, as measured by spectrophotometry. (B) Feeding gmr>Httexlp Q93 flies $100 \mathrm{mM}$ butyrate either throughout their lives or only as adults, diminishes the pigment loss; the measurements shown are from 15-day-old flies.

\section{$\underline{\text { Summary }}$}

We have shown by multiple assays that broad spectrum histone deacetylase inhibitor treatment improves the phenotypes of flies expressing a pathogenic fragment of $\mathrm{Htt}$ : it reduces the loss of pigment cells or photoreceptor neurons, and ameliorates the movement defects of Httexlp Q93 flies. 


\section{Modulating Specific HDACs as a Therapeutic Strategy}

\section{Generation and characterization of HDAC mutants}

To better understand the positive effect observed by administering the HDAC inhibitor compounds, we sought to investigate the contribution of each of the individual HDAC loci to Httexlp Q93 pathology. The 10 Drosophila histone deacetylases can be grouped into four classes based on sequence homology and mechanism of action, and they represent each class of the mammalian histone deacetylases (Table 1) [Frye, 2000; Gregoretti et al., 2004]. The 5 Zn-dependent HDACs, (HDAC1/Rpd3, HDAC3, HDAC4, HDAC6 and HDAC11) are all inhibited by butyric acid or SAHA [Davie, 2003; Glaser, 2007], therefore the phenotypic improvements seen by drug administration to Httex $1 p$ Q93 flies can be attributed to reducing the activity of any one or all of these enzymes. To test the contribution of each HDAC locus to Htt pathology, we obtained the available mutant alleles from stock centers and other investigators, and also made RNAi constructs for HDACs 3, 4, 6 and 11.

\begin{tabular}{|c|c|c|c|c|c|}
\hline & & & Homo sapiens & $\begin{array}{c}\text { Drosophila } \\
\text { melanogaster }\end{array}$ & $\begin{array}{c}\text { Caenorhabditis } \\
\text { elegans }\end{array}$ \\
\hline \multirow{11}{*}{ 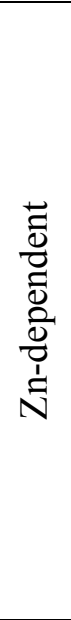 } & \multirow{4}{*}{\multicolumn{2}{|c|}{ Class I }} & HDAC1 & \multirow{2}{*}{ Rpd3 } & \multirow{2}{*}{ hda-1, hda-3 } \\
\hline & & & HDAC2 & & \\
\hline & & & HDAC3 & HDAC3 & hda-2 \\
\hline & & & HDAC8 & & \\
\hline & \multirow{6}{*}{ Class II } & \multirow{4}{*}{$\mathrm{a}$} & HDAC4 & \multirow{4}{*}{ HDAC4 } & \multirow{4}{*}{ hda-4 } \\
\hline & & & HDAC5 & & \\
\hline & & & HDAC7 & & \\
\hline & & & HDAC9 & & \\
\hline & & \multirow{2}{*}{$\mathrm{b}$} & HDAC6 & \multirow{2}{*}{ HDAC6 } & hda-6 \\
\hline & & & HDAC10 & & hda-5, hda10 \\
\hline & \multicolumn{2}{|l|}{ Class IV } & HDAC11 & HDAC11 & hda-11 \\
\hline \multirow{7}{*}{ 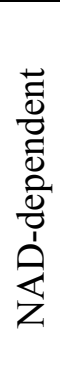 } & \multirow{7}{*}{ Class III } & $\mathrm{Ia}$ & SIRT1 & Sir2 & $\operatorname{sir} 2.1$ \\
\hline & & \multirow{2}{*}{$\mathrm{Ib}$} & SIRT2 & \multirow{2}{*}{ Sirt2 } & \\
\hline & & & SIRT3 & & \\
\hline & & II & SIRT4 & Sirt4 & $\operatorname{sir} 2.2, \operatorname{sir} 2.3$ \\
\hline & & III & SIRT5 & & \\
\hline & & IVa & SIRT6 & Sirt6 & $\operatorname{sir} 2.4$ \\
\hline & & $\mathrm{IVb}$ & SIRT7 & Sirt7 & \\
\hline
\end{tabular}

Table 1. HDAC orthologs in worm, fly and human are shown for reference 
The RNAi constructs were made by cloning into a modified pWIZ vector a fragment of the gene in question, first in reverse, followed by the forward orientation, separated by an intron from the $w g$ gene. Transgenic lines were generated by injecting $w$ embryos following a standard protocol; and 3-15 independent lines were established for each transgene.

To test the new HDAC-RNAi constructs and evaluate their ability to reduce endogenous HDAC levels in the nervous system, several lines for each were crossed to the elav-Gal4 driver, RNA was prepared from the heads of the resulting offspring, reverse transcribed and quantitative real time PCR was performed. At least three independent RNA extractions were made using the TRIzol reagent for both the experimental genotypes (elav $>H D A C-R N A i)$ as well as internal control siblings that do not express the RNAi construct (they carry a balancer chromosome in addition to elav-Gal4). Random hexamer primers were used to reverse transcribe $1 \mu \mathrm{g}$ of purified total RNA; the primers for the qPCR reaction were designed to overlap an intron to prevent amplification of the potential genomic DNA contamination in the sample. As a standard, a parallel qPCR reaction was run for each sample using primers for the ribosomal protein $r p 49$. In addition, we also ran a 5 step dilution series for each primer, the results of which were used to calculate an efficiency curve to ensure that proper conditions (primer concentrations and temperature) were chosen in the qPCR reaction. Ultimately we identified at least one RNAi line from each construct that reduced the endogenous HDAC levels by at least half $(\mathrm{P}<0.05)$ (Fig. $6 \mathrm{~A}$ ), that is their expression resulted in a mutant similar to a heterozygous null; these were selected for further analysis.

First we performed a survival analysis of the $H D A C-R N A i$ lines using the ubiquitous actin-Gal4 driver, which is heterozygous over a TM6 balancer chromosome. When compared to siblings with normal levels of HDAC (i.e. UAS-RNAi/TM6b), flies expressing HDAC4 and HDAC6 RNAi are fully viable, while $H D A C 11$ affects the viability of males only (reducing their eclosion rate to about $25 \%$; the females are fully viable and hence the overall eclosion is $75 \%$ of control). In contrast, we found that reducing HDAC3 levels results in complete lethality, with some animals surviving until the pharate adult stage, but without a single animal eclosing (Fig. 6B).

To assess the effect of HDAC mutations in the nervous system, we also crossed the RNAi lines to the elav-Gal4 driver. For these experiments, we prepared 5-10 vials for each transgenic construct by placing 100 fertilized eggs of the genotype elav $>H D A C$ $R N A i$ in each, incubated them at $25^{\circ} \mathrm{C}$ until eclosion, and counted the adults that emerged. 


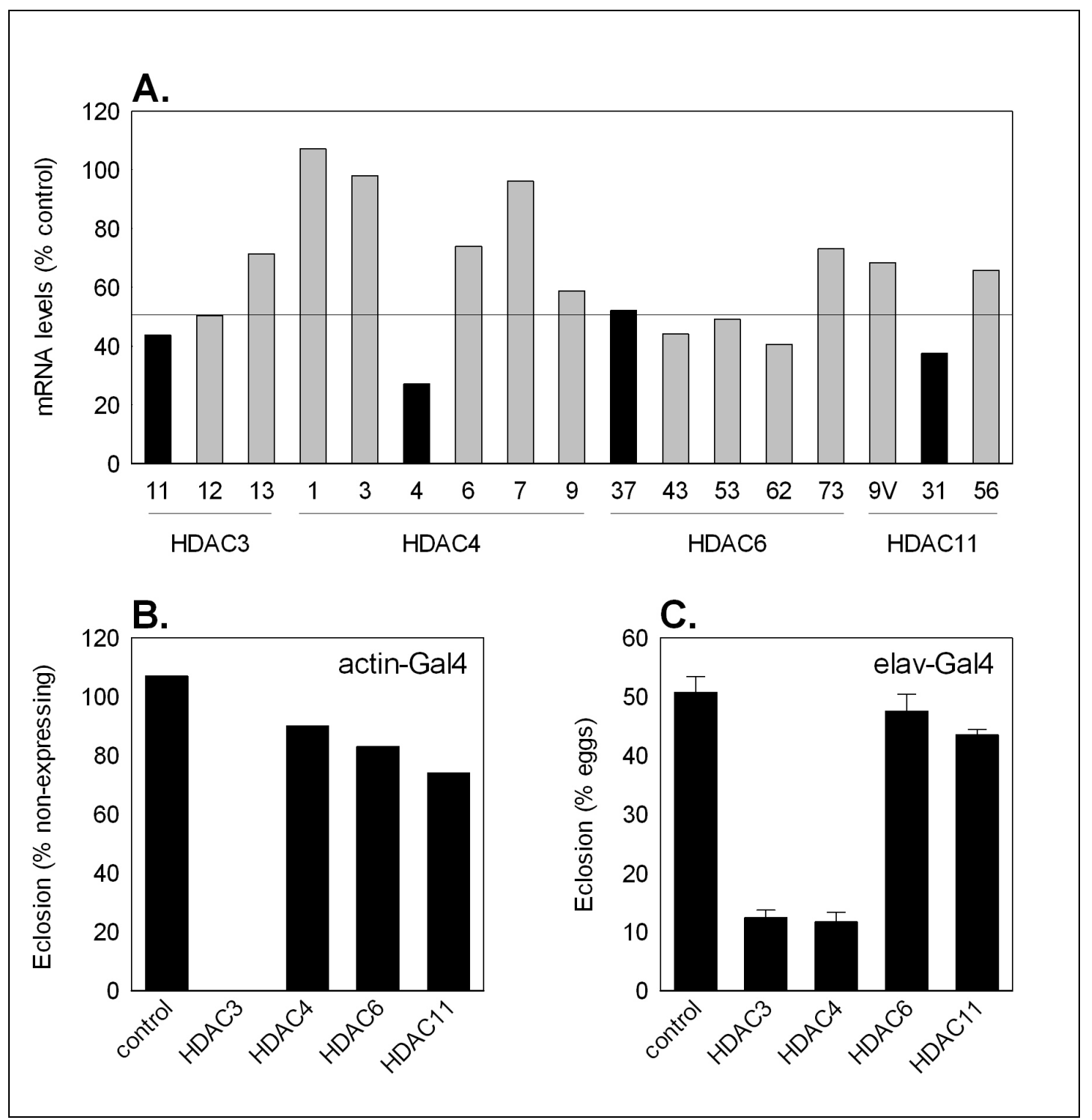

Figure 6. Characterization of the HDAC-RNAi lines.

(A) Quantitative real time PCR measurements of HDAC transcript levels in elav $>H D A C$ $R N A i$ flies compared to controls not expressing the RNAi transgene. The lines used in the eclosion rate studies are highlighted with black bars. (B) Ubiquitous expression of the HDAC3 RNAi transgene is lethal, while flies with reduced HDAC4, HDAC6 or HDAC11 levels eclose in similar numbers as controls. (C) Neuronal expression of HDAC3 or HDAC4 RNAi reduces the viability of flies. The controls in both experiments are animals carrying the $\mathrm{CyO}$ balancer chromosome in addition to the Gal4 driver.

We found that while reducing HDAC6 or HDAC11 levels in the nervous system has no impact on the survival of the flies, HDAC3 and HDAC4 both reduce the eclosion rate to about a quarter (Fig. 6C). The surviving animals of all genotypes appeared phenotypically normal, without gross malformations. 
Selected HDAC mutants have impact on Httex 1p Q93 induced pathology

To determine the consequences of altered HDAC activity on HD pathology, we compared the phenotypes of Httexlp Q93 expressing animals with normal levels of a particular HDAC to their siblings with partially reduced levels of the same enzyme. In a typical experiment, we first generated males that carry the elav-Gal4 driver on their $\mathrm{X}$ chromosome as well as an HDAC mutation on one of their autosomes, then crossed these males to UAS-Httexlp Q93 females (for sex-linked genes a different approach was used, see Materials and Methods). We monitored the eclosion of the resulting offspring, as well as the extent of neuronal degeneration using the pseudopupil technique.

Using two independent mutations, the null $m 5-5$ and the hypomorphic $\mathrm{P}$ element insertion 04556, we found that heterozygous reduction of the levels of Drosophila Rpd3 markedly increases survival of mutant Htt-challenged flies by 2-3 fold (Fig. 7A), and neuronal survival is also increased, as measured by the number of remaining photoreceptor neurons in the eye: from 4.79 in the control group of elav>Httexlp Q93/Sb to 5.62 in the elav>Httex1p Q93/Rpd3[04456] $(\mathrm{P}<0.002)$, and from 5.26 to 5.99 for the $m 5-5$ allele (Fig. 7B). In contrast, we did not observe any suppression of lethality or of neuronal degeneration in animals with reduced levels of HDAC3, HDAC4, HDAC6 or HDAC11. While the hypomorphic alleles of HDAC3 ( $I$ and $J$ ) had no impact on either survival or photoreceptor degeneration, the null allele $N$ slightly worsened both phenotypes and the RNAi lines (11 and 12) reduced viability by half $(\mathrm{P}<0.05)$ (Fig 7A). We could not evaluate the effect of the RNAi lines in the pseudopupil assay because the animals did not survive the first week of their adult lives. Since the $H D A C 3-R N A i$ lines also reduced viability in experiments independent of Httexlp Q93 (see previous segment), we conclude that the increased toxicity observed with the mutant Htt construct does not necessarily implicate HDAC3 in HD pathology, but rather it reflects the importance of this deacetylase in Drosophila homeostasis. The two class II deacetylases, HDAC4 and HDAC6, were tested using a classical allele (a P element insertion or a deficiency) and an RNAi allele for each, and we found that reducing the levels of either of these deacetylases has no significant impact on the survival or neurodegeneration of Httexlp Q93 flies; nor did the class IV deacetylase HDAC11 show any effect. Taken together, we conclude that among the classic, metal-dependent (class I, II and IV) HDACs, neuronal survival is uniquely sensitive to Rpd3 levels in Drosophila challenged with mutant Httex 1p [Pallos et al., 2008]. 

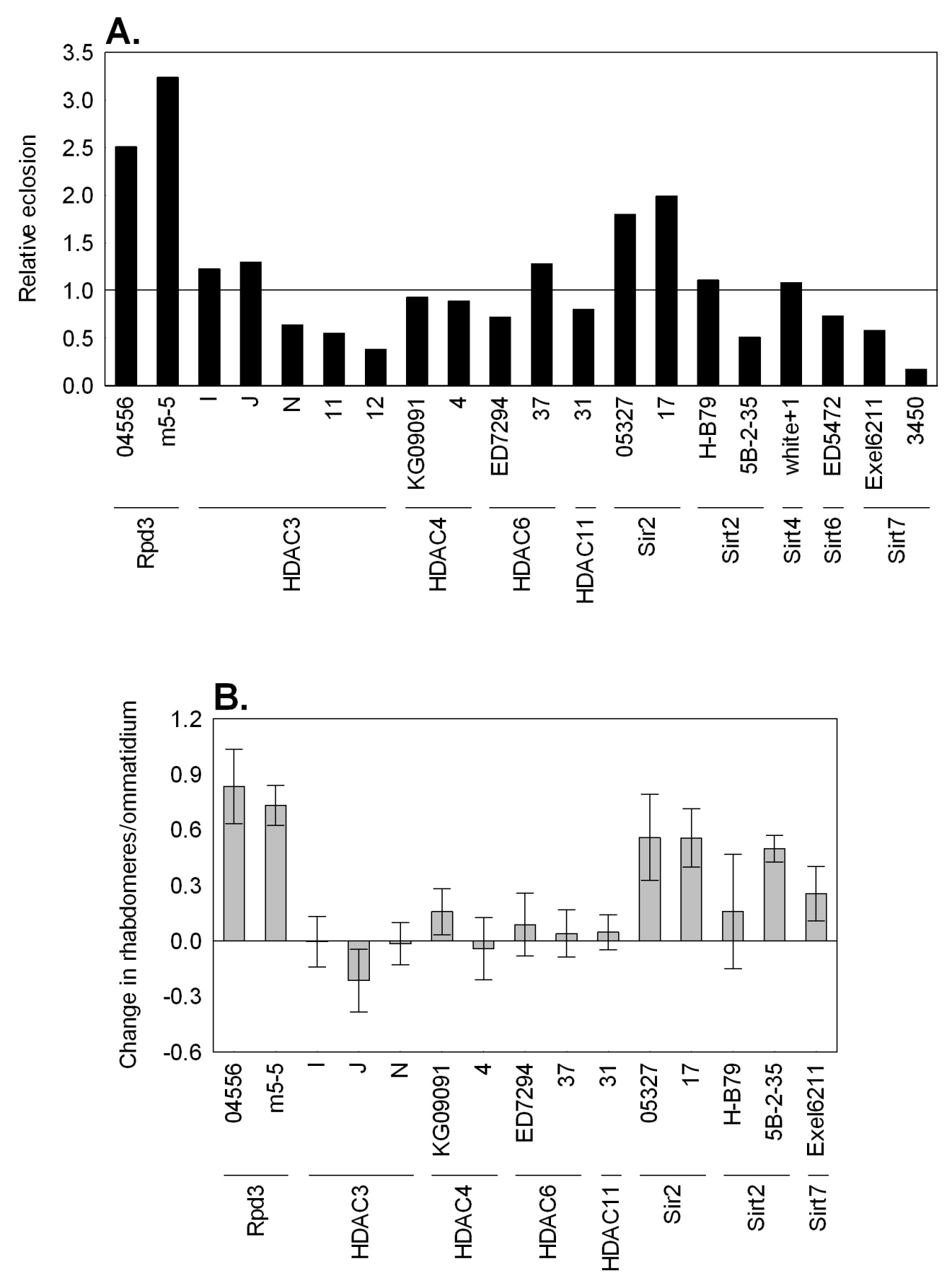

Figure 7. Select HDAC mutations affect HD pathology.

(A) The eclosion rate of elav $>$ Httex $1 p$ Q93 flies carrying a heterozygous HDAC mutation is shown compared to elav>Httexlp Q93 siblings with normal levels of HDAC; the ratio was normalized to the eclosion ratio of non-Htt siblings with and without the HDAC mutation. (B) The difference in the average rhabdomeres per ommatidium in 7-day-old expanded $H t t$ expressing flies with and without an HDAC mutation is shown. 
We also tested the impact of reducing the sirtuin levels, or class III HDACs, on HD pathology. These enzymes have an $\mathrm{NAD}^{+}$-dependent catalytic mechanism distinct from the classic deacetylases, and are therefore insensitive to the chemical inhibitors of the other group [Barlow et al., 2001; Cho et al., 2005]. Following experiments similar to the ones described above, we found that reducing the levels of 2 of the 5 sirtuin enzymes (Sir2 and Sirt2) improves Httex1p Q93 pathology. The P-element induced allele 05327 and the null allele 17 of Sir2 both double the eclosion rate of Httex1p Q93 flies (Fig. 7A), and increase the surviving rhabdomeres at day 7 post-eclosion from 5.27 to $5.83(\mathrm{P}<0.03)$, and from 4.8 to $5.34(\mathrm{P}<0.01)$, respectively (Fig. 7B). While heterozygous loss of Sirt2 using a large deletion did not significantly alter the viability or the eye phenotype of the flies, a null allele, which worsened the eclosion rate somewhat, reduced the photoreceptor degeneration of the flies to an extent similar to Sir2 (average increase from 5.27 to 5.77, $\mathrm{P}<10^{-5}$ ) (Fig. 7B) [Pallos et al., 2008]. We did not observe a change in eclosion rate using a loss of function allele of Sirt4, while the deficiencies that uncover Sirt6 or Sirt7 both enhanced the lethality of the expanded polyglutamine carrying flies (Fig. 7A). The extent of neuronal degeneration remained unchanged in Sirt7 deficient flies; the effect of the Sirt6 loss could not be measured as the animals died early, before the pseudopupil analysis was performed.

Sirtuin inhibitor feeding reproduces the protective effect seen with loss of function $\underline{\text { mutations }}$

We next explored whether pharmacological modulation of sirtuin activity could mimic the effects observed with genetic modulation. Sirtinol is an inhibitor of Sir2 that exhibits no activity against classic HDACs such as Rpd3 [Grozinger et al., 2001]. Feeding Httex1p Q93-challenged flies sirtinol-containing food reduces the loss of photoreceptor neurons: at $100 \mu \mathrm{M}$ concentration, a rescue of 5.17 to 5.63 rhabdomeres per ommatidium was observed $(\mathrm{P}<0.001)$ (Fig. 8A). We also raised flies on nicotinamide, a strong, noncompetitive inhibitor of sirtuins [Landry et al., 2000; Bitterman et al., 2002], as well as niacin, which is identical in its vitamin B3 activity to nicotinamide, and found that at 20 $\mathrm{mM}$ concentration, these drugs also increase the survival of photoreceptor neurons, from 4.86 to $5.32(\mathrm{P}<0.01)$ (Fig. 8B), and from 4.93 to 5.59 ( $\mathrm{P}<0.01)$ (Fig. 8C), respectively [Pallos et al., 2008]. Recently, several drug inhibitors were developed to specifically inhibit SIRT2 [Outeiro et al., 2007], and we found that all three of the drugs tested 

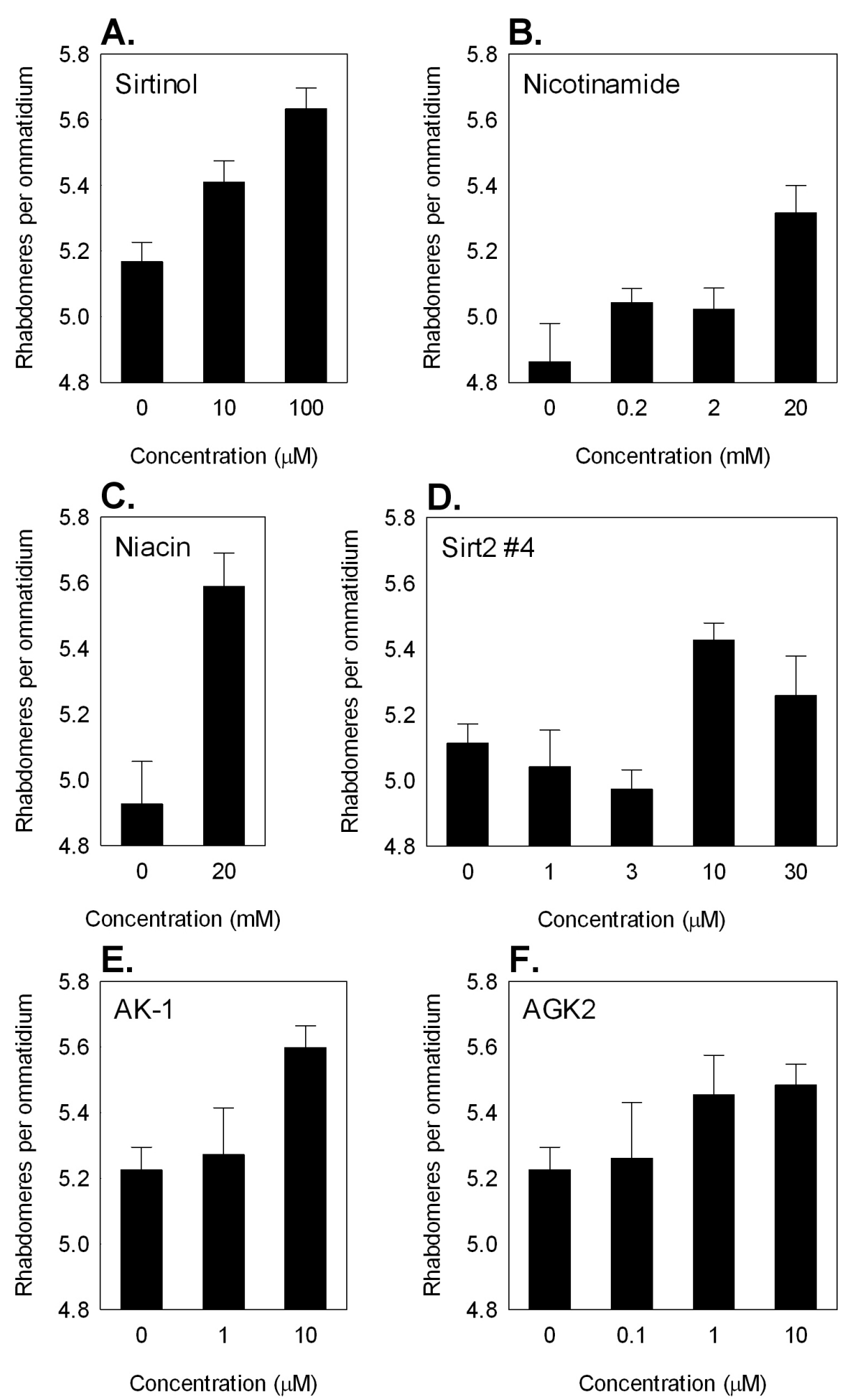

Figure 8. Sirtuin inhibitors rescue Httex1p Q93 induced pathology.

Administration of (A) sirtinol, (B) nicotinamide or (C) niacin, drugs that inhibit all sirtuins, reduces photoreceptor neuron degeneration. Administration of compounds that specifically inhibit Sirt2, such as (D) \#4, (E) AK-1 or (F) AGK2, is also protective. 
significantly reduced the photoreceptor degeneration in our Drosophila HD model at 10 $\mu \mathrm{M}$ concentration: \#4 increases the average rhabdomeres per ommatidium preserved at day 7 post-eclosion from 5.11 to $5.43(\mathrm{P}<0.01)$ (Fig. 8D), while AK-1 and AGK2 improve it from 5.23 to 5.60 and 5.48, respectively $(\mathrm{P}<0.01)$ (Fig. 8E-F). These drugs were shown to rescue the $\alpha$-synuclein-mediated toxicity in cellular and Drosophila models of Parkinson's disease [Outeiro et al., 2007], and also improve the touch receptor phenotype in a $C$. elegans model of Huntington's disease, as well as reduce toxicity and aggregate formation in a primary neuron model of HD [Luthi-Carter et al., 2010].

\section{Combinatorial reduction of HDAC activities}

To determine whether Rpd3, Sir2 and Sirt2 affect different mechanisms or the beneficial effect of the various loss of function mutations is due modulation of the same cellular pathway, we examined the phenotypes of double HDAC mutant, as well as the phenotypes of sirtuin homozygous Httexlp Q93 expressing flies (the Rpd3 locus is homozygous lethal). Interestingly, while the two sirtuins are highly related, mutant Htt expressing flies homozygous for Sir2 or Sirt2 null alleles have opposite phenotypes: Sir2 homozygosity results in more extensive neurodegeneration than heterozygous loss of the gene (average rhabdomeres per ommatidium 4.97 vs $5.70, \mathrm{P}<0.05$ ), while Sirt2 homozygous null flies show less neurotoxicity than their heterozygous siblings (average rhabdomeres per ommatidium 6.05 vs 5.38, $\mathrm{P}<10^{-5}$ ) (Fig. 9A). The double heterozygous sirtuin mutant flies show further improvement over animals carrying the Sir2 mutation alone (average rhabdomeres per ommatidium 5.43 vs $5.05, \mathrm{P}<0.05$ ), but no improvement over the Sirt2 nulls (Fig. 9B).

Combining the sirtuins with the class I deacetylase Rpd3, we found that introducing the Rpd3[04556] allele further reduces the neurodegeneration of elav $>$ Httex $1 p$ Q93 flies also carrying the Sir2 or the Sirt2 mutation. More precisely, the average rhabdomeres per ommatidium in one week old females increases from 5.33 to 5.67 on Sir2 [05327] background ( $<<0.01)$, from 5.26 to 5.47 on Sir2 [17] background $(\mathrm{P}<0.02)$, and from 5.41 to $5.70(\mathrm{P}<0.05)$ in the case of the Sirt2 null allele (Fig. 9C-E).

We also replicated this result pharmacologically by feeding the flies nicotinamide and butyric acid simultaneously, using low doses that do not convey significant rescue when administered alone [Pallos et al., 2008]. We observed an increase from 5.43 to 5.74 rhabdomeres per ommatidium $(\mathrm{P}<0.001)$ when $10 \mathrm{mM}$ butyrate and $2 \mathrm{mM}$ nicotinamide were used in combination (Fig. 9F). The co-feeding of the higher doses of $100 \mathrm{mM}$ 


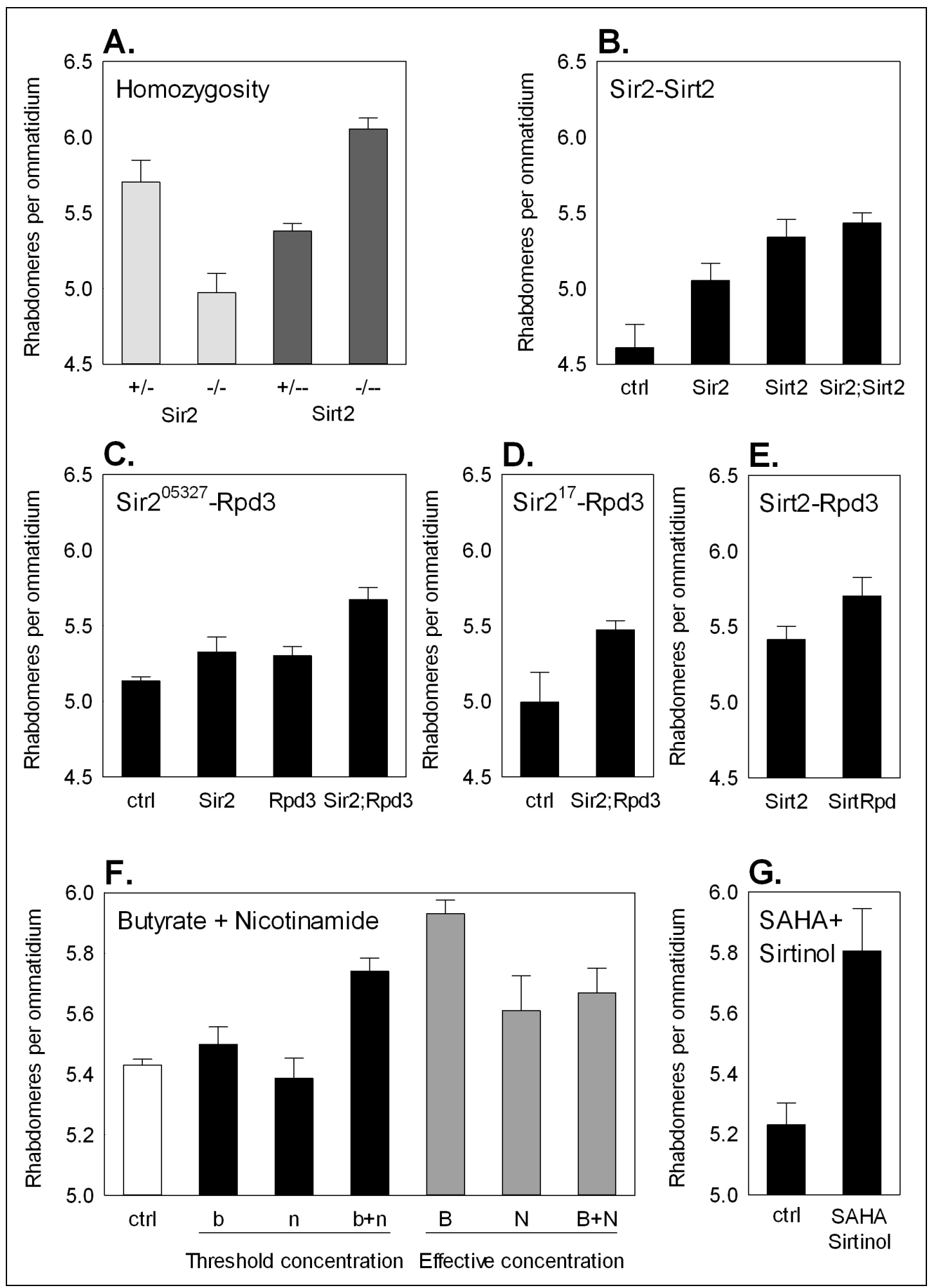

Figure 9. Combinatorial reduction of HDAC activities.

(A) Neurodegeneration in elav $>$ Httex1p Q93 flies homozygous and heterozygous for Sir2 or Sirt2. Flies carrying heterozygous mutations for two HDACs, such as (B) Sir2 and Sirt2, (C) Rpd3 and Sir2 [05327], (D) Rpd3 and Sir2 [17] or (E) Rpd3 and Sirt2 show less neurodegeneration than single mutants. (F) Feeding low doses of butyrate (b) or nicotinamide $(\mathrm{n})$ in combination or $(\mathbf{G})$ co-feeding SAHA and sirtinol is protective. 
butyrate and $20 \mathrm{mM}$ nicotinamide also resulted in an improvement over animals raised on control food (average rhabdomeres per ommatidium of 5.67), but not over animals kept on effective doses of the single drugs; an observation we have made previously using different compounds [Agrawal et al., 2005], and which can likely be attributed to toxicity. We also detected an improvement of the eye phenotype in flies fed SAHA and sirtinol in combination (5.23 to 5.82, $\mathrm{P}<0.02$ ) (Fig. 9G).

These results collectively suggest that the lessening of neurodegeneration in Httex1p Q93 flies that the loss of function alleles of the three histone deacetylases convey is either due to Rpd3, Sir2 and Sirt2 affecting entirely distinct cellular pathways when ameliorating HD pathology, or they might all influence histones and transcriptional output, but by altering a distinct subset of genes. Importantly, the improvement in neurodegenerative phenotypes of flies heterozygous for the HDAC mutations is not due to altered transcription levels of the Httexlp Q93 transgene itself, as measured by reverse transcription polymerase chain reaction (RT-PCR) (Fig. 10).

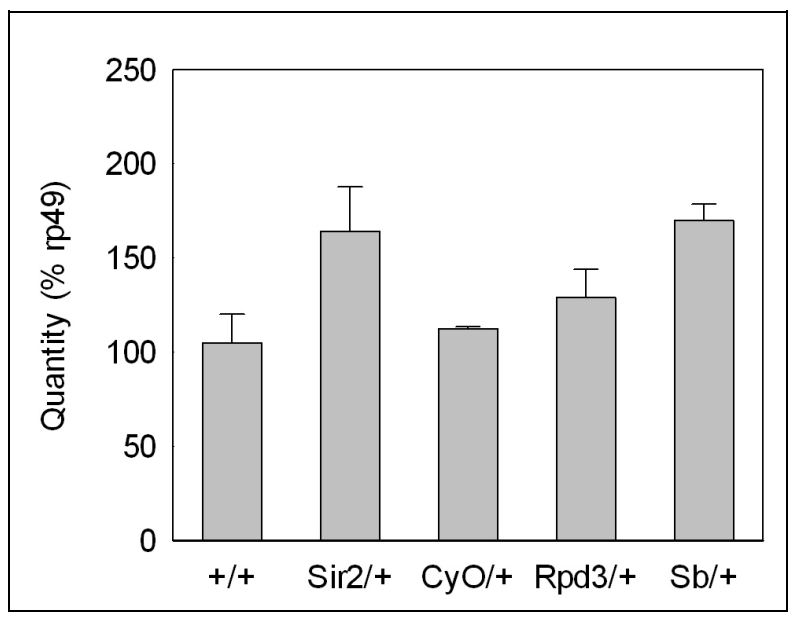

Figure 10. Htt transgene levels are unaltered by HDAC mutations.

Quantitative PCR measurements of the transgene levels in elav>Httexlp Q93 females on wild type $(+/+)$ or HDAC mutant $(\operatorname{Sir} 2 /+$ or Rpd3/+) background show that the neuroprotection seen with these HDACs is not due to downregulation of the UAS transgene itself. The $\mathrm{CyO} /+$ and the $\mathrm{Sb} /+$ animals are the internal control siblings from the Sir2 and $\operatorname{Rpd} 3$ crosses, respectively.

\section{Summary}

Our results indicate that selective targeting of specific HDACs can provide much of the neuroprotection seen with general, pharmacological HDAC inhibition in Htt-challenged Drosophila. We find that Rpd3 reduction can provide the bulk of the improvement observed with butyrate or SAHA. We show that pharmacological inhibition of sirtuins, the class III deacetylases, is also beneficial, and that two of the targeted enzymes, Sir2 and Sirt2 are responsible for this effect. Additionally, simultaneous reduction of class I and class III deacetylases results in greater neuroprotection over any single treatment alone. 


\section{The Mechanism of Deacetylase Action}

\section{$\underline{\text { Rpd3 does not regulate Sir2 levels }}$}

Studies with different outcomes have shown that class I-II histone deacetylases can regulate sirtuin transcription. One study in Drosophila suggested that reducing Rpd3 levels increases transcription of Sir2 [Rogina et al., 2002], while another demonstrated that chemical inhibitors of the metal-dependent deacetylases, such as trichostatin A or butyrate, decrease SIRT1 and increase SIRT2 mRNA levels in cultured neuronal cells [Kyrylenko et al., 2003]. We therefore sought to re-examine the response of Sir2 levels to reduced Rpd3. Using the same P element allele (04556) as previously reported [Rogina et al., 2002] and real time quantitative RT-PCR, we found that Sir2 mRNA levels are normal and unchanged in Rpd3 heterozygotes in two different genetic backgrounds (Oregon-R and white), as well as in Htt-challenged animals, indicating that Rpd3 does not regulate Sir2 expression levels (Fig. 11). This finding suggests that Rpd3 and Sir2 act independently and in parallel, a result that is consistent with our genetic interaction experiments using double mutants.

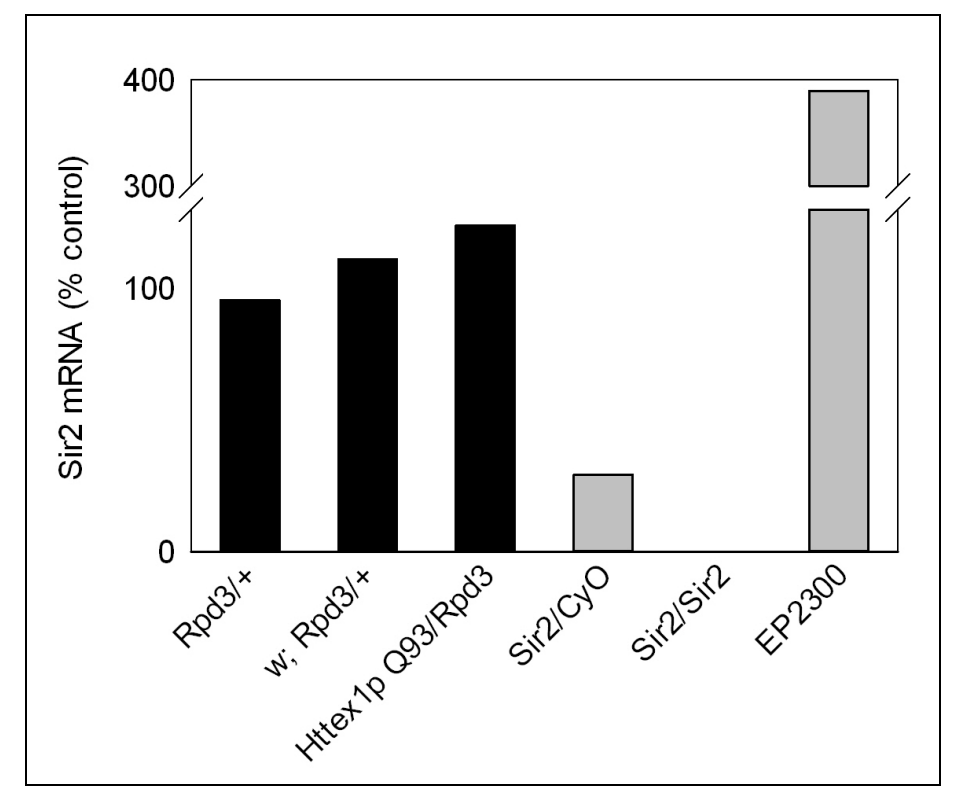

Figure 11. Reduced levels of Rpd3 do not lead to increased Sir 2 expression.

The plot shows Sir2 mRNA levels in Rpd3 mutants normalized to internal control (TM3) siblings on three different genetic backgrounds: ORE-R, $w$ or elav>Httexlp Q93. Quantitative PCR measurements of Sir2 heterozygous, homozygous or overexpressing (elav $>E P 2300)$ flies demonstrate the sensitivity of the experiment. 


\section{Effects of deacetylase levels on life span}

The two most studied Drosophila histone deacetylases, Rpd3 and Sir2, have both been implicated in regulating longevity. Reduced levels of Rpd3, either using mutants or by administering 4-phenylbutyrate, have been reported to increase life span in Drosophila [Rogina et al., 2002; Kang et al., 2002]; while increasing Sir2 levels either using genetic tools or by caloric restriction also extends life span of the fly [Rogina and Helfand, 2004]. In contrast, heterozygous reduction of Sir2 levels does not alter the longevity of Drosophila [Newman et al., 2002].

Since Drosophila expressing the expanded Httexlp transgene are short lived, and mutations of both Rpd3 and Sir2 impact the neurodegeneration of these animals, we sought to determine if the improvement seen with the HDAC mutations translates into an increased longevity of Httex1p Q93 flies. We introduced the mutant HDAC alleles into the expanded Httexlp expressing background and monitored the life span of the resulting progeny. We found that heterozygous loss of Rpd3 improves longevity: the median life span of control (non-Htt) animals increased from 49 to 56 days with the Rpd3 mutation (a survival rate increase of 1.55 fold, $\mathrm{P}<0.004$ ), while the median life span of Httex1p Q93 flies carrying the Rpd3 mutation changed by less than a day compared to Httex1p Q93 flies with wild type levels of the deacetylase (1.27 fold increase in survival rate, $\mathrm{P}<0.003$ ) (Fig. 12A). In contrast, heterozygous loss of either Sir2 or Sirt2 failed to significantly alter the survival rate of mutant $H t t$ expressing flies (Fig. 12B).

To evaluate the impact of increased Sir2 activity, we first tested the effect of caloric restriction on Htt flies, and aged the animals on a $50 \%$ diluted food as described earlier [Partridge et al., 2005]. We found that non-Htt flies benefit from this regimen, as their median life span increases from 59 to 72 days (corresponding to a 1.95 fold increase in survival rate, $\mathrm{P}<10^{-10}$ ) (Fig. 12C). In contrast, both the life span and the neurodegeneration of mutant $\mathrm{Htt}$ expressing animals remained unchanged (Fig. 12C-D). Genetic overexpression of Sir2 significantly increases the longevity of animals: from 45 to 55 days in non-Htt animals (survival rate increase of 2.5 fold, $\mathrm{P}<10^{-9}$ ), and it also results in an increase from 9 to 11 days in Httexlp Q93 expressing flies (survival rate increase of 1.77 fold, $\mathrm{P}<10^{-7}$ ) (Fig. 12E); however, it has no effect on the eclosion rate or the photoreceptor neuron degeneration (Fig. 12F-G).

We also tested the effect of resveratrol, a plant polyphenol reported to extend life span in worms and in flies by increasing Sir2 activity [Howitz et al., 2003; Wood et al., 2004], and found that resveratrol can rescue neuronal degeneration in Htt-challenged flies 


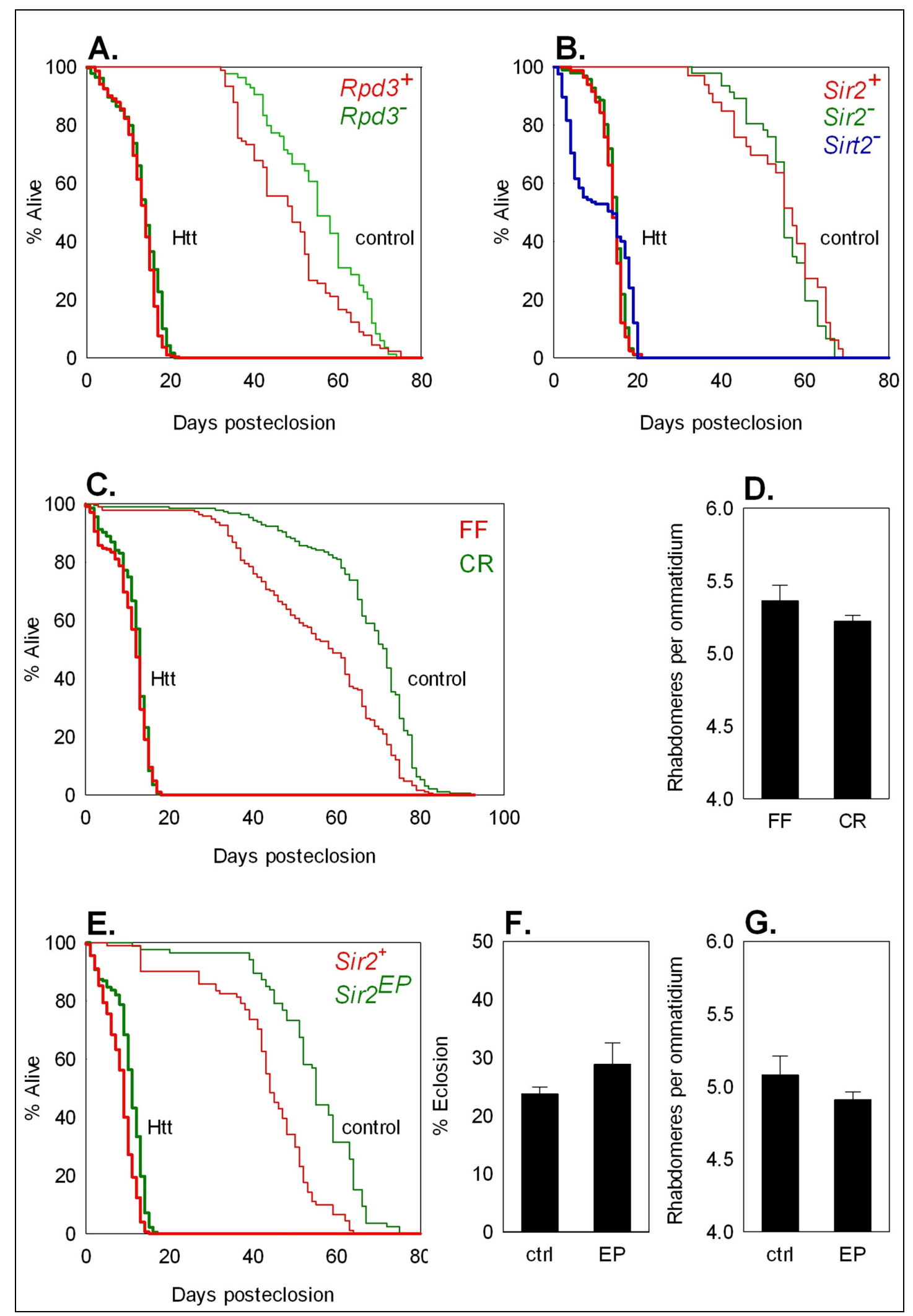

Figure 12. The effect of histone deacetylases on life span. 
in a dose-dependent manner (from 5.14 to 5.43 rhabdomeres per ommatidium at $10 \mu \mathrm{M}$ concentration, $\mathrm{P}<0.01$ ) (Fig. 13A), although it does not alter the early death phenotype of flies expressing Httexlp Q93 (Fig. 13B). We also found that Htt-challenged flies homozygous for the Sir2 null mutation are rescued to a similar extent (4.95 to 5.32 rhabdomeres per ommatidium, $\mathrm{P}<0.02$ ), indicating that the ability of resveratrol to suppress neurodegeneration does not depend on Sir2 (Fig. 13C).

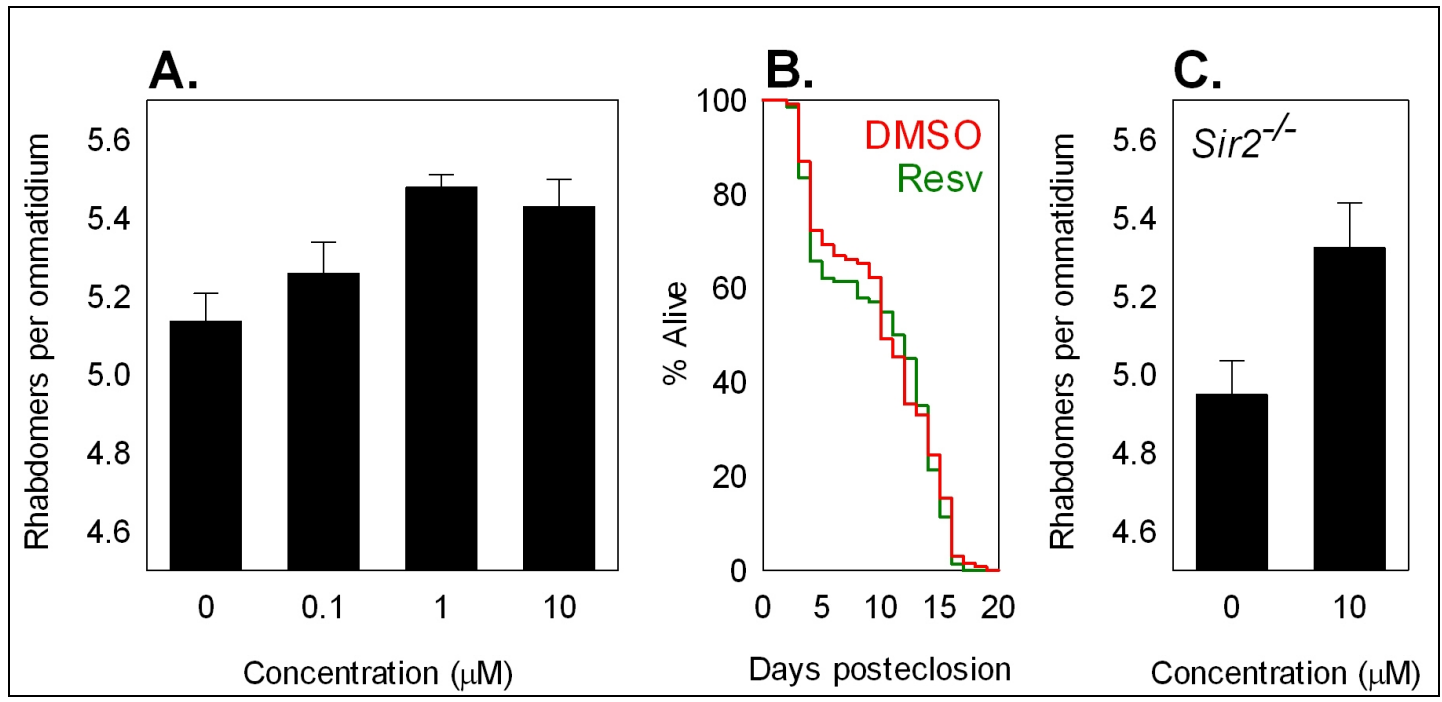

Figure 13. Resveratrol feeding.

(A) Resveratrol feeding results in a dose-dependent increase in neuronal survival of elav>Httexlp Q93 animals. (B) $10 \mu \mathrm{M}$ resveratrol does not rescue the early death phenotype of Htt-challenged flies. (C) Resveratrol reduces neurodegeneration in Sir2 homozygous null Httex $1 p$ Q93 flies.

Taken together we conclude that the mechanism by which histone deacetylases increase life span is likely distinct from their effect on Htt pathology, since the manipulation that best improves longevity (Sir2 overexpression) does not reduce neuronal loss, while manipulations that positively impact neurodegeneration do not (Sir2, Sirt2 loss) or barely (Rpd3 loss) extend the life span of expanded Huntingtin expressing flies.

\section{Figure 12. (Previous page) The effect of histone deacetylases on life span.}

(A) Heterozygous loss of Rpd3 increases the longevity of wild type or mutant $\mathrm{Htt}$ expressing flies, while heterozygous loss of the sirtuins (B) has no effect. (C) Caloric restriction (CR) increases the life span of wild type flies compared to "fully fed" (FF) animals, but does not alter the life span or photoreceptor neuron loss (D) of mutant Htt challenged females. (E) Increasing Sir2 levels genetically using the EP2300 line increases the longevity of wild type and elav $>$ Httexlp $Q 93$ flies, but does not improve their eclosion rate $(\mathbf{F})$, or photoreceptor neuron degeneration $(\mathbf{G})$. 


\section{$\underline{\text { Sir2 improves sleep anomalies seen in HD expressing flies }}$}

Recent evidence shows that the HDAC activity of SIRT1 is regulated in a circadian matter and that the protein itself is recruited to promoters of several core clock genes [Asher et al., 2008; Nakahata et al., 2008], although a functional physiological relationship between Sir2 and sleep/wake cycles has not yet been reported. Sleep disturbances are a prominent feature of Huntington's disease that can interfere with quality of life, as patients often have difficulty sleeping at night and staying awake during the day; these phenotypes have been replicated in several models of HD [Morton et al., 2005; Videnovic et al., 2009; Gonzales and Yin, 2010; Kudo et al., 2011]. We hypothesized that, if our Httexlp Q93 model also exhibits abnormal sleep behavior and if the reported biochemical interaction of Sir2 with clock genes is indicative of a regulatory relationship between Sir2 and the circadian machinery in vivo, reducing Sir2 levels might improve the altered activity rhythms of mutant $H t t$ expressing flies.

To measure the behavior of Htt flies in detail and around the clock, we used a TriKinetics activity monitor, which measures the activity of individual flies, registering each time the flies cross the midline of a horizontal $65 \mathrm{~mm}$ long glass tube that is bisected in the middle by an infrared beam. We placed freshly eclosed elav $>$ Httex $1 p$ Q93 flies with and without the Sir2 null mutation, as well as elav/w controls in the monitors, and kept them on a 12 hour light/dark cycle for two weeks (until all of the Htt expressing flies were dead). We detected several phenotypes in mutant $H t t$ expressing flies resembling the behavior of Huntington's disease patients. First, Httex1p Q93 expressing flies move less overall than wild type (Fig. 14A), which might in part reflect a reduced control over voluntary movements similar to the reduction in climbing ability described earlier, or it might be attributed to a difference in the amount of time spent moving (or resting). To distinguish between these two possibilities, we measured the peak activity of the flies, as defined by the number of beam crossings during the most active 30 minutes of the day [Hendricks et al., 2003]. We found that although young mutant Htt expressing animals do show less activity than wild type (average of 69.8 versus 92.4, $\mathrm{P}<0.05$ ), this difference diminishes as the flies age, as the peak activity of the wild type flies reduces faster than that of the mutant Htt-challenged ones (Fig. 14B). We therefore concluded that the bulk of the difference in the total of beam crossings must come from the mutant Htt expressing flies resting more than the control flies. Indeed, the amount of time Httex1p Q93 flies spend sleeping (as defined by 5 minutes of continuous inactivity [Shaw, 2003]) is much 


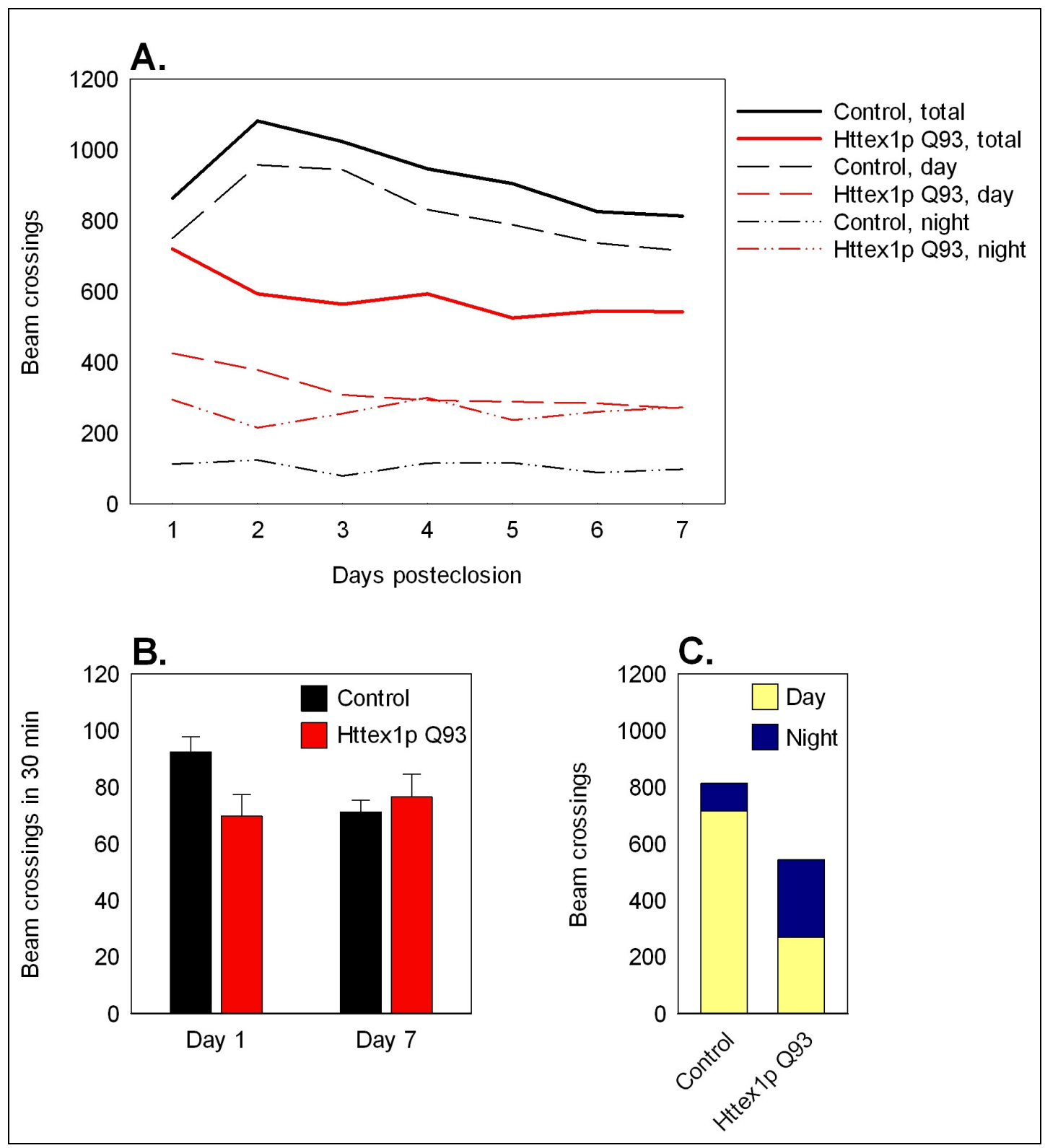

Figure 14. Activity patterns of Httex1p Q93 flies.

(A) elav $>$ Httex $1 p$ Q93 flies show reduced total activity but increased nighttime activity compared to animals carrying the elav-Gal4 driver alone. (B) The peak activity of young mutant Htt expressing flies is reduced but does not worsen further and becomes comparable to controls as the animals age. (C) The ratio of day/night activity is significantly altered in elav $>$ Httex $1 p$ Q93 animals; day 7 is shown as an example.

higher: a total of 16.6 hours at day 7 , as opposed to 11.5 in control animals $\left(\mathrm{P}<10^{-5}\right)$. More interestingly, their activity displays a diminished circadian pattern: while control flies move approximately 8 times more during the light cycle than in the dark, the day/night activity ratio of Httexlp $Q 93$ animals is close to 1:1 (Fig. 14C). Again, this 
difference is mostly due to altered sleep patterns: for example, while 7-day-old wild type flies spend an average of 1.2 hours asleep during the day, expanded $H t t$ expressing flies sleep for a total of 8.4 hours $\left(\mathrm{P}<10^{-8}\right)$; meanwhile, the nighttime activity level of elav>Httexlp Q93 flies is increased (Fig. 15A), and their nighttime sleep is reduced (8.2 hours in $H t t$ expressing flies compared to 10.3 hours in controls, $\mathrm{P}<0.05$ ) (Fig. 15B-C).

In addition to altered sleep rhythm in HD flies, we also observed a fragmentation of sleep, which is characteristic of human patients. This is reflected by two parameters: the number of sleep bouts and the length of each bout. During the light cycle, mutant $\mathrm{Htt}$ expressing flies have more and longer sleep bouts, reflecting the increase in total sleep (Fig. 15B). More interestingly, we found that although Httexlp Q93 expressing flies sleep less overall during the dark cycle, the number of sleep bouts approximately doubles (e.g. from 6.6 to 12.5 at day $7, \mathrm{P}<0.02$ ), while the average length of a bout falls to less than a third (from 190 to 59 minutes at day $7, \mathrm{P}<0.01$ ), and the length of the longest sleep session decreases by half (from 6.7 to 3.6 hours at day 7, $\mathrm{P}<0.02$ ) (Fig. 15C). Therefore, mutant Htt expressing flies exhibit a fragmented sleep pattern of frequent short rest periods during the night. Finally, Httexlp Q93 expressing flies also demonstrate a diminished ability to fall asleep after the lights are turned off in the evening: one week old elav>Httexlp Q93 animals take a little over an hour to settle down for the night, while wild type flies do so after 20 minutes $(\mathrm{P}<0.01)$ (Fig 15C).

We found that introducing a null allele of Sir2 to the mutant $\mathrm{Htt}$ expressing flies affects their activity pattern significantly. Mutant $\mathrm{Htt}$ expressing flies heterozygous for the Sir2 null mutation exhibit nighttime activity levels similar to wild type (Fig. 15A) and they sleep for a similar amount of time (10 hours at day 7, $\mathrm{P}<0.05$ compared to Httex $1 p$ Q93 flies not carrying the Sir2 mutation) (Fig. 15C). They also display a more consolidated nighttime sleep pattern (i.e. fewer and longer sleep bouts), and they fall asleep quickly (in 15 minutes at day 7) after lights off ( $\mathrm{P}<10^{-6}$ for all parameters) (Fig. 15C). Interestingly, the daytime phenotypes are entirely unaffected: the activity levels, daytime sleep duration and fragmentation pattern of mutant $\mathrm{Htt}$ expressing flies with and without the Sir2 mutation is almost identical (Fig. 15B). This suggests that Sir2 plays an important role in establishing the circadian rhythm in flies, with an emphasis on nighttime sleep regulation. 


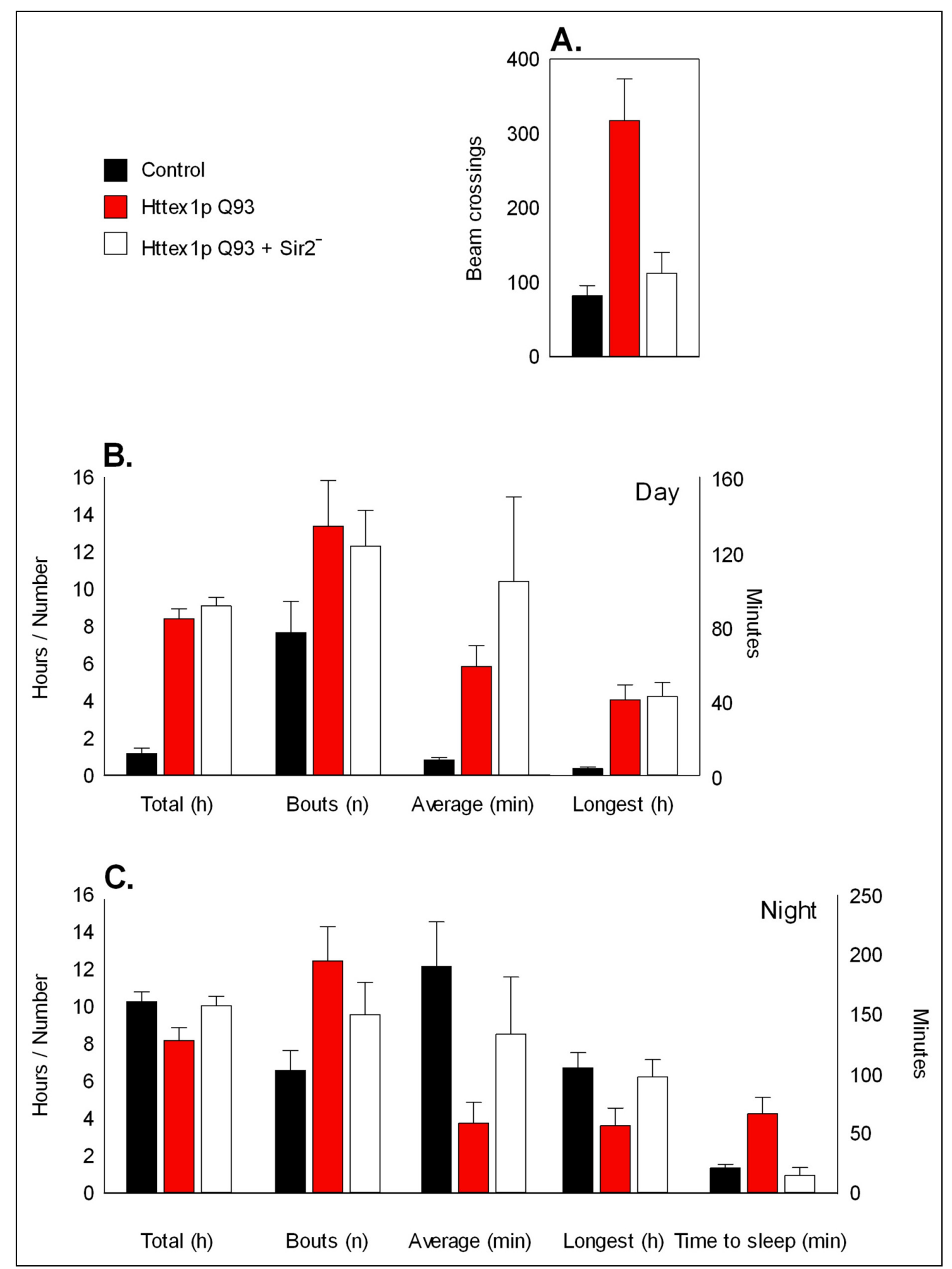

Figure 15. Loss of Sir 2 corrects nighttime sleep anomalies of elav>Httex $1 p$ Q93 flies.

(A) Mutant Htt expressing flies are more active at night. They sleep more during the day (B) and less at night $(\mathbf{C})$ than controls, and their sleep consists of more bouts, which are longer during the day and shorter at night. The time to fall asleep is also increased (C). Loss of Sir2 reduces nighttime hyperactivity (A); it does not affect daytime sleep (B) but corrects all nighttime sleep anomalies $(\mathbf{C})$. Results from day 7 are shown as an example. 
Butyrate treatment has no effect on inclusion body formation

The accumulation of large cytoplasmic or nuclear aggregates is a hallmark of Huntington's disease. To evaluate the effect of histone deacetylase inhibitors on inclusion body formation, we used an exon 1 transgene that contains $96 \mathrm{CAG}$ repeats fused to the green fluorescent protein (UAS-Httex1Q96p-GFP), and an inducible Gal4 driver (elav-GSGal4). This approach takes advantage of the GeneSwitch (GS) system, in which the UAS transgene remains silent even in the presence of Gal4, until the Gal4 is activated by administration of mifepristone [Osterwalder et al., 2001]. A further advantage of this model is that the Httexon 1 transgene is fused to GFP, allowing easy visualization of the Htt aggregates without the need for antibody staining.

We crossed elav-GS-Gal4 females to UAS-Httex1pQ96-GFP males, and divided the resulting fertilized eggs between standard Drosophila medium and medium supplemented with $100 \mathrm{mM}$ butyric acid. We induced the expression of the mutant $\mathrm{Htt}$ transgene at various stages of development using $200 \mu \mathrm{g} / \mathrm{ml}$ mifepristone, and dissected the brains of the larvae once they reached late third instar stage. We found that the expression of the transgene (i.e. GFP accumulation) is apparent at $8 \mathrm{~h}$ post-induction, without the presence of large aggregates (Fig. 16). Inclusion bodies appear around $24 \mathrm{~h}$ post-induction, first in the mushroom bodies (parts of the brain involved in learning and memory) and then in the ventral nerve cord. There was no detectable difference in the number of visible aggregates in butyric acid treated and untreated flies in the mushroom bodies; in the ventral nerve cord, inclusions appeared a little earlier in the larvae fed butyric acid, but this difference disappeared by $48 \mathrm{~h}$ post-induction (Fig 16). Flies containing GFP alone without the Htt transgene did not show any aggregation even at 48 $h$. These results indicate that butyrate treatment does not exert its positive effects on HD pathology through the inhibition of polyQ aggregation. 


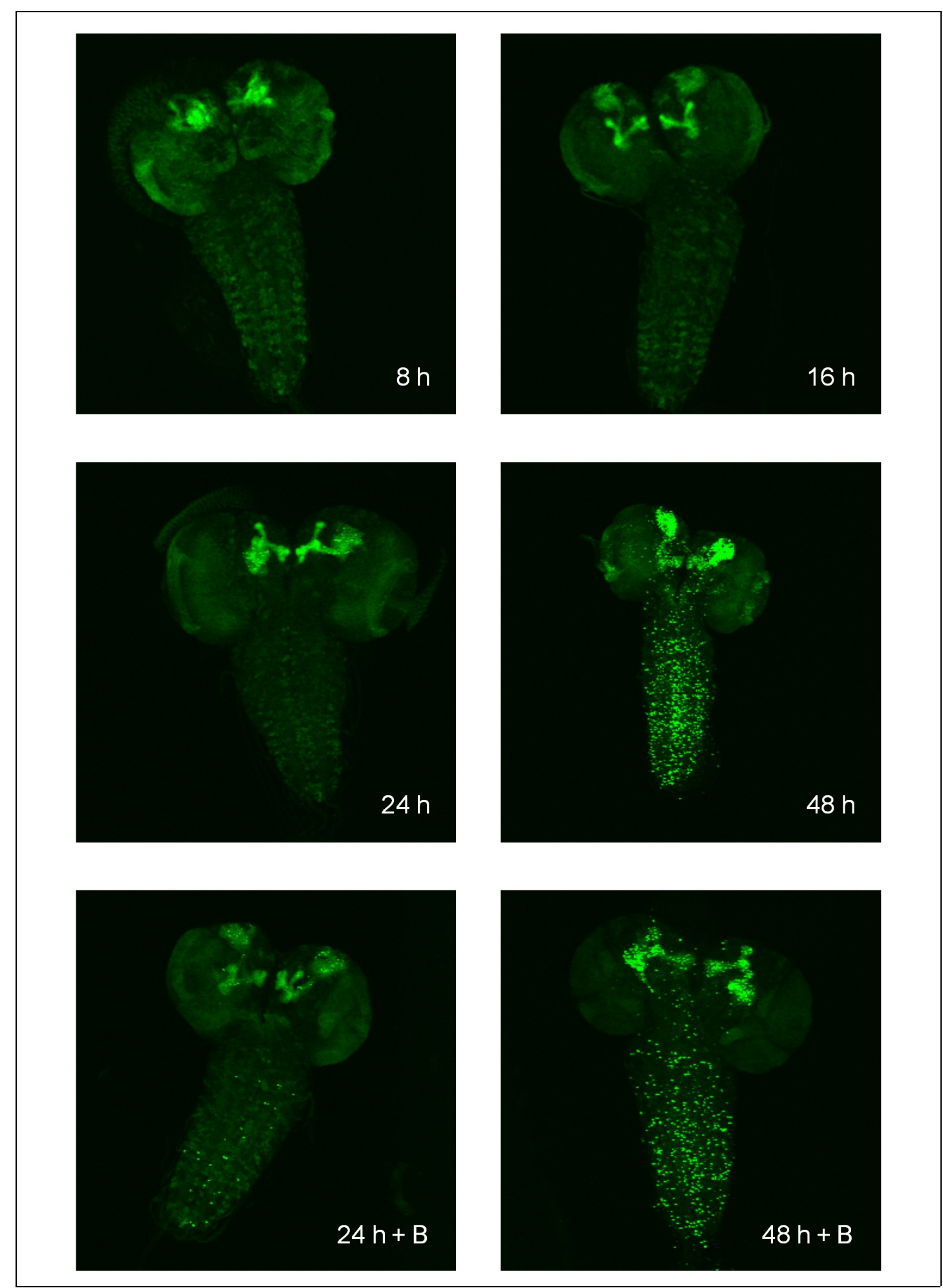

Figure 16. Butyrate treatment does not reduce inclusion body formation.

Brains of elav-GS>Httex 1pQ96-GFP larvae 8, 16, 24 and 48 hours after induction, as well as larvae fed $100 \mathrm{mM}$ butyrate (B) 24 and $48 \mathrm{~h}$ after induction are shown. 
Butyrate treatment corrects hypoacetylation of H3K27 in Httex1p Q93 flies

Lysine 27 of histone H3 (H3K27) is acetylated by CBP in Drosophila [Tie et al., 2009], a histone acetyltransferase that is directly bound to and inhibited by the mutant Huntingtin protein [Steffan et al., 2001; Cong et al., 2005]. Deacetylation of this residue involves Rpd3 [Tie et al., 2009], which we have shown plays an important role in disease pathogenesis. We theorized that the phenotypic improvements seen in flies with reduced HDAC activity (whether Rpd3 mutants or HDAC inhibitor treated), are a result of the impaired acetylation state of histones being at least partially corrected, thereby realigning transcription.

To test this hypothesis, we performed a Western blot analysis on flies expressing Httex1p Q93 in their nervous system. We found that acetyl-H3K27 is reduced by $60 \%$ in flies challenged with HD, while their siblings who were fed $100 \mathrm{mM}$ butyric acid show acetyl histone levels similar to that of wild type (Fig 17A-B). This result mirrors the finding that treating HD transgenic mice with anthracyclines, clinically approved DNA/RNA binding drug agents that can realign chromatin homeostasis, corrects global histone hypoacetylation [Stack et al., 2007]; and suggests a mechanism for the improvement of neurological phenotypes seen following reduction of histone deacetylase activity, namely that HDAC inhibition improves acetylation balance and restores transcriptional output toward pre-disease states in mutant $\mathrm{Htt}$ expressing animals.

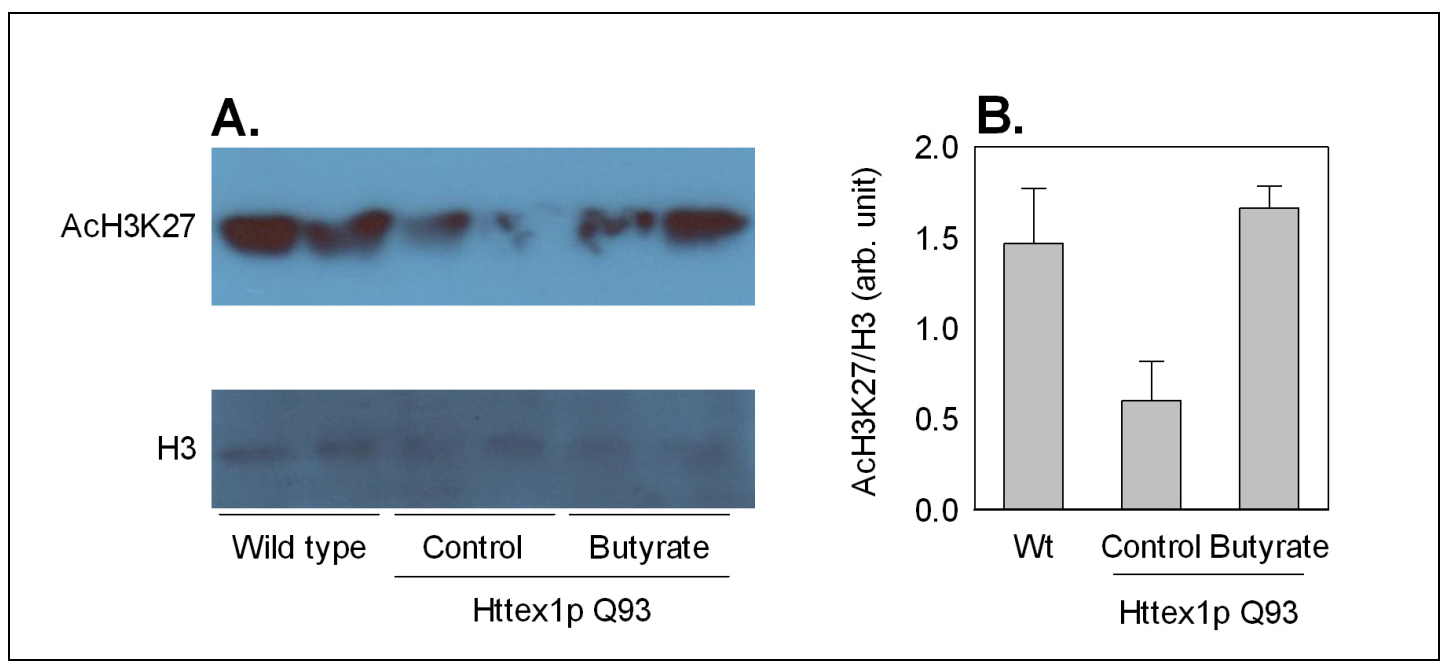

Figure 17. Butyrate administration corrects H3K27 hypoacetylation.

(A) Western analysis shows that acetylation of lysine 27 of histone $\mathrm{H} 3$ is reduced in mutant $\mathrm{Htt}$ expressing flies; feeding flies $100 \mathrm{mM}$ butyrate restores acetyl H3K27 levels. (B) Quantification of the blots using ImageJ software. 
Transcriptional dysregulation of Httex1p Q93 flies is corrected by HDAC mutants

The finding that butyrate treatment can realign the acetylation state of chromatin in Httexlp Q93 animals suggested that reducing histone deacetylase activity exerts its beneficial effects by correcting the transcriptional output of dysregulated genes. We therefore sought to demonstrate this directly using a quantitative real time PCR approach on a set of candidate genes.

Several years ago, in collaboration with Leslie Thompson's laboratory at the University of California, Irvine, we conducted an Affymetrix GeneChip Drosophila microarray experiment to identify genes that are differentially regulated in our Httex $1 p$ Q93 flies. We used this dataset to select genes that appeared to be good candidates for demonstrating transcriptional dysregulation in Htt flies using quantitative RT-PCR. The microarray experiment was repeated in two independent Httexlp Q93 lines (P463 and P468), and the results were analyzed using two different algorithms, DChip and Affymetrix. We first chose genes that showed good reproducibility between the Htt lines and the algorithms, and if possible, contained introns to aid the primer design; we tested msta, trpl (transient receptor potential like), CG5966, CG11426, and CG11489 based on these criteria. We also included in the analysis a few genes that appeared to be biologically relevant, even if the microarray results suggested they were dysregulated in one of the Httex1p Q93 lines only: such as Relish (Rel), the Drosophila NF-кB gene, since striatal cells from HD transgenic mice have been shown to have elevated nuclear factorkappaB activity [Khoshnan et al., 2004]; the heat shock protein $h s p 70 B c$, since related molecular chaperones have been demonstrated to exert therapeutic effects in several polyglutamine models [Nagai et al., 2010]; and Hmgs, the HMG Coenzyme A synthase that is homologous to the human HMGCS1, a gene upregulated in Htt171-82Q primary neurons [Luthi-Carter et al., 2010]. Finally, we included a set of antimicrobial peptides, namely Metchnikowin (Mtk), Defensin (Def) and Diptericin (Dpt), because these genes appeared to be among the most highly altered ones (i.e. with highest fold change values) upon mutant $\mathrm{Htt}$ expression. Interestingly, in a recent study, reduced acetyl H3K9 and K14 levels in mutants of dADA2b, a member of the Drosophila SAGA histone acetyltransferase complex, led to the upregulation of only a small subset of genes, many of which are involved in antibacterial defense mechanisms [Zsindely et al., 2009].

First, we performed experiments to validate the microarray results, that is, to test if the mRNA levels of the 11 genes listed above are indeed altered in Httex1p Q93 flies. We purified triplicate samples of RNA from the heads elav>Httex 1p Q93 females or females 

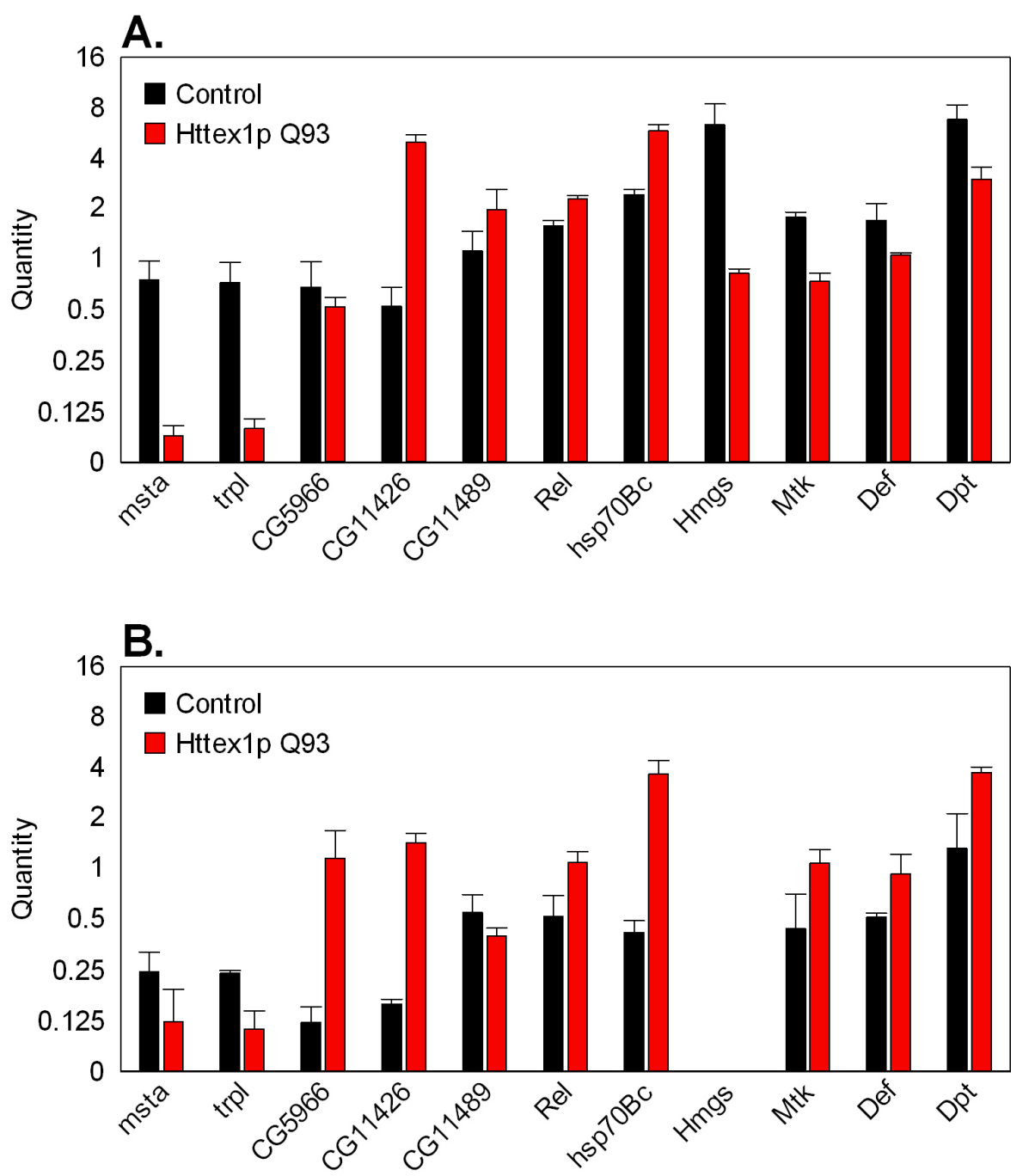

Figure 18. Transcriptional dysregulation in Httex1p flies.

Quantitative RT-PCR measurements of transcript levels of 11 genes in (A) freshly eclosed or (B) one-week-old elav-Gal4 (control) and elav>Httexlp Q93 flies.

carrying the driver only (elav-Gal4) without the reporter transgene, either immediately following eclosion or from flies that had been aged for a week, and compared the expression levels of the candidate genes. We found that 6 of the 11 genes showed a significant change either in the samples from freshly eclosed animals (msta and trpl, $\mathrm{P}<0.05$, and CG11426, $\mathrm{P}<0.01$ ) (Fig. 18A) or from one-week-old animals (Rel and $h s p 70 B c, \mathrm{P}<0.05, C G 11426$ and Dpt, $\mathrm{P}<0.01$ ) (Fig. 18B). Interestingly, CG11426 changed in the opposite direction as expected from the microarray experiment, while $D p t$ (as well as the other microbial peptides) appear repressed in the freshly eclosed flies, they 
are upregulated in the older animals (and in the microarray experiment, and which was performed at 3 days posteclosion) (Fig 18A-B).

Next, we wanted to test if the HDAC mutants that improve the viability and neuronal degeneration also correct the underlying transcriptional dysregulation. We crossed loss of function alleles of Rpd3, Sir2 and Sirt2 into mutant Htt expressing background, and compared the transcript levels in Httexlp Q93 flies with or without the HDAC mutation, as well as in wild type controls of 5 genes: msta, trpl, Rel, hsp 70Bc, as well as Hmgs, which we felt was a promising candidate as its level of significance was just slightly above the cutoff in the study described above. We found that introducing the

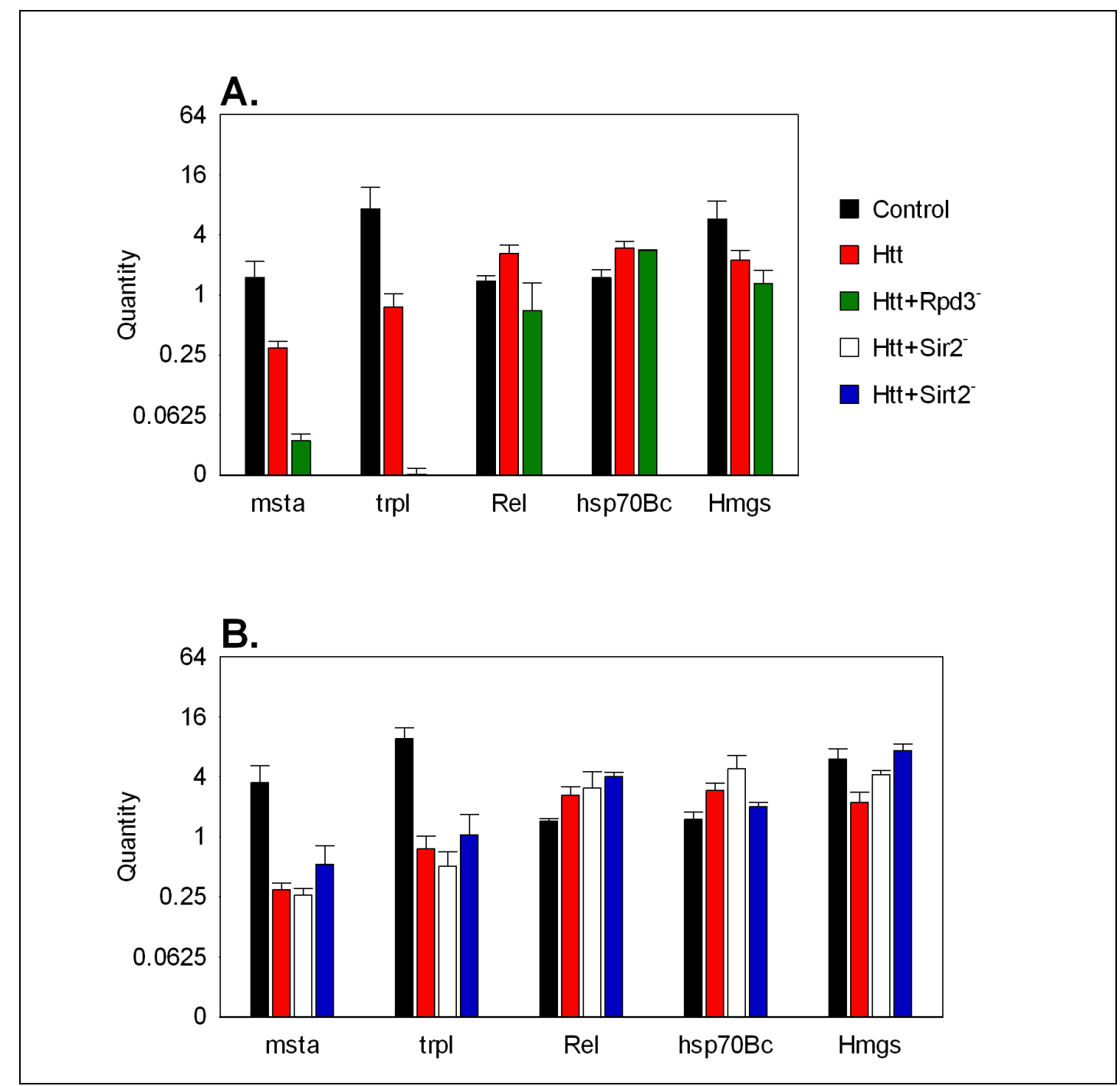

Figure 19. HDAC mutations partially correct altered gene expression in mutant $\mathrm{Htt}$ expressing flies.

Quantitative RT-PCR measurements of transcript levels of five genes in mutant $\mathrm{Htt}$ expressing flies and in elav>Httex1p Q93 flies also mutant for (A) Rpd3 or (B) Sir2 and Sirt2. Control animals carry the elav-Gal4 driver only. 
Rpd3 mutation into the mutant Htt background reduces the transcript level of the upregulated gene $\operatorname{Rel}(\mathrm{P}<0.01)$, while does not alter the transcriptional output of $h s p 70 B c$ or Hmgs (Fig. 19A). Interestingly, Rpd3 also further reduced the mRNA levels of two of the genes downregulated in Httexlp Q93 flies (msta, $\mathrm{P}<0.001 ; \operatorname{trpl}, \mathrm{P}<0.05$ ). The two sirtuin mutations, Sir2 and Sirt2, in contrast, only affected the expression of Hmgs, bringing its mRNA levels close to wild type $(\mathrm{P}<0.05)$ (Fig. 19B).

These data demonstrate that reducing HDAC activity can indeed result in transcriptional changes in mutant $H t t$ expressing flies. While a larger scale experiment that includes many more loci could be more informative in terms of which genes play a key role in pathogenesis, this small data set can serve as a proof of principle study that histone deacetylase inhibition can correct some of the transcriptional dysregulation seen in HD.

\section{$\underline{\text { Summary }}$}

Our results show that histone deacetylases play an important role in several pathways implicated in HD pathology, such as sleep or transcriptional regulation. We show that although deacetylases can affect the longevity of Httexlp Q93 flies, life span extending strategies are distinct from manipulations resulting in better phenotypic outcomes. Histone deacetylases do not appear to regulate inclusion body formation, but they affect the acetylation state of histones and have an impact on the transcription of a small set of dysregulated genes. 


\section{DiSCUSSION}

We have developed a Drosophila exon1 model of Huntington's disease that recapitulates several properties of this disorder: it causes progressive cellular dysfunction and death, resulting in a range of abnormal phenotypes including neuronal loss, movement impairments and altered sleep patterns, which culminate in the premature death of the animal. Importantly, several of these phenotypes are readily quantifiable, which enables us to search for modifiers that could lead to better understanding of the pathology of HD and hopefully better treatment options or even cures of this disease.

We found that inhibiting histone deacetylase activity is effective in ameliorating the effects of Huntington's disease, as it arrests the progressive degeneration of photoreceptor neurons (Fig. 3, 8) [Steffan et al., 2001], as well as improves the motor performance (Fig. 4) and reduces the loss of pigment cells (Fig. 5) in flies expressing a truncated Htt peptide with an expanded polyglutamine domain. Our studies indicate that much of the neuroprotection seen with chemical inhibitors can be achieved by inhibiting the activity of a select few histone deacetylases, namely Rpd3, Sir2 and Sirt2 (Fig. 7, 20) [Pallos et al., 2008]. We show that genetic reduction of Rpd3 and Sir2 activities can not only attenuate the photoreceptor neuron loss of Httex 1p Q93 flies, but also improve their

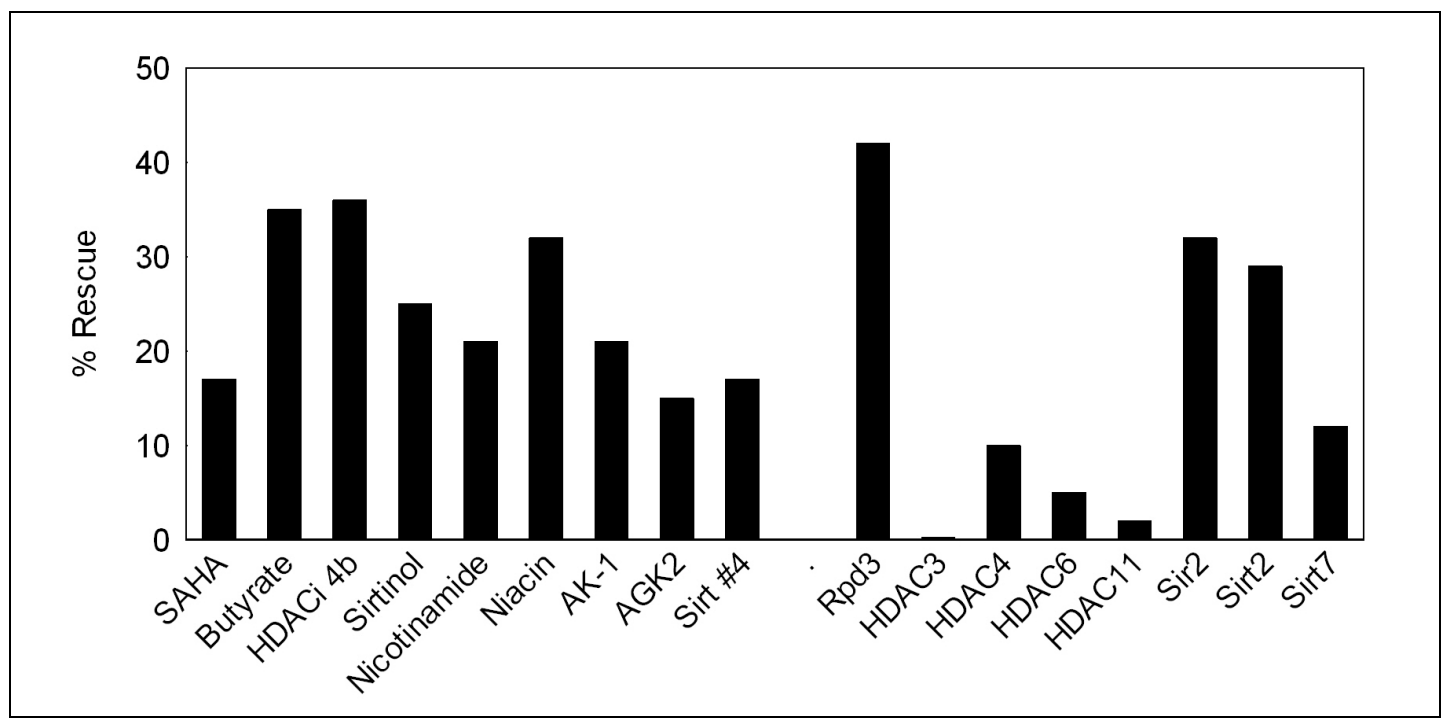

Figure 20. Comparison of manipulations to reduce HDAC activities.

This summary figure shows the extent of rescue of photoreceptor neuron degeneration achieved by HDAC inhibitor treatment or by introducing loss of function HDAC mutations. The best concentration or allele is shown. 
eclosion rate (Fig. 7A), an effect that we did not see with the chemical HDAC inhibitors, likely because of the limited availability of any pharmacological agent during the pupal stages of Drosophila development. It is important to note that our observations do not mean that other deacetylases do not have a role in neuronal survival: for example, reducing HDAC3 expression protects against low-potassium-induced neuronal death of rat cerebellar granule neurons while its forced expression induces death in several neuronal cell types [Bardai and D'Mello, 2011]. Overexpression of HDAC6 rescues degeneration in a spinobulbar muscular atrophy model [Pandey et al., 2007], as well as reduces $\alpha$ synuclein-induced dopaminergic neuron loss and retinal degeneration a Parkinson's disease model in Drosophila [Du et al., 2010], although we did not see a demonstrable change in response to a $\sim 50 \%$ reduction of HDAC6 in our HD model. Similarly, overexpressing HDAC3, HDAC6 or HDAC11 was recently shown to suppress neurodegeneration in a Drosophila model of Fragile X Tremor Ataxia Syndrome, a neurodegenerative disorder caused by expansion of a CGG trinucleotide repeat in the 5'UTR of the fragile X syndrome gene [Todd et al., 2010]. These differences suggest that either there is a disease specific difference in response to the deacetylases or that the particular enzyme is not rate-limiting. Also, we did not observe a rescue of neurodegeneration when reducing HDAC4 activity, although similar experiments in a mouse model of HD showed a protective effect (personal communication, Gillian P. Bates, Kings College London); this difference can be due to the fact that reducing HDAC4 levels in the nervous system is deleterious in the flies (Fig. 6C), which could mask any beneficial outcome in a mutant $\mathrm{Htt}$ expressing context. Alternatively, the Drosophila HDAC4 could have slightly different properties than its mammalian homolog, as suggested by the fact that it does not respond to chemical inhibitors as well as the human protein [Cho et al., 2005].

Impaired acetylation balance has been linked to a wide range of clinical disorders, such as fragile $\mathrm{X}$ syndrome, leukemia, various cancers, and neurodegenerative diseases, including not only Huntington's disease, but Amyotrophic lateral sclerosis and Alzheimer's disease as well [Langley et al., 2005]. Inhibition of classic histone deacetylase activity using broad spectrum pharmacological agents, such as TSA, SAHA or butyric acid, has been subsequently shown to reduce neurodegeneration in various models [Chang et al., 2001; Steffan et al., 2001; Hockly et al., 2003; Ferrante et al., 2003; Minamiyama et al., 2004; Gardian et al., 2005]. The role of sirtuins in neuronal survival is likely more complex, however. One study suggested that while overexpression of some 
sirtuins (e.g. SIRT1) protects cerebellar granule neurons from apoptosis, others (e.g. SIRT2) induce apoptosis in the same cells, while yet others (SIRT5) affect neuronal viability depending on their subcellular localization; interestingly, the neuroprotection by SIRT1 was independent from its deacetylase activity [Pfister et al., 2008]. The interpretation of Pfister et al. must be taken with caution, however, since accompanying loss of function experiments were not reported and no independent means of determining that the overexpression indeed lead to increased activity was provided; thus, the results could also be attributed to dominant negative effects due to overexpression of one member of a complex of proteins. In polyglutamine diseases, increasing sirtuin gene dose has been shown to suppress expanded Htt-induced neuronal dysfunction phenotypes in Caenorhabditis elegans [Parker et al., 2005; Bates et al., 2006], while we did not see any effect on neurodegeneration of Httex1p Q93 flies upon overexpression of Sir2 (Fig. 12G), and increased Sir2 enhances degeneration in Drosophila models of Spinocerebellar ataxia type 1 [Fernandez-Funez et al., 2000; Ghosh and Feany, 2004]. Reduction of SIRT1 in cultured neurons can be neuroprotective in the face of oxidative challenge [Li et al., 2008] and pharmacological inhibition of Sir2 with nicotinamide suppresses neuronal degeneration of Kenyon cells in a Drosophila model expressing mutant Ataxin-3 [Ghosh and Feany, 2004], while reducing Sirt2 levels protects against $\alpha$-synuclein-mediated toxicity in cell culture and Drosophila models of Parkinson's disease [Outeiro et al., 2007]. Genetic reduction of sir2.1, the C. elegans homolog of Sir2, is deleterious [Bates et al., 2006], while pharmacological inhibition of sirtuins using agents that selectively target mammalian SIRT2 has recently shown to be neuroprotective in a worm model of Huntington's disease [Luthi-Carter et al., 2010]. We find that reducing Sir2 and Sirt2 activity is beneficial in HD (Fig. 7); recent evidence shows that Sirt2 inhibition protects against Htt171-82Q toxicity in primary striatal neurons as well [Luthi-Carter et al., 2010].

Our results suggest that reduction of the three deacetylases, Rpd3, Sir2 and Sirt2, achieves neuroprotection independently. We find no evidence of Rpd3 regulating Sir2 directly, as Sir2 mRNA levels are unchanged in Rpd3 mutant flies (Fig. 11); the discrepancy between our observations and earlier ones using the same Rpd3 allele [Rogina et al., 2002] might be due to improved sensitivity of RNA detection methods in recent years or due to the means of identifying the mutant versus control genotypes (we used a dominant marker while previous studies used the variable variegation phenotype of Rpd3 mutants, leaving open the possibility for bias). Our genetic data also suggests that $\mathrm{Rpd} 3$ and Sir2 act via separate pathways, since animals heterozygous for both deacetylases show 
reduced neurotoxicity compared to either mutation alone (Fig. 9C-E). Finally, the observation that homozygosity for Sir2 or Sirt2 results in opposite outcomes in Httex1p Q93 expressing flies compared to heterozygous siblings carrying the same sirtuin mutation (Fig. 9A) leads us to conclude that the two sirtuins have a distinct role in HD pathology.

In an effort to pinpoint the mechanism by which reducing HDAC levels improves Httexlp Q93 induced degenerative phenotypes, we examined the life span of mutant $\mathrm{Htt}$ expressing animals, since both Rpd3 and Sir2 have been implicated in longevity of Drosophila and other metazoans [Rogina et al., 2002; Kang et al., 2002; Rogina and Helfand, 2004; Michan and Sinclair, 2007]. Similarly, we evaluated the extent of neurodegeneration in Httexlp Q93 flies that have undergone manipulations that increase the life span of healthy animals, such as overexpressing Sir2, caloric restriction and feeding the drug resveratrol. We found that Rpd3 has very minor effect on the early death phenotype of Httex1p Q93 animals, while loss of sirtuins has no effect at all (Fig. 12A-B). On the other hand, Sir2 overexpression can increase longevity in mutant Htt expressing flies but does not ameliorate the neurodegeneration (Fig. 12E-G). Taken together, these studies indicate that manipulations that positively impact aging do not necessarily positively impact the effects of neurodegeneration, suggesting that the molecular mechanisms underlying the two are distinct.

Resveratrol has been shown to reduce toxicity in C. elegans, Drosophila, mouse, and rat models of HD [Parker et al., 2005; Kumar et al., 2006; Pallos et al., 2008], and in other neurodegenerative disorders, including Alzheimer's disease and Parkinson's disease [Sun et al., 2010]. Although it has previously been suggested to act by elevating SIRT1 activity [Howitz et al., 20031; Lagouge et al., 2006], the basis for this conclusion has been questioned [Kaeberlein et al., 2005; Kaeberlein, 2008; Pacholec et al., 2010], and new cellular targets as well as SIRT1-independent activities of resveratrol have been identified, including inhibition of IкB kinase, of the mTOR signaling or insulin signaling pathways, or igniting autophagy, stimulating the AMP kinase activity and activating ERK [Kundu et al., 2006; Zhang, 2006; Dasgupta and Milbrandt, 2007; Liu et al., 2010; Morselli et al., 2010; Tang, 2010; Kim et al., 2011; Maher et al., 2011; Shi et al., 2011]. Our results confirm the value of resveratrol in reducing neurodegeneration, and we find that it does so independently of Sir2/SIRT1 (Fig. 13A, C). We find that resveratrol does not increase the life span of Httex1p Q93 flies (Fig. 13B); however, the life span extending property of the drug has also been disputed recently, as a group of investigators found no significant effects on longevity in seven independent trials in Drosophila, and little or no effect in $C$. 
elegans [Bass et al., 2007]. Thus, suggestions that increased Sir2 levels are helpful for suppressing neurodegenerative disorders that are based on resveratrol studies must be considered with caution.

There are multiple mechanisms whereby altered deacetylase levels may affect neuronal survival. Our studies with butyrate suggest that inclusion body formation is not affected when we manipulate HDAC activities (Fig. 16); similar results were obtained for another histone deacetylase inhibitor, SAHA, in organotypic hippocampal slice cultures from HD mice [Hockly et al., 2003]. Although the formation of intracellular aggregates is a hallmark of HD, the role of inclusion bodies in neuronal survival has long been debated, and their formation has been separated from events that regulate cell death [Kim et al., 1999; Miller et al., 2010]. Instead, we find that butyrate treatment corrects the altered acetylation state of histone $\mathrm{H} 3$ at lysine 27 (Fig. 17), a residue that is modified by CBP. Mutant Huntingtin represses the histone acetyltransferase activity of CBP [Steffan et al., 2001; Cong et al., 2005], and increasing CBP activity is protective in several models of HD [Taylor et al., 2003; Jiang et al., 2006], suggesting that reducing the levels of Rpd3, the opposing deacetylase, might be similarly beneficial. On the other hand, SIRT1 directly deacetylates and represses the activity of p300 [Bouras et al., 2005], a HAT related to CBP which is also impaired in HD [Steffan et al., 2001], as well as Tip60, which promotes apoptosis [Wang and Chen, 2010], suggesting that decreasing the levels of SIRT1/Sir2 might be relevant to pathology by increasing the activities of key histone acetylating enzymes.

We theorized that correcting the altered acetylation balance of histones would lead to corrected transcriptional output of dysregulated genes. In a small, proof of principle study, we found that all three of the HDACs that reduce neurodegeneration in our model can also normalize the transcriptional output of some gene (Fig. 19). The cholesterol biosynthetic pathway is impaired in HD cells, mice, and in human subjects [Valenza et al., 2005; Luthi-Carter et al., 2010], and we find that heterozygous loss of either sirtuin corrects the transcription of Hmgs, a gene whose human homolog is regulated by Sirt2 and is involved in sterol biosynthesis [Luthi-Carter et al., 2010]. Partial loss of Rpd3 on the other hand reduces the expression of Relish, the Drosophila homolog of NF- $\mathrm{B}$, which we find is upregulated in Httexlp Q93 expressing flies. While some have shown that NF-kB signaling is downregulated by mutant Huntingtin protein [Reijonen et al., 2010], others find the opposite, and show that its activation in striatal cells from HD transgenic mice contributes to neurotoxicity [Khoshnan et al., 2004]. We find that in Rpd3 mutants, 
transcription of two genes, msta and trpl, which are downregulated in Httexlp Q93 flies, is further reduced. Trpl is an ankyrin domain protein that regulates the permeability of the cell membrane to a variety of ions, and it is involved in phototransduction [Padinjat and Andrews, 2004]; while msta is a protein with unknown function. Since nothing is known about either gene product in the context of neurodegeneration, it is difficult to speculate about the phenotypic outcome of their downregulation in Httexlp Q93 flies. One can imagine three scenarios: that their reduction is deleterious, in which case the Rpd3 mutation would further worsen the phenotype, but this effect is negligible and hence other, beneficial outcomes of reducing Rpd3 activity dominate; or their levels might not be important in mature neurons undergoing cell death; or their reduction is a result of a coping mechanism, and therefore further inhibition of their transcription by the presence of the Rpd3 mutation increases the viability of the cell. Although we performed the qPCR analysis on freshly eclosed animals, it is possible that some mechanisms that enable the cell to cope with the expression of the mutant Huntingtin protein have already been activated. For example, we find that the chaperone protein hsp70Bc is upregulated in these flies (and its levels are unaltered by HDAC mutants), and chaperones are commonly expressed in response to cellular stresses, including accumulation of misfolded proteins [Wyttenbach, 2004]; molecular and chemical chaperones have also been found to be effective agents for suppressing polyglutamine diseases in several animal models [Nagai et al., 2010]. In all, we find that reducing HDAC levels can restore altered expression of genes in the HD fly toward predisease levels.

We describe here yet another avenue for ameliorating pathology by reducing Sir2 activity: namely, that loss of Sir2 corrects the abnormal sleep patterns of Httex1p Q93 expressing flies (Fig. 15). HD patients display sleep disturbances, including insomnia and altered circadian rhythms [Taylor et al., 1997; Morton et al., 2005], and this aspect of the disease is mirrored in animal models [Morton et al., 2005; Rudenko et al., 2009; Gonzales and Yin, 2010; Kudo et al., 2011; Oakeshott et al., 2011]. In two recently published studies, SIRT1 was shown to counteract the activity of the clock machinery and regulate several circadian genes [Asher et al., 2008; Nakahata et al., 2008]. Importantly, recent reports show that correcting sleep anomalies by pharmacologically managing the sleep/wake cycles with psychostimulants or sedatives slows the progression of cognitive decline in HD mice [Pallier et al., 2007; Pallier and Morton, 2009]. Our results indicate that inhibiting sirtuin activity, in addition to reducing neurodegeneration, also corrects most sleep abnormalities in Httexlp Q93 expressing flies, although it is unclear if it does 
so by altering the transcriptional output of clock genes. Interestingly, melatonin, the hormone secreted by the pineal gland which as a supplement has been long used to treat insomnia [Turek and Gillette, 2004], has recently been shown to inhibit SIRT1 activity [Hill et al., 2009].

In summary, our results show that Httexlp Q93 induced neurodegeneration in Drosophila is most readily impacted by inhibition of selected HDACs either individually or in combination. We find that reducing the activity of these deacetylases can counteract the negative effects of the expanded polyglutamine peptide, improve the acetylation balance of histones and correct the transcription of dysregulated genes. Our studies suggest that therapeutic strategies designed to target Rpd3, Sir2 and Sirt2 activities specifically, and administered in combination, are likely to result in improved benefit, by reducing neuronal death, improving circadian rhythm and restoring the altered expression of dysregulated genes. 


\section{SUMMARY}

Huntington's disease (HD) belongs to a family of disorders that includes at least nine dominant, late-onset diseases that are caused by expanded CAG triplet repeat sequences that encode expanded polyglutamine (polyQ) repeats in the affected protein. This mutant form of the protein interacts aberrantly with itself, resulting in the accumulation of various forms of oligomers and aggregates, which might by themselves be toxic to the cell, as well as with a number of cellular proteins, leading to disturbed homeostasis, neuronal dysfunction, and death. Transcriptional regulators, such as the histone acetyltransferases or methyltransferases, are an example of proteins with which the mutant Huntingtin protein interacts abnormally, resulting in altered nucleosomal balance and dysregulation of transcription. Chemical agents that restore the acetylation levels at least partially have shown great promise in ameliorating the effects of the mutant polyQ protein in several model systems, and some histone deacetylase (HDAC) inhibitors are currently in human clinical trials. The studies described here seek to bring a better understanding of the role of histone deacetylases in HD pathology.

- We demonstrated both genetically and pharmacologically that histone deacetylases are a valid therapeutic target for Huntington's disease.

- We showed that administering histone deacetylase inhibitors to mutant Huntingtin (Httex1p Q93) expressing flies not only reduces photoreceptor neuron degeneration, but improves their motor function, as well as reduces pigment cell loss; these independent assays further validate the therapeutic value of HDAC inhibitors. Genetic studies support this conclusion.

- We showed that chemical inhibition of the sirtuin class of deacetylases also reduces the progressive neuron loss of Httex 1p Q93 expressing flies.

- We demonstrated that the mutant Htt induced pathology is most sensitive to only three of the ten deacetylases, Rpd3, Sir2 and Sirt2, and that these deacetylases

likely target different pathways, as reducing them in combination, whether 
genetically or pharmacologically, results in an improved outcome over targeting a single enzyme.

- We established that reducing HDAC levels does not increase the life span of Httex1p Q93 animals significantly, while regimens that increase their longevity, such as upregulation of Sir2, do not improve their neuronal loss. These studies uncouple the longevity and neuronal degeneration in mutant Htt expressing flies.

- We showed that animals expressing the expanded Htt transgene display aberrant activity rhythms, by sleeping extensively during the day and having short, fragmented sleep at night, and that all night related sleep phenotypes can be rescued by introducing a heterozygous null mutation for Sir2; this study is the first functional analysis of the effects of a Sir2 mutation on circadian behavior.

- We showed that inhibition of HDAC activity with butyrate does not significantly alter the inclusion body formation seen in mutant $\mathrm{Htt}$ expressing flies, and this was validated in mice in collaboration with Bates et al.

- We determined that histone H3 is hypoacetylated in Httexlp Q93 animals and that this anomaly can be corrected by butyrate treatment.

- Using quantitative real time PCR, we identified a set of genes that are dysregulated in mutant Htt expressing flies, and we showed that partial loss of Rpd3, Sir2 or Sirt 2 can correct the aberrant transcription of some of these genes.

- We demonstrate that while resveratrol can reduce neurodegeneration, it does so by a mechanism independent of Sir2 in our HD model.

- We generated new double stranded RNA alleles for four deacetylases in the fly.

Our studies show that inhibition of specific deacetylases is a valid strategy for ameliorating the effects of Huntington's disease, especially if HDAC inhibitors are administered in combination. These agents can reduce the neuronal loss by improving the 
nucleosomal imbalance and at least partially correcting the transcriptional dysregulation, which is an early event in pathogenesis. Partial inhibition of selective HDAC activities reduces cell loss, improves motor performance and rescues night related sleep abnormalities in mutant $\mathrm{Htt}$ expressing flies, which could translate into a promising therapeutic strategy for the treatment of this devastating disease. 


\section{ACKNOWLEDGEMENTS}

I would like to express my gratitude to my PI, Larry Marsh. He has often given me the green light to follow my instincts and desires as to where the research would lead me and kindly stirred me back on track when I seemed to veer too far from the useful path. He has shaped my thinking and played an important role in my development as a researcher.

I would also like to thank all members of his laboratory, but especially Namita Agrawal, Charity Aiken and Tamas Lukacsovich, for sharing their thoughts and expertise with me and for the fun times together. A special thank you goes to Laszlo Bodai, my oldest friend, with whom I have had the privilege of working for several years, and whose inputs on experimental details, statistical analysis or data presentation, as well as his insights on life in general were always welcome.

I am indebted to several members of the UCI community: Leslie Thompson and her laboratory for the countless good meetings and discussions, Bruce Blumberg for sharing his qPCR equipment, and Todd Holmes, for allowing me to use his TriKinetics activity monitors.

I am most grateful to my husband for encouraging me to embark on this journey and for his endless support throughout our years together. Without his persistent help this dissertation would not have been possible. I also need to thank my children that they behaved well more often than not, allowing me to work. Thanks to my parents and my sister, for showing me the value of education and always setting the bar high.

Finally, I need to thank the following organizations for providing financial support to the work described here: the Hereditary Disease Foundation, the Huntington's Disease Society of America and the National Institutes of Health. 


\section{REFERENCES}

Agrawal N, Pallos J, Slepko N, Apostol BL, Bodai L, Chang LW, Chiang AS, Thompson LM, Marsh JL. Identification of combinatorial drug regimens for treatment of Huntington's disease using Drosophila. Proc Natl Acad Sci U S A. 2005 Mar $8 ; 102(10): 3777-81$.

Aiken CT, Steffan JS, Guerrero CM, Khashwji H, Lukacsovich T, Simmons D, Purcell JM, Menhaji K, Zhu YZ, Green K, Laferla F, Huang L, Thompson LM, Marsh JL. Phosphorylation of threonine 3: implications for Huntingtin aggregation and neurotoxicity. J Biol Chem. 2009 Oct 23;284(43):29427-36.

Apostol BL, Illes K, Pallos J, Bodai L, Wu J, Strand A, Schweitzer ES, Olson JM, Kazantsev A, Marsh JL, Thompson LM. Mutant Huntingtin alters MAPK signaling pathways in PC12 and striatal cells: ERK1/2 protects against mutant Huntingtin-associated toxicity. Hum Mol Genet. 2006 Jan 15;15(2):273-85.

Arrasate M, Mitra S, Schweitzer ES, Segal MR, Finkbeiner S. Inclusion body formation reduces levels of mutant Huntingtin and the risk of neuronal death. Nature. 2004 Oct 14;431(7010):805-10.

Asher G, Gatfield D, Stratmann M, Reinke H, Dibner C, Kreppel F, Mostoslavsky R, Alt FW, Schibler U. SIRT1 regulates circadian clock gene expression through PER2 deacetylation. Cell. 2008 Jul 25;134(2):317-28.

Ashizawa T, Wong LJ, Richards CS, Caskey CT, Jankovic J. CAG repeat size and clinical presentation in Huntington's disease. Neurology. 1994 Jun;44(6):1137-43.

Atwal RS, Xia J, Pinchev D, Taylor J, Epand RM, Truant R. Huntingtin has a membrane association signal that can modulate Huntingtin aggregation, nuclear entry and toxicity. Hum Mol Genet. 2007 Nov 1;16(21):2600-15.

Auerbach W, Hurlbert MS, Hilditch-Maguire P, Wadghiri YZ, Wheeler VC, Cohen SI, Joyner AL, MacDonald ME, Turnbull DH. The HD mutation causes progressive lethal neurological disease in mice expressing reduced levels of Huntingtin. Hum Mol Genet. 2001 Oct 15;10(22):2515-23.

Augood SJ, Faull RL, Emson PC. Dopamine D1 and D2 receptor gene expression in the striatum in Huntington's disease. Ann Neurol. 1997 Aug;42(2):215-21.

Augood SJ, Faull RL, Love DR, Emson PC. Reduction in enkephalin and substance P messenger RNA in the striatum of early grade Huntington's disease: a detailed cellular in situ hybridization study. Neuroscience. 1996 Jun;72(4):1023-36.

Ayala A, Venero JL, Cano J, Machado A. Mitochondrial toxins and neurodegenerative diseases. Front Biosci, 2007, 12, 986-1007. 
Bardai FH, D'Mello SR. Selective toxicity by HDAC3 in neurons: regulation by Akt and GSK3beta. J Neurosci. 2011 Feb 2;31(5):1746-51.

Barlow AL, van Drunen CM, Johnson CA, Tweedie S, Bird A, Turner BM. dSIR2 and dHDAC6: two novel, inhibitor-resistant deacetylases in Drosophila melanogaster. Exp Cell Res. 2001 Apr 15;265(1):90-103.

Bass TM, Weinkove D, Houthoofd K, Gems D, Partridge L. Effects of resveratrol on lifespan in Drosophila melanogaster and Caenorhabditis elegans. Mech Ageing Dev. 2007 Oct;128(10):546-52.

Bates EA, Victor M, Jones AK, Shi Y, Hart AC. Differential contributions of Caenorhabditis elegans histone deacetylases to Huntingtin polyglutamine toxicity. J Neurosci. 2006 Mar 8;26(10):2830-8.

Beal MF, Kowall NW, Ellison DW, Mazurek MF, Swartz KJ, Martin JB. Replication of the neurochemical characteristics of Huntington's disease by quinolinic acid. Nature. 1986 May 8-14;321(6066):168-71.

Becher MW, Kotzuk JA, Sharp AH, Davies SW, Bates GP, Price DL, Ross CA. Intranuclear neuronal inclusions in Huntington's disease and dentatorubral and pallidoluysian atrophy: correlation between the density of inclusions and IT15 CAG triplet repeat length. Neurobiol Dis. 1998 Apr;4(6):387-97.

Benn CL, Landles C, Li H, Strand AD, Woodman B, Sathasivam K, Li SH, Ghazi-Noori S, Hockly E, Faruque SM, Cha JH, Sharpe PT, Olson JM, Li XJ, Bates GP. Contribution of nuclear and extranuclear polyQ to neurological phenotypes in mouse models of Huntington's disease. Hum Mol Genet. 2005 Oct 15;14(20):3065-78.

Benn CL, Sun T, Sadri-Vakili G, McFarland KN, DiRocco DP, Yohrling GJ, Clark TW, Bouzou B, Cha JH. Huntingtin modulates transcription, occupies gene promoters in vivo, and binds directly to DNA in a polyglutamine-dependent manner. J Neurosci. 2008 Oct $15 ; 28(42): 10720-33$.

Bennett EJ, Shaler TA, Woodman B, Ryu KY, Zaitseva TS, Becker CH, Bates GP, Schulman H, Kopito RR. Global changes to the ubiquitin system in Huntington's disease. Nature. 2007 Aug 9;448(7154):704-8.

Berger Z, Ravikumar B, Menzies FM, Oroz LG, Underwood BR, Pangalos MN, Schmitt I, Wullner U, Evert BO, O'Kane CJ, Rubinsztein DC. Rapamycin alleviates toxicity of different aggregate-prone proteins. Hum Mol Genet. 2006 Feb 1;15(3):433-42.

Bhutani N, Venkatraman P, Goldberg AL. Puromycin-sensitive aminopeptidase is the major peptidase responsible for digesting polyglutamine sequences released by proteasomes during protein degradation. EMBO J. 2007 Mar 7;26(5):1385-96.

Bitterman KJ, Anderson RM, Cohen HY, Latorre-Esteves M, Sinclair DA. Inhibition of silencing and accelerated aging by nicotinamide, a putative negative regulator of yeast sir2 and human SIRT1. J Biol Chem. 2002 Nov 22;277(47):45099-107. 
Bodner RA, Outeiro TF, Altmann S, Maxwell MM, Cho SH, Hyman BT, McLean PJ, Young AB, Housman DE, Kazantsev AG. Pharmacological promotion of inclusion formation: a therapeutic approach for Huntington's and Parkinson's diseases. Proc Natl Acad Sci U S A. 2006 Mar 14;103(11):4246-51.

Borovecki F, Lovrecic L, Zhou J, Jeong H, Then F, Rosas HD, Hersch SM, Hogarth P, Bouzou B, Jensen RV, Krainc D. Genome-wide expression profiling of human blood reveals biomarkers for Huntington's disease. Proc Natl Acad Sci U S A. 2005 Aug 2;102(31):11023-8.

Bouras T, Fu M, Sauve AA, Wang F, Quong AA, Perkins ND, Hay RT, Gu W, Pestell RG. SIRT1 deacetylation and repression of p300 involves lysine residues 1020/1024 within the cell cycle regulatory domain 1. J Biol Chem. 2005 Mar 18;280(11):10264-76.

Boutell JM, Thomas P, Neal JW, Weston VJ, Duce J, Harper PS, Jones AL. Aberrant interactions of transcriptional repressor proteins with the Huntington's disease gene product, Huntingtin. Hum Mol Genet. 1999 Sep;8(9):1647-55.

Brandt J, Bylsma FW, Gross R, Stine OC, Ranen N, Ross CA. Trinucleotide repeat length and clinical progression in Huntington's disease. Neurology. 1996 Feb;46(2):527-31.

Brouillet E, Conde F, Beal MF, Hantraye P. Replicating Huntington's disease phenotype in experimental animals. Prog Neurobiol. 1999 Dec;59(5):427-68.

Burke JR, Enghild JJ, Martin ME, Jou YS, Myers RM, Roses AD, Vance JM, Strittmatter WJ. Huntingtin and DRPLA proteins selectively interact with the enzyme GAPDH. Nat Med. 1996 Mar;2(3):347-50.

Caine ED, Shoulson I. Psychiatric syndromes in Huntington's disease. Am J Psychiatry. 1983 Jun;140(6):728-33.

Carter RJ, Lione LA, Humby T, Mangiarini L, Mahal A, Bates GP, Dunnett SB, Morton AJ. Characterization of progressive motor deficits in mice transgenic for the human Huntington's disease mutation. J Neurosci. 1999 Apr 15;19(8):3248-57.

Cattaneo E, Rigamonti D, Goffredo D, Zuccato C, Squitieri F, Sipione S. Loss of normal Huntingtin function: new developments in Huntington's disease research. Trends Neurosci. 2001 Mar;24(3):182-8.

Cha JH. Transcriptional signatures in Huntington's disease. Prog Neurobiol. 2007 Nov;83(4):228-48.

Cha JH, Frey AS, Alsdorf SA, Kerner JA, Kosinski CM, Mangiarini L, Penney JB Jr, Davies SW, Bates GP, Young AB. Altered neurotransmitter receptor expression in transgenic mouse models of Huntington's disease. Philos Trans R Soc Lond B Biol Sci. 1999 Jun 29;354(1386):981-9.

Chan EY, Luthi-Carter R, Strand A, Solano SM, Hanson SA, DeJohn MM, Kooperberg C, Chase KO, DiFiglia M, Young AB, Leavitt BR, Cha JH, Aronin N, Hayden MR, Olson JM. Increased Huntingtin protein length reduces the number of polyglutamine-induced 
gene expression changes in mouse models of Huntington's disease. Hum Mol Genet. 2002 Aug 15;11(17):1939-51.

Chan HY, Bonini NM. Drosophila models of human neurodegenerative disease. Cell Death Differ. 2000 Nov;7(11):1075-80.

Chang JG, Hsieh-Li HM, Jong YJ, Wang NM, Tsai CH, Li H. Treatment of spinal muscular atrophy by sodium butyrate. Proc Natl Acad Sci U S A. 2001 Aug 14;98(17):9808-13.

Chen M, Ona VO, Li M, Ferrante RJ, Fink KB, Zhu S, Bian J, Guo L, Farrell LA, Hersch SM, Hobbs W, Vonsattel JP, Cha JH, Friedlander RM. Minocycline inhibits caspase-1 and caspase- 3 expression and delays mortality in a transgenic mouse model of Huntington disease. Nat Med. 2000 Jul;6(7):797-801.

Cherra SJ 3rd, Dagda RK, Chu CT. Review: autophagy and neurodegeneration: survival at a cost? Neuropathol Appl Neurobiol. 2010 Apr;36(2):125-32.

Chiu E, Alexander L. Causes of death in Huntington's disease. Med J Aust. 1982 Feb 20;1(4):153.

Cho Y, Griswold A, Campbell C, Min KT. Individual histone deacetylases in Drosophila modulate transcription of distinct genes. Genomics. 2005 Nov;86(5):606-17.

Claes S, Van Zand K, Legius E, Dom R, Malfroid M, Baro F, Godderis J, Cassiman JJ. Correlations between triplet repeat expansion and clinical features in Huntington's disease. Arch Neurol. 1995 Aug;52(8):749-53.

Cong SY, Pepers BA, Evert BO, Rubinsztein DC, Roos RA, van Ommen GJ, Dorsman JC. Mutant Huntingtin represses CBP, but not p300, by binding and protein degradation. Mol Cell Neurosci. 2005 Dec;30(4):560-71.

Cornett J, Cao F, Wang CE, Ross CA, Bates GP, Li SH, Li XJ. Polyglutamine expansion of Huntingtin impairs its nuclear export. Nat Genet. 2005 Feb;37(2):198-204.

Cummings JL. Behavioral and psychiatric symptoms associated with Huntington's disease. Adv Neurol. 1995;65:179-86.

Dasgupta B, Milbrandt J. Resveratrol stimulates AMP kinase activity in neurons. Proc Natl Acad Sci U S A. 2007 Apr 24;104(17):7217-22.

Davie JR. Inhibition of histone deacetylase activity by butyrate. J Nutr. 2003 Jul;133(7 Suppl):2485S-2493S.

De Almeida LP, Ross CA, Zala D, Aebischer P, Deglon N. Lentiviral-mediated delivery of mutant Huntingtin in the striatum of rats induces a selective neuropathology modulated by polyglutamine repeat size, Huntingtin expression levels, and protein length. J Neurosci. 2002 May 1;22(9):3473-83. 
Demuro A, Mina E, Kayed R, Milton SC, Parker I, Glabe CG. Calcium dysregulation and membrane disruption as a ubiquitous neurotoxic mechanism of soluble amyloid oligomers. J Biol Chem. 2005 Apr 29;280(17):17294-300.

Desai UA, Pallos J, Ma AA, Stockwell BR, Thompson LM, Marsh JL, Diamond MI. Biologically active molecules that reduce polyglutamine aggregation and toxicity. Hum Mol Genet. 2006 Jul 1;15(13):2114-24.

Díaz-Hernández M, Valera AG, Morán MA, Gómez-Ramos P, Alvarez-Castelao B, Castaño JG, Hernández F, Lucas JJ. Inhibition of $26 \mathrm{~S}$ proteasome activity by Huntingtin filaments but not inclusion bodies isolated from mouse and human brain. J Neurochem. 2006 Sep;98(5):1585-96.

DiFiglia M, Sapp E, Chase KO, Davies SW, Bates GP, Vonsattel JP, Aronin N. Aggregation of Huntingtin in neuronal intranuclear inclusions and dystrophic neurites in brain. Science. 1997 Sep 26;277(5334):1990-3.

Dorsman JC, Smoor MA, Maat-Schieman ML, Bout M, Siesling S, van Duinen SG, Verschuuren JJ, den Dunnen JT, Roos RA, van Ommen GJ. Analysis of the subcellular localization of Huntingtin with a set of rabbit polyclonal antibodies in cultured mammalian cells of neuronal origin: comparison with the distribution of Huntingtin in Huntington's disease autopsy brain. Philos Trans R Soc Lond B Biol Sci. 1999 Jun 29;354(1386):1061-7.

Dragatsis I, Levine MS, Zeitlin S. Inactivation of Hdh in the brain and testis results in progressive neurodegeneration and sterility in mice. Nat Genet. 2000 Nov;26(3):300-6.

Du G, Liu X, Chen X, Song M, Yan Y, Jiao R, Wang CC. Drosophila histone deacetylase 6 protects dopaminergic neurons against \{alpha\}-synuclein toxicity by promoting inclusion formation. Mol Biol Cell. 2010 Jul 1;21(13):2128-37.

Duffy JB. GAL4 system in Drosophila: a fly geneticist's Swiss army knife. Genesis. 2002 Sep-Oct;34(1-2):1-15.

Dunah AW, Jeong H, Griffin A, Kim YM, Standaert DG, Hersch SM, Mouradian MM, Young AB, Tanese N, Krainc D. Sp1 and TAFII130 transcriptional activity disrupted in early Huntington's disease. Science. 2002 Jun 21;296(5576):2238-43.

Duyao M, Ambrose C, Myers R, Novelletto A, Persichetti F, Frontali M, Folstein S, Ross C, Franz M, Abbott M, Gray J, Conneally P, Young A, Penney J, Hollingsworth Z, Shoulson I, Lazzarini A, Falek A, Koroshetz W, Sax D, Bird E, Vonsattel JP, Bonilla E, Alvir J, Bickham Conde J, Cha JH, Dure L, Gomez F, Ramos M, Sanchez-Ramos J, Snodgrass S, de Young M, Wexler N, Moscowitz C, Penchaszadeh G, MacFarlane H, Anderson M, Jenkins B, Srinidhi J, Barnes G, Gusella J, MacDonald M. Trinucleotide repeat length instability and age of onset in Huntington's disease. Nat Genet. 1993 Aug;4(4):387-92.

Duyao MP, Auerbach AB, Ryan A, Persichetti F, Barnes GT, McNeil SM, Ge P, Vonsattel JP, Gusella JF, Joyner AL, MacDonald ME. Inactivation of the mouse Huntington's disease gene homolog Hdh. Science. 1995 Jul 21;269(5222):407-10. 
Dyer RB, McMurray CT. Mutant protein in Huntington disease is resistant to proteolysis in affected brain. Nat Genet. 2001 Nov;29(3):270-8.

Engelender S, Sharp AH, Colomer V, Tokito MK, Lanahan A, Worley P, Holzbaur EL, Ross CA. Huntingtin-associated protein 1 (HAP1) interacts with the p150Glued subunit of dynactin. Hum Mol Genet. 1997 Dec;6(13):2205-12.

Faber PW, Alter JR, MacDonald ME, Hart AC. Polyglutamine mediated dysfunction and apoptotic death of a Caenorhabditis elegans sensory neuron. Proc Natl Acad Sci U S A. 1999 Jan 5;96(1):179-84.

Faber PW, Barnes GT, Srinidhi J, Chen J, Gusella JF, MacDonald ME. Huntingtin interacts with a family of WW domain proteins. Hum Mol Genet. 1998 Sep;7(9):1463-74.

Farrer L.A. Diabetes mellitus in Huntington disease. Clin Genet. 1985 Jan;27(1):62-7.

Farrer LA. Suicide and attempted suicide in Huntington disease: implications for preclinical testing of persons at risk. Am J Med Genet. 1986 Jun;24(2):305-11.

Fernandez-Funez P, Nino-Rosales ML, de Gouyon B, She WC, Luchak JM, Martinez P, Turiegano E, Benito J, Capovilla M, Skinner PJ, McCall A, Canal I, Orr HT, Zoghbi HY, Botas J. Identification of genes that modify ataxin-1-induced neurodegeneration. Nature. 2000 Nov 2;408(6808):101-6.

Ferrante RJ, Kubilus JK, Lee J, Ryu H, Beesen A, Zucker B, Smith K, Kowall NW, Ratan RR, Luthi-Carter R, Hersch SM. Histone deacetylase inhibition by sodium butyrate chemotherapy ameliorates the neurodegenerative phenotype in Huntington's disease mice. J Neurosci. 2003 Oct 15;23(28):9418-27.

Ferrante RJ, Ryu H, Kubilus JK, D'Mello S, Sugars KL, Lee J, Lu P, Smith K, Browne S, Beal MF, Kristal BS, Stavrovskaya IG, Hewett S, Rubinsztein DC, Langley B, Ratan RR. Chemotherapy for the brain: the antitumor antibiotic mithramycin prolongs survival in a mouse model of Huntington's disease. J Neurosci. 2004 Nov 17;24(46):10335-42.

Foroud T, Gray J, Ivashina J, Conneally PM. Differences in duration of Huntington's disease based on age at onset. J Neurol Neurosurg Psychiatry. 1999 Jan;66(1):52-6.

Frye RA. Phylogenetic classification of prokaryotic and eukaryotic Sir2-like proteins. Biochem Biophys Res Commun. 2000 Jul 5;273(2):793-8.

Furtado S, Suchowersky O, Rewcastle B, Graham L, Klimek ML, Garber A. Relationship between trinucleotide repeats and neuropathological changes in Huntington's disease. Ann Neurol. 1996 Jan;39(1):132-6.

Gafni J, Ellerby LM. Calpain activation in Huntington's disease. J Neurosci. 2002 Jun 15;22(12):4842-9. 
Gafni J, Hermel E, Young JE, Wellington CL, Hayden MR, Ellerby LM. Inhibition of calpain cleavage of Huntingtin reduces toxicity: accumulation of calpain/caspase fragments in the nucleus. J Biol Chem. 2004 May 7;279(19):20211-20.

Gardian G, Browne SE, Choi DK, Klivenyi P, Gregorio J, Kubilus JK, Ryu H, Langley B, Ratan RR, Ferrante RJ, Beal MF. Neuroprotective effects of phenylbutyrate in the N17182Q transgenic mouse model of Huntington's disease. J Biol Chem. 2005 Jan 7;280(1):556-63.

Gervais FG, Singaraja R, Xanthoudakis S, Gutekunst CA, Leavitt BR, Metzler M, Hackam AS, Tam J, Vaillancourt JP, Houtzager V, Rasper DM, Roy S, Hayden MR, Nicholson DW. Recruitment and activation of caspase- 8 by the Huntingtin-interacting protein Hip-1 and a novel partner Hippi. Nat Cell Biol. 2002 Feb;4(2):95-105.

Ghosh S, Feany MB. Comparison of pathways controlling toxicity in the eye and brain in Drosophila models of human neurodegenerative diseases. Hum Mol Genet. 2004 Sep 15;13(18):2011-8.

Gil JM, Rego AC. Mechanisms of neurodegeneration in Huntington's disease. Eur J Neurosci. 2008 Jun;27(11):2803-20.

Gil JM, Rego AC. The R6 lines of transgenic mice: a model for screening new therapies for Huntington's disease. Brain Res Rev. 2009 Mar;59(2):410-31.

Glabe CG. Common mechanisms of amyloid oligomer pathogenesis in degenerative disease. Neurobiol Aging. 2006 Apr;27(4):570-5.

Glaser KB. HDAC inhibitors: clinical update and mechanism-based potential. Biochem Pharmacol. 2007 Sep 1;74(5):659-71.

Goldberg YP, Nicholson DW, Rasper DM, Kalchman MA, Koide HB, Graham RK, Bromm M, Kazemi-Esfarjani P, Thornberry NA, Vaillancourt JP, Hayden MR. Cleavage of Huntingtin by apopain, a proapoptotic cysteine protease, is modulated by the polyglutamine tract. Nat Genet. 1996 Aug;13(4):442-9.

Gonzales E, Yin J. Drosophila Models of Huntington's Disease exhibit sleep abnormalities. PLoS Curr. 2010 Sep 29;2. pii: RRN1185.

Gonzalez-Alegre P, Afifi AK. Clinical characteristics of childhood-onset (juvenile) Huntington disease: report of 12 patients and review of the literature. J Child Neurol. 2006 Mar;21(3):223-9.

Graham RK, Deng Y, Slow EJ, Haigh B, Bissada N, Lu G, Pearson J, Shehadeh J, Bertram L, Murphy Z, Warby SC, Doty CN, Roy S, Wellington CL, Leavitt BR, Raymond LA, Nicholson DW, Hayden MR. Cleavage at the caspase- 6 site is required for neuronal dysfunction and degeneration due to mutant Huntingtin. Cell. 2006 Jun 16;125(6):117991. 
Gregoretti IV, Lee YM, Goodson HV. Molecular evolution of the histone deacetylase family: functional implications of phylogenetic analysis. J Mol Biol. 2004 Apr $16 ; 338(1): 17-31$.

Grozinger CM, Chao ED, Blackwell HE, Moazed D, Schreiber SL. Identification of a class of small molecule inhibitors of the sirtuin family of NAD-dependent deacetylases by phenotypic screening. J Biol Chem. 2001 Oct 19;276(42):38837-43.

Gu X, Greiner ER, Mishra R, Kodali R, Osmand A, Finkbeiner S, Steffan JS, Thompson LM, Wetzel R, Yang XW. Serines 13 and 16 are critical determinants of full-length human mutant Huntingtin induced disease pathogenesis in HD mice. Neuron. 2009 Dec 24;64(6):828-40.

Gutekunst CA, Li SH, Yi H, Mulroy JS, Kuemmerle S, Jones R, Rye D, Ferrante RJ, Hersch SM, Li XJ. Nuclear and neuropil aggregates in Huntington's disease: relationship to neuropathology. J Neurosci. 1999 Apr 1;19(7):2522-34.

Halliday GM, McRitchie DA, Macdonald V, Double KL, Trent RJ, McCusker E. Regional specificity of brain atrophy in Huntington's disease. Exp Neurol. 1998 Dec;154(2):663-72.

Harper PS. The epidemiology of Huntington's disease. Hum Genet. 1992 Jun;89(4):36576.

Heiser V, Engemann S, Bröcker W, Dunkel I, Boeddrich A, Waelter S, Nordhoff E, Lurz R, Schugardt N, Rautenberg S, Herhaus C, Barnickel G, Böttcher H, Lehrach H, Wanker EE. Identification of benzothiazoles as potential polyglutamine aggregation inhibitors of Huntington's disease by using an automated filter retardation assay. Proc Natl Acad Sci U S A. 2002 Dec 10;99 Suppl 4:16400-6.

Hendricks JC, Lu S, Kume K, Yin JC, Yang Z, Sehgal A. Gender dimorphism in the role of cycle (BMAL1) in rest, rest regulation, and longevity in Drosophila melanogaster. $\mathrm{J}$ Biol Rhythms. 2003 Feb;18(1):12-25.

Hermel E, Gafni J, Propp SS, Leavitt BR, Wellington CL, Young JE, Hackam AS, Logvinova AV, Peel AL, Chen SF, Hook V, Singaraja R, Krajewski S, Goldsmith PC, Ellerby HM, Hayden MR, Bredesen DE, Ellerby LM. Specific caspase interactions and amplification are involved in selective neuronal vulnerability in Huntington's disease. Cell Death Differ. 2004 Apr;11(4):424-38.

Hill SM, Frasch T, Xiang S, Yuan L, Duplessis T, Mao L. Molecular mechanisms of melatonin anticancer effects. Integr Cancer Ther. 2009 Dec;8(4):337-46.

Hockly E, Richon VM, Woodman B, Smith DL, Zhou X, Rosa E, Sathasivam K, GhaziNoori S, Mahal A, Lowden PA, Steffan JS, Marsh JL, Thompson LM, Lewis CM, Marks PA, Bates GP. Suberoylanilide hydroxamic acid, a histone deacetylase inhibitor, ameliorates motor deficits in a mouse model of Huntington's disease. Proc Natl Acad Sci U S A. 2003 Feb 18;100(4):2041-6. 
Hodges JR, Salmon DP, Butters N. Differential impairment of semantic and episodic memory in Alzheimer's and Huntington's diseases: a controlled prospective study. J Neurol Neurosurg Psychiatry. 1990 Dec;53(12):1089-95.

Hodgson JG, Agopyan N, Gutekunst CA, Leavitt BR, LePiane F, Singaraja R, Smith DJ, Bissada N, McCutcheon K, Nasir J, Jamot L, Li XJ, Stevens ME, Rosemond E, Roder JC, Phillips AG, Rubin EM, Hersch SM, Hayden MR. A YAC mouse model for Huntington's disease with full-length mutant Huntingtin, cytoplasmic toxicity, and selective striatal neurodegeneration. Neuron. 1999 May;23(1):181-92.

Hoffner G, Island ML, Djian P. Purification of neuronal inclusions of patients with Huntington disease reveals a broad range of $\mathrm{N}$-terminal fragments of expanded Huntingtin and insoluble polymers. J Neurochem. 2005 Oct;95(1):125-36.

Hoffner G, Kahlem P, Djian P. Perinuclear localization of Huntingtin as a consequence of its binding to microtubules through an interaction with $\beta$-tubulin: relevance to Huntington's disease. J Cell Sci. 2002 Mar 1;115(Pt 5):941-8.

Howitz KT, Bitterman KJ, Cohen HY, Lamming DW, Lavu S, Wood JG, Zipkin RE, Chung P, Kisielewski A, Zhang LL, Scherer B, Sinclair DA. Small molecule activators of sirtuins extend Saccharomyces cerevisiae lifespan. Nature. 2003 Sep 11;425(6954):191-6.

Huang CC, Faber PW, Persichetti F, Mittal V, Vonsattel JP, MacDonald ME, Gusella JF. Amyloid formation by mutant Huntingtin: threshold, progressivity and recruitment of normal polyglutamine proteins. Somat Cell Mol Genet. 1998 Jul;24(4):217-33.

Humbert S, Bryson EA, Cordelières FP, Connors NC, Datta SR, Finkbeiner S, Greenberg ME, Saudou F. The IGF-1/Akt pathway is neuroprotective in Huntington's disease and involves Huntingtin phosphorylation by Akt. Dev Cell. 2002 Jun;2(6):831-7.

Huntington G. On chorea. Med Surg Rep. 1872 Apr 13; 26(25):317-21. Republished in: J Neuropsychiatry Clin Neurosci. 2003 Winter;15(1):109-12.

Huntington's Disease Collaborative Research Group. A novel gene containing a trinucleotide repeat that is expanded and unstable on Huntington's disease chromosomes. Cell. 1993 Mar 26;72(6):971-83.

Illarioshkin SN, Igarashi S, Onodera O, Markova ED, Nikolskaya NN, Tanaka H, Chabrashwili TZ, Insarova NG, Endo K, Ivanova-Smolenskaya IA, Tsuji S. Trinucleotide repeat length and rate of progression of Huntington's disease. Ann Neurol. 1994 Oct;36(4):630-5.

Iuchi S, Hoffner G, Verbeke P, Djian P, Green H. Oligomeric and polymeric aggregates formed by proteins containing expanded polyglutamine. Proc Natl Acad Sci U S A. 2003 Mar 4;100(5):2409-14.

Jackson GR, Salecker I, Dong X, Yao X, Arnheim N, Faber PW, MacDonald ME, Zipursky SL. Polyglutamine-expanded human Huntingtin transgenes induce degeneration of Drosophila photoreceptor neurons. Neuron. 1998 Sep;21(3):633-42. 
Jacobsen JC, Bawden CS, Rudiger SR, McLaughlan CJ, Reid SJ, Waldvogel HJ, Macdonald ME, Gusella JF, Walker SK, Kelly JM, Webb GC, Faull RL, Rees MI, Snell RG. An ovine transgenic Huntington's disease model. Hum Mol Genet. 2010 May $15 ; 19(10): 1873-82$.

Jana NR, Zemskov EA, Wang Gh, Nukina N. Altered proteasomal function due to the expression of polyglutamine-expanded truncated $\mathrm{N}$-terminal Huntingtin induces apoptosis by caspase activation through mitochondrial cytochrome c release. Hum Mol Genet. 2001 May 1;10(10):1049-59.

Jeong H, Then F, Melia TJ Jr, Mazzulli JR, Cui L, Savas JN, Voisine C, Paganetti P, Tanese N, Hart AC, Yamamoto A, Krainc D. Acetylation targets mutant Huntingtin to autophagosomes for degradation. Cell. 2009 Apr 3;137(1):60-72.

Jiang H, Poirier MA, Liang Y, Pei Z, Weiskittel CE, Smith WW, DeFranco DB, Ross CA. Depletion of CBP is directly linked with cellular toxicity caused by mutant Huntingtin. Neurobiol Dis. 2006 Sep;23(3):543-51.

Kaeberlein M. The ongoing saga of sirtuins and aging. Cell Metab. 2008 Jul;8(1):4-5.

Kaeberlein M, McDonagh T, Heltweg B, Hixon J, Westman EA, Caldwell SD, Napper A, Curtis R, DiStefano PS, Fields S, Bedalov A, Kennedy BK. Substrate-specific activation of sirtuins by resveratrol. J Biol Chem. 2005 Apr 29;280(17):17038-45.

Kalchman MA, Graham RK, Xia G, Koide HB, Hodgson JG, Graham KC, Goldberg YP, Gietz RD, Pickart CM, Hayden MR. Huntingtin is ubiquitinated and interacts with a specific ubiquitin-conjugating enzyme. J Biol Chem. 1996 Aug 9;271(32):19385-94.

Kalchman MA, Koide HB, McCutcheon K, Graham RK, Nichol K, Nishiyama K, Kazemi-Esfarjani P, Lynn FC, Wellington C, Metzler M, Goldberg YP, Kanazawa I, Gietz RD, Hayden MR. HIP1, a human homologue of S. cerevisiae Sla2p, interacts with membrane-associated Huntingtin in the brain. Nat Genet. 1997 May;16(1):44-53.

Kaltenbach LS, Romero E, Becklin RR, Chettier R, Bell R, Phansalkar A, Strand A, Torcassi C, Savage J, Hurlburt A, Cha GH, Ukani L, Chepanoske CL, Zhen Y, Sahasrabudhe S, Olson J, Kurschner C, Ellerby LM, Peltier JM, Botas J, Hughes RE. Huntingtin interacting proteins are genetic modifiers of neurodegeneration. PLoS Genet. 2007 May 11;3(5):e82.

Kang HL, Benzer S, Min KT. Life extension in Drosophila by feeding a drug. Proc Natl Acad Sci U S A. 2002 Jan 22;99(2):838-43.

Kazantsev A, Preisinger E, Dranovsky A, Goldgaber D, Housman D. Insoluble detergentresistant aggregates form between pathological and nonpathological lengths of polyglutamine in mammalian cells. Proc Natl Acad Sci U S A. 1999 Sep 28; 96(20):11404-9.

Kazemi-Esfarjani P, Benzer S. Genetic suppression of polyglutamine toxicity in Drosophila. Science. 2000 Mar 10;287(5459):1837-40. 
Kegel KB, Kim M, Sapp E, McIntyre C, Castaño JG, Aronin N, DiFiglia M. Huntingtin expression stimulates endosomal-lysosomal activity, endosome tubulation, and autophagy. J Neurosci. 2000 Oct 1;20(19):7268-78.

Kegel KB, Meloni AR, Yi Y, Kim YJ, Doyle E, Cuiffo BG, Sapp E, Wang Y, Qin ZH, Chen JD, Nevins JR, Aronin N, DiFiglia M. Huntingtin is present in the nucleus, interacts with the transcriptional corepressor $\mathrm{C}$-terminal binding protein, and represses transcription. J Biol Chem. 2002 Mar 1;277(9):7466-76.

Khoshnan A, Ko J, Watkin EE, Paige LA, Reinhart PH, Patterson PH. Activation of the IkappaB kinase complex and nuclear factor-kappaB contributes to mutant Huntingtin neurotoxicity. J Neurosci. 2004 Sep 15;24(37):7999-8008.

Kieburtz K, MacDonald M, Shih C, Feigin A, Steinberg K, Bordwell K, Zimmerman C, Srinidhi J, Sotack J, Gusella J, Shoulson I. Trinucleotide repeat length and progression of illness in Huntington's disease. J Med Genet. 1994 Nov;31(11):872-4.

Kim M, Lee HS, LaForet G, McIntyre C, Martin EJ, Chang P, Kim TW, Williams M, Reddy PH, Tagle D, Boyce FM, Won L, Heller A, Aronin N, DiFiglia M. Mutant Huntingtin expression in clonal striatal cells: dissociation of inclusion formation and neuronal survival by caspase inhibition. J Neurosci. 1999 Feb 1;19(3):964-73.

Kim MH, Yoo DS, Lee SY, Byeon SE, Lee YG, Min T, Rho HS, Rhee MH, Lee J, Cho JY. The TRIF/TBK1/IRF-3 activation pathway is the primary inhibitory target of resveratrol, contributing to its broad-spectrum anti-inflammatory effects. Pharmazie. 2011 Apr;66(4):293-300.

Kim MO, Chawla P, Overland RP, Xia E, Sadri-Vakili G, Cha JH. Altered histone monoubiquitylation mediated by mutant Huntingtin induces transcriptional dysregulation. J Neurosci. 2008 Apr 9;28(15):3947-57.

Kim YJ, Yi Y, Sapp E, Wang Y, Cuiffo B, Kegel KB, Qin ZH, Aronin N, DiFiglia M. Caspase 3-cleaved N-terminal fragments of wild-type and mutant Huntingtin are present in normal and Huntington's disease brains, associate with membranes, and undergo calpaindependent proteolysis. Proc Natl Acad Sci U S A. 2001 Oct 23;98(22):12784-9.

Kremer B, Goldberg P, Andrew SE, Theilmann J, Telenius H, Zeisler J, Squitieri F, Lin B, Bassett A, Almqvist E, Bird TD, Hayden MR. A worldwide study of the Huntington's disease mutation. The sensitivity and specificity of measuring CAG repeats. $\mathrm{N}$ Engl $\mathrm{J}$ Med. 1994 May 19;330(20):1401-6.

Kudo T, Schroeder A, Loh DH, Kuljis D, Jordan MC, Roos KP, Colwell CS. Dysfunctions in circadian behavior and physiology in mouse models of Huntington's disease. Exp Neurol. 2011 Mar;228(1):80-90.

Kuemmerle S, Gutekunst CA, Klein AM, Li XJ, Li SH, Beal MF, Hersch SM, Ferrante RJ. Huntington aggregates may not predict neuronal death in Huntington's disease. Ann Neurol. 1999 Dec;46(6):842-9. 
Kuhn A, Goldstein DR, Hodges A, Strand AD, Sengstag T, Kooperberg C, Becanovic K, Pouladi MA, Sathasivam K, Cha JH, Hannan AJ, Hayden MR, Leavitt BR, Dunnett SB, Ferrante RJ, Albin R, Shelbourne P, Delorenzi M, Augood SJ, Faull RL, Olson JM, Bates GP, Jones L, Luthi-Carter R. Mutant Huntingtin's effects on striatal gene expression in mice recapitulate changes observed in human Huntington's disease brain and do not differ with mutant Huntingtin length or wild-type Huntingtin dosage. Hum Mol Genet. 2007 Aug 1;16(15):1845-61.

Kumar P, Kalonia H, Kumar A. Huntington's disease: pathogenesis to animal models. Pharmacol Rep. 2010 Jan-Feb;62(1):1-14.

Kumar P, Padi SS, Naidu PS, Kumar A. Effect of resveratrol on 3-nitropropionic acidinduced biochemical and behavioural changes: possible neuroprotective mechanisms. Behav Pharmacol. 2006 Sep;17(5-6):485-92.

Kundu JK, Shin YK, Kim SH, Surh YJ. Resveratrol inhibits phorbol ester-induced expression of COX-2 and activation of NF-kappaB in mouse skin by blocking IkappaB kinase activity. Carcinogenesis. 2006 Jul;27(7):1465-74.

Kyrylenko S, Kyrylenko O, Suuronen T, Salminen A. Differential regulation of the Sir2 histone deacetylase gene family by inhibitors of class I and II histone deacetylases. Cell Mol Life Sci. 2003 Sep;60(9):1990-7.

Lagouge M, Argmann C, Gerhart-Hines Z, Meziane H, Lerin C, Daussin F, Messadeq N, Milne J, Lambert P, Elliott P, Geny B, Laakso M, Puigserver P, Auwerx J. Resveratrol improves mitochondrial function and protects against metabolic disease by activating SIRT1 and PGC-1alpha. Cell. 2006 Dec 15;127(6):1109-22.

Lajoie P, Snapp EL. Formation and toxicity of soluble polyglutamine oligomers in living cells. PLoS One. 2010 Dec 28;5(12):e15245.

Landles C, Sathasivam K, Weiss A, Woodman B, Moffitt H, Finkbeiner S, Sun B, Gafni J, Ellerby LM, Trottier Y, Richards WG, Osmand A, Paganetti P, Bates GP. Proteolysis of mutant Huntingtin produces an exon 1 fragment that accumulates as an aggregated protein in neuronal nuclei in Huntington disease. J Biol Chem. 2010 Mar 19;285(12):8808-23.

Landry J, Slama JT, Sternglanz R. Role of NAD $(+)$ in the deacetylase activity of the SIR2like proteins. Biochem Biophys Res Commun. 2000 Nov 30;278(3):685-90.

Lange H, Thörner G, Hopf A, Schröder KF. Morphometric studies of the neuropathological changes in choreatic diseases. J Neurol Sci. 1976 Aug;28(4):401-25.

Langley B, Gensert JM, Beal MF, Ratan RR. Remodeling chromatin and stress resistance in the central nervous system: histone deacetylase inhibitors as novel and broadly effective neuroprotective agents. Curr Drug Targets CNS Neurol Disord. 2005 Feb;4(1):41-50.

Leblhuber F, Peichl M, Neubauer C, Reisecker F, Steinparz FX, Windhager E, Maschek W. Serum dehydroepiandrosterone and cortisol measurements in Huntington's chorea. J Neurol Sci. 1995 Sep;132(1):76-9. 
Legleiter J, Lotz GP, Miller J, Ko J, Ng C, Williams GL, Finkbeiner S, Patterson PH, Muchowski PJ. Monoclonal antibodies recognize distinct conformational epitopes formed by polyglutamine in a mutant Huntingtin fragment. J Biol Chem. 2009 Aug 7;284(32):21647-58.

Li H, Li SH, Yu ZX, Shelbourne P, Li XJ. Huntingtin aggregate-associated axonal degeneration is an early pathological event in Huntington's disease mice. J Neurosci. 2001 Nov 1;21(21):8473-81.

$\mathrm{Li} \mathrm{SH}, \mathrm{Li}$ XJ. Huntingtin-protein interactions and the pathogenesis of Huntington's disease. Trends Genet. 2004 Mar;20(3):146-54.

Li W, Serpell LC, Carter WJ, Rubinsztein DC, Huntington JA. Expression and characterization of full-length human Huntingtin, an elongated HEAT repeat protein. J Biol Chem. 2006 Jun 9;281(23):15916-22.

Li XJ, Li S. Proteasomal dysfunction in aging and Huntington disease. Neurobiol Dis. $2011 \mathrm{Jul} ; 43(1): 4-8$.

Li XJ, Li SH, Sharp AH, Nucifora FC Jr, Schilling G, Lanahan A, Worley P, Snyder SH, Ross CA. A Huntingtin-associated protein enriched in brain with implications for pathology. Nature. 1995 Nov 23;378(6555):398-402.

Li Y, Xu W, McBurney MW, Longo VD. SirT1 inhibition reduces IGF-I/IRS2/Ras/ERK1/2 signaling and protects neurons. Cell Metab. 2008 Jul;8(1):38-48.

Lione LA, Carter RJ, Hunt MJ, Bates GP, Morton AJ, Dunnett SB. Selective discrimination learning impairments in mice expressing the human Huntington's disease mutation. J Neurosci. 1999 Dec 1;19(23):10428-37.

Liu M, Wilk SA, Wang A, Zhou L, Wang RH, Ogawa W, Deng C, Dong LQ, Liu F. Resveratrol inhibits mTOR signaling by promoting the interaction between mTOR and DEPTOR. J Biol Chem. 2010 Nov 19;285(47):36387-94.

Lunkes A, Lindenberg KS, Ben-Haïem L, Weber C, Devys D, Landwehrmeyer GB, Mandel JL, Trottier Y. Proteases acting on mutant Huntingtin generate cleaved products that differentially build up cytoplasmic and nuclear inclusions. Mol Cell. 2002 Aug;10(2):259-69.

Luo S, Vacher C, Davies JE, Rubinsztein DC. Cdk5 phosphorylation of Huntingtin reduces its cleavage by caspases: implications for mutant Huntingtin toxicity. J Cell Biol. 2005 May 23;169(4):647-56.

Luthi-Carter R, Strand A, Peters NL, Solano SM, Hollingsworth ZR, Menon AS, Frey AS, Spektor BS, Penney EB, Schilling G, Ross CA, Borchelt DR, Tapscott SJ, Young AB, Cha $\mathrm{JH}$, Olson JM. Decreased expression of striatal signaling genes in a mouse model of Huntington's disease. Hum Mol Genet. 2000 May 22;9(9):1259-71.

Luthi-Carter R, Taylor DM, Pallos J, Lambert E, Amore A, Parker A, Moffitt H, Smith DL, Runne H, Gokce O, Kuhn A, Xiang Z, Maxwell MM, Reeves SA, Bates GP, Neri C, 
Thompson LM, Marsh JL, Kazantsev AG. SIRT2 inhibition achieves neuroprotection by decreasing sterol biosynthesis. Proc Natl Acad Sci U S A. 2010 Apr 27;107(17):7927-32.

Maher P, Dargusch R, Bodai L, Gerard PE, Purcell JM, Marsh JL. ERK activation by the polyphenols fisetin and resveratrol provides neuroprotection in multiple models of Huntington's disease. Hum Mol Genet. 2011 Jan 15;20(2):261-70.

Mangiarini L, Sathasivam K, Seller M, Cozens B, Harper A, Hetherington C, Lawton M, Trottier Y, Lehrach H, Davies SW, Bates GP. Exon 1 of the HD gene with an expanded CAG repeat is sufficient to cause a progressive neurological phenotype in transgenic mice. Cell. 1996 Nov 1;87(3):493-506.

Markianos M, Panas M, Kalfakis N, Vassilopoulos D. Plasma testosterone in male patients with Huntington's disease: relations to severity of illness and dementia. Ann Neurol. 2005 Apr;57(4):520-5.

Marsh JL, Pallos J, Thompson LM. Fly models of Huntington's disease. Hum Mol Genet. 2003 Oct 15;12 Spec No 2:R187-93.

Marsh JL, Walker H, Theisen H, Zhu YZ, Fielder T, Purcell J, Thompson LM. Expanded polyglutamine peptides alone are intrinsically cytotoxic and cause neurodegeneration in Drosophila. Hum Mol Genet. 2000 Jan 1;9(1):13-25.

Martindale D, Hackam A, Wieczorek A, Ellerby L, Wellington C, McCutcheon K, Singaraja R, Kazemi-Esfarjani P, Devon R, Kim SU, Bredesen DE, Tufaro F, Hayden MR. Length of Huntingtin and its polyglutamine tract influences localization and frequency of intracellular aggregates. Nat Genet. 1998 Feb;18(2):150-4.

McGuire JR, Rong J, Li SH, Li XJ. Interaction of Huntingtin-associated protein-1 with kinesin light chain: implications in intracellular trafficking in neurons. J Biol Chem. 2006 Feb 10;281(6):3552-9.

Menalled LB, Sison JD, Wu Y, Olivieri M, Li XJ, Li H, Zeitlin S, Chesselet MF. Early motor dysfunction and striosomal distribution of Huntingtin microaggregates in Huntington's disease knock-in miceJ Neurosci. 2002 Sep 15;22(18):8266-76.

Metzler M, Legendre-Guillemin V, Gan L, Chopra V, Kwok A, McPherson PS, Hayden MR. HIP1 functions in clathrin-mediated endocytosis through binding to clathrin and adaptor protein 2. J Biol Chem. 2001 Oct 19;276(42):39271-6.

Michalik A, Van Broeckhoven C. Proteasome degrades soluble expanded polyglutamine completely and efficiently. Neurobiol Dis. 2004 Jun;16(1):202-11.

Michan S, Sinclair D. Sirtuins in mammals: insights into their biological function. Biochem J. 2007 May 15;404(1):1-13.

Miller J, Arrasate M, Shaby BA, Mitra S, Masliah E, Finkbeiner S. Quantitative relationships between Huntingtin levels, polyglutamine length, inclusion body formation, and neuronal death provide novel insight into huntington's disease molecular pathogenesis. J Neurosci. 2010 Aug 4;30(31):10541-50. 
Miller VM, Nelson RF, Gouvion CM, Williams A, Rodriguez-Lebron E, Harper SQ, Davidson BL, Rebagliati MR, Paulson HL. CHIP suppresses polyglutamine aggregation and toxicity in vitro and in vivo. J Neurosci. 2005 Oct 5;25(40):9152-61.

Minamiyama M, Katsuno M, Adachi H, Waza M, Sang C, Kobayashi Y, Tanaka F, Doyu M, Inukai A, Sobue G. Sodium butyrate ameliorates phenotypic expression in a transgenic mouse model of spinal and bulbar muscular atrophy. Hum Mol Genet. 2004 Jun 1;13(11):1183-92.

Mochel F, Charles P, Seguin F, Barritault J, Coussieu C, Perin L, Le Bouc Y, Gervais C, Carcelain G, Vassault A, Feingold J, Rabier D, Durr A. Early energy deficit in Huntington disease: identification of a plasma biomarker traceable during disease progression. PLoS One. 2007 Jul 25;2(7):e647.

Modregger J, DiProspero NA, Charles V, Tagle DA, Plomann M. PACSIN 1 interacts with Huntingtin and is absent from synaptic varicosities in presymptomatic Huntington's disease brains. Hum Mol Genet. 2002 Oct 1;11(21):2547-58.

Montoya A, Price BH, Menear M, Lepage M. Brain imaging and cognitive dysfunctions in Huntington's disease. J Psychiatry Neurosci. 2006 Jan;31(1):21-9.

Morselli E, Maiuri MC, Markaki M, Megalou E, Pasparaki A, Palikaras K, Criollo A, Galluzzi L, Malik SA, Vitale I, Michaud M, Madeo F, Tavernarakis N, Kroemer G. The life span-prolonging effect of sirtuin-1 is mediated by autophagy. Autophagy. 2010 Jan;6(1):186-8.

Morton AJ, Wood NI, Hastings MH, Hurelbrink C, Barker RA, Maywood ES. Disintegration of the sleep-wake cycle and circadian timing in Huntington's disease. J Neurosci. 2005 Jan 5;25(1):157-63.

Myers RH, MacDonald ME, Koroshetz WJ, Duyao MP, Ambrose CM, Taylor SA, Barnes G, Srinidhi J, Lin CS, Whaley WL, Lazzarini AM, Schwarz M, Wolff G, Bird ED, Vonsattel JP, Gusella JF. De novo expansion of a (CAG)n repeat in sporadic Huntington's disease. Nat Genet. 1993 Oct;5(2):168-73.

Nagai Y, Fujikake N, Popiel HA, Wada K. Induction of molecular chaperones as a therapeutic strategy for the polyglutamine diseases. Curr Pharm Biotechnol. 2010 Feb;11(2):188-97.

Nakahata Y, Kaluzova M, Grimaldi B, Sahar S, Hirayama J, Chen D, Guarente LP, Sassone-Corsi P. The NAD+-dependent deacetylase SIRT1 modulates CLOCK-mediated chromatin remodeling and circadian control. Cell. 2008 Jul 25;134(2):329-40.

Nance MA, Myers RH. Juvenile onset Huntington's disease - clinical and research perspectives. Ment Retard Dev Disabil Res Rev. 2001;7(3):153-7.

Nasir J, Floresco SB, O'Kusky JR, Diewert VM, Richman JM, Zeisler J, Borowski A, Marth JD, Phillips AG, Hayden MR. Targeted disruption of the Huntington's disease gene 
results in embryonic lethality and behavioral and morphological changes in heterozygotes. Cell. 1995 Jun 2;81(5):811-23.

Newman BL, Lundblad JR, Chen Y, Smolik SM. A Drosophila homologue of Sir2 modifies position-effect variegation but does not affect life span. Genetics. 2002 Dec;162(4):1675-85.

Oakeshott S, Balci F, Filippov I, Murphy C, Port R, Connor D, Paintdakhi A, Lesauter J, Menalled L, Ramboz S, Kwak S, Howland D, Silver R, Brunner D. Circadian Abnormalities in Motor Activity in a BAC Transgenic Mouse Model of Huntington's Disease. PLoS Curr. 2011 Apr 5;3:RRN1225.

Ona VO, Li M, Vonsattel JP, Andrews LJ, Khan SQ, Chung WM, Frey AS, Menon AS, Li XJ, Stieg PE, Yuan J, Penney JB, Young AB, Cha JH, Friedlander RM. Inhibition of caspase-1 slows disease progression in a mouse model of Huntington's disease. Nature. 1999 May 20;399(6733):263-7.

Orr, HT. Microarrays and polyglutamine disorders: reports from the Hereditary Disease Array Group. Hum Mol Genet. 2002 Aug 15;11(17):1909-10.

Osterwalder T, Yoon KS, White BH, Keshishian H. A conditional tissue-specific transgene expression system using inducible GAL4. Proc Natl Acad Sci U S A. 2001 Oct 23;98(22):12596-601.

Outeiro TF, Kontopoulos E, Altmann SM, Kufareva I, Strathearn KE, Amore AM, Volk CB, Maxwell MM, Rochet JC, McLean PJ, Young AB, Abagyan R, Feany MB, Hyman BT, Kazantsev AG. Sirtuin 2 inhibitors rescue alpha-synuclein-mediated toxicity in models of Parkinson's disease. Science. 2007 Jul 27;317(5837):516-9.

Pacholec M, Bleasdale JE, Chrunyk B, Cunningham D, Flynn D, Garofalo RS, Griffith D, Griffor M, Loulakis P, Pabst B, Qiu X, Stockman B, Thanabal V, Varghese A, Ward J, Withka J, Ahn K. SRT1720, SRT2183, SRT1460, and resveratrol are not direct activators of SIRT1. J Biol Chem. 2010 Mar 12;285(11):8340-51.

Padinjat R, Andrews S. TRP channels at a glance. J Cell Sci. 2004 Nov 15;117(Pt 24):5707-9.

Palidwor GA, Shcherbinin S, Huska MR, Rasko T, Stelzl U, Arumughan A, Foulle R, Porras P, Sanchez-Pulido L, Wanker EE, Andrade-Navarro MA. Detection of alpha-rod protein repeats using a neural network and application to Huntingtin. PLoS Comput Biol. 2009 Mar;5(3):e1000304.

Pallier PN, Maywood ES, Zheng Z, Chesham JE, Inyushkin AN, Dyball R, Hastings MH, Morton AJ. Pharmacological imposition of sleep slows cognitive decline and reverses dysregulation of circadian gene expression in a transgenic mouse model of Huntington's disease. J Neurosci. 2007 Jul 18;27(29):7869-78.

Pallier PN, Morton AJ. Management of sleep/wake cycles improves cognitive function in a transgenic mouse model of Huntington's disease. Brain Res. 2009 Jul 7;1279:90-8. 
Pallos J, Bodai L, Lukacsovich T, Purcell JM, Steffan JS, Thompson LM, Marsh JL. Inhibition of specific HDACs and sirtuins suppresses pathogenesis in a Drosophila model of Huntington's disease. Hum Mol Genet. 2008 Dec 1;17(23):3767-75.

Pandey UB, Nie Z, Batlevi Y, McCray BA, Ritson GP, Nedelsky NB, Schwartz SL, DiProspero NA, Knight MA, Schuldiner O, Padmanabhan R, Hild M, Berry DL, Garza D, Hubbert CC, Yao TP, Baehrecke EH, Taylor JP. HDAC6 rescues neurodegeneration and provides an essential link between autophagy and the UPS. Nature. 2007 Jun 14;447(7146):859-63.

Parker JA, Arango M, Abderrahmane S, Lambert E, Tourette C, Catoire H, Néri C. Resveratrol rescues mutant polyglutamine cytotoxicity in nematode and mammalian neurons. Nat Genet. 2005 Apr;37(4):349-50.

Parker JA, Connolly JB, Wellington C, Hayden M, Dausset J, Neri C. Expanded polyglutamines in Caenorhabditis elegans cause axonal abnormalities and severe dysfunction of PLM mechanosensory neurons without cell death. Proc Natl Acad Sci U S A. 2001 Nov 6;98(23):13318-23.

Partridge L, Piper MD, Mair W. Dietary restriction in Drosophila. Mech Ageing Dev. 2005 Sep;126(9):938-50.

Penney JB Jr, Vonsattel JP, MacDonald ME, Gusella JF, Myers RH. CAG repeat number governs the development rate of pathology in Huntington's disease. Ann Neurol. 1997 May;41(5):689-92.

Petersén A, Larsen KE, Behr GG, Romero N, Przedborski S, Brundin P, Sulzer D. Expanded CAG repeats in exon 1 of the Huntington's disease gene stimulate dopaminemediated striatal neuron autophagy and degeneration. Hum Mol Genet. 2001 Jun $1 ; 10(12): 1243-54$.

Pfister JA, Ma C, Morrison BE, D'Mello SR. Opposing effects of sirtuins on neuronal survival: SIRT1-mediated neuroprotection is independent of its deacetylase activity. PLoS One. 2008;3(12):e4090.

Pollitt SK, Pallos J, Shao J, Desai UA, Ma AA, Thompson LM, Marsh JL, Diamond MI. A rapid cellular FRET assay of polyglutamine aggregation identifies a novel inhibitor. Neuron. 2003 Nov 13;40(4):685-94.

Pratley RE, Salbe AD, Ravussin E, Caviness JN. Higher sedentary energy expenditure in patients with Huntington's disease. Ann Neurol. 2000 Jan;47(1):64-70.

Ranen NG, Stine OC, Abbott MH, Sherr M, Codori AM, Franz ML, Chao NI, Chung AS, Pleasant N, Callahan C, Kasch LM, Ghaffari M, Chase GA, Kazazian HH, Brandt J, Folstein SE, Ross CA. Anticipation and instability of IT-15 (CAG)n repeats in parentoffspring pairs with Huntington disease. Am J Hum Genet. 1995 Sep;57(3):593-602.

Ravikumar B, Vacher C, Berger Z, Davies JE, Luo S, Oroz LG, Scaravilli F, Easton DF, Duden R, O'Kane CJ, Rubinsztein DC. Inhibition of mTOR induces autophagy and 
reduces toxicity of polyglutamine expansions in fly and mouse models of Huntington disease. Nat Genet. 2004 Jun;36(6):585-95.

Reddy PH, Williams M, Charles V, Garrett L, Pike-Buchanan L, Whetsell WO Jr, Miller G, Tagle DA. Behavioral abnormalities and selective neuronal loss in HD transgenic mice expressing mutated full-length HD cDNA. Nat Genet. 1998 Oct;20(2):198-202.

Rega S, Stiewe T, Chang DI, Pollmeier B, Esche H, Bardenheuer W, Marquitan G, Pützer BM. Identification of the full-length Huntingtin-interacting protein $\mathrm{p} 231 \mathrm{HBP} / \mathrm{HYPB}$ as a DNA-binding factor. Mol Cell Neurosci. 2001 Jul;18(1):68-79.

Reijonen S, Kukkonen JP, Hyrskyluoto A, Kivinen J, Kairisalo M, Takei N, Lindholm D, Korhonen L. Downregulation of NF-kappaB signaling by mutant Huntingtin proteins induces oxidative stress and cell death. Cell Mol Life Sci. 2010 Jun;67(11):1929-41.

Rogina B, Helfand SL. Sir2 mediates longevity in the fly through a pathway related to calorie restriction. Proc Natl Acad Sci U S A. 2004 Nov 9;101(45):15998-6003.

Rogina B, Helfand SL, Frankel S. Longevity regulation by Drosophila Rpd3 deacetylase and caloric restriction. Science. 2002 Nov 29;298(5599):1745.

Romero E, Cha GH, Verstreken P, Ly CV, Hughes RE, Bellen HJ, Botas J. Suppression of neurodegeneration and increased neurotransmission caused by expanded full-length Huntingtin accumulating in the cytoplasm. Neuron. 2008 Jan 10;57(1):27-40.

Rosas HD, Koroshetz WJ, Chen YI, Skeuse C, Vangel M, Cudkowicz ME, Caplan K, Marek K, Seidman LJ, Makris N, Jenkins BG, Goldstein JM. Evidence for more widespread cerebral pathology in early HD: an MRI-based morphometric analysis. Neurology. 2003 May 27;60(10):1615-20.

Rozas JL, Gómez-Sánchez L, Tomás-Zapico C, Lucas JJ, Fernández-Chacón R. Increased neurotransmitter release at the neuromuscular junction in a mouse model of polyglutamine disease. J Neurosci. 2011 Jan 19;31(3):1106-13.

Roze E, Betuing S, Deyts C, Marcon E, Brami-Cherrier K, Pagès C, Humbert S, Mérienne $\mathrm{K}$, Caboche J. Mitogen- and stress-activated protein kinase-1 deficiency is involved in expanded-Huntingtin-induced transcriptional dysregulation and striatal death. FASEB J. 2008 Apr;22(4):1083-93.

Rudenko O, Tkach V, Berezin V, Bock E. Detection of early behavioral markers of Huntington's disease in R6/2 mice employing an automated social home cage. Behav Brain Res. 2009 Nov 5;203(2):188-99.

Ryu H, Lee J, Hagerty SW, Soh BY, McAlpin SE, Cormier KA, Smith KM, Ferrante RJ. ESET/SETDB1 gene expression and histone H3 (K9) trimethylation in Huntington's disease. Proc Natl Acad Sci U S A. 2006 Dec 12;103(50):19176-81.

Sadri-Vakili G, Bouzou B, Benn CL, Kim MO, Chawla P, Overland RP, Glajch KE, Xia E, Qiu Z, Hersch SM, Clark TW, Yohrling GJ, Cha JH. Histones associated with 
downregulated genes are hypo-acetylated in Huntington's disease models. Hum Mol Genet. 2007 Jun 1;16(11):1293-306.

Sadri-Vakili G, Menon AS, Farrell LA, Keller-McGandy CE, Cantuti-Castelvetri I, Standaert DG, Augood SJ, Yohrling GJ, Cha JH. Huntingtin inclusions do not downregulate specific genes in the R6/2 Huntington's disease mouse. Eur J Neurosci. 2006 Jun;23(12):3171-5.

Sayer JA, Manczak M, Akileswaran L, Reddy PH, Coghlan VM. Interaction of the nuclear matrix protein NAKAP with HypA and Huntingtin: implications for nuclear toxicity in Huntington's disease pathogenesis. Neuromolecular Med. 2005;7(4):297-310.

Schaffar G, Breuer P, Boteva R, Behrends C, Tzvetkov N, Strippel N, Sakahira H, Siegers K, Hayer-Hartl M, Hartl FU. Cellular toxicity of polyglutamine expansion proteins: mechanism of transcription factor deactivation. Mol Cell. 2004 Jul 2;15(1):95-105.

Scherzinger E, Lurz R, Turmaine M, Mangiarini L, Hollenbach B, Hasenbank R, Bates GP, Davies SW, Lehrach H, Wanker EE. Huntingtin-encoded polyglutamine expansions form amyloid-like protein aggregates in vitro and in vivo. Cell. 1997 Aug 8;90(3):549-58.

Schilling B, Gafni J, Torcassi C, Cong X, Row RH, LaFevre-Bernt MA, Cusack MP, Ratovitski T, Hirschhorn R, Ross CA, Gibson BW, Ellerby LM. Huntingtin phosphorylation sites mapped by mass spectrometry. Modulation of cleavage and toxicity. J Biol Chem. 2006 Aug 18;281(33):23686-97.

Schilling G, Becher MW, Sharp AH, Jinnah HA, Duan K, Kotzuk JA, Slunt HH, Ratovitski T, Cooper JK, Jenkins NA, Copeland NG, Price DL, Ross CA, Borchelt DR. Intranuclear inclusions and neuritic aggregates in transgenic mice expressing a mutant NH2-terminal fragment of Huntingtin. Hum Mol Genet. 1999 Mar;8(3):397-407.

Seong IS, Woda JM, Song JJ, Lloret A, Abeyrathne PD, Woo CJ, Gregory G, Lee JM, Wheeler VC, Walz T, Kingston RE, Gusella JF, Conlon RA, Macdonald ME. Huntingtin facilitates polycomb repressive complex 2. Hum Mol Genet. 2010 Feb 15;19(4):573-83.

Shaw P. Awakening to the behavioral analysis of sleep in Drosophila. J Biol Rhythms. 2003 Feb;18(1):4-11.

Shelbourne PF, Killeen N, Hevner RF, Johnston HM, Tecott L, Lewandoski M, Ennis M, Ramirez L, Li Z, Iannicola C, Littman DR, Myers RM. A Huntington's disease CAG expansion at the murine $\mathrm{Hdh}$ locus is unstable and associated with behavioural abnormalities in mice. Hum Mol Genet. 1999 May;8(5):763-74.

Shi Y, Yang S, Troup S, Lu X, Callaghan S, Park DS, Xing Y, Yang X. Resveratrol induces apoptosis in breast cancer cells by E2F1-mediated up-regulation of ASPP1. Oncol Rep. 2011 Jun;25(6):1713-9.

Shiwach RS, Norbury CG. A controlled psychiatric study of individuals at risk for Huntington's disease. Br J Psychiatry. 1994 Oct;165(4):500-5. 
Sipione S, Rigamonti D, Valenza M, Zuccato C, Conti L, Pritchard J, Kooperberg C, Olson JM, Cattaneo E. Early transcriptional profiles in Huntingtin-inducible striatal cells by microarray analyses. Hum Mol Genet. 2002 Aug 15;11(17):1953-65.

Slepko N, Bhattacharyya AM, Jackson GR, Steffan JS, Marsh JL, Thompson LM, Wetzel R. Normal-repeat-length polyglutamine peptides accelerate aggregation nucleation and cytotoxicity of expanded polyglutamine proteins. Proc Natl Acad Sci U S A. 2006 Sep 26;103(39):14367-72.

Slow EJ, Graham RK, Osmand AP, Devon RS, Lu G, Deng Y, Pearson J, Vaid K, Bissada $\mathrm{N}$, Wetzel R, Leavitt BR, Hayden MR. Absence of behavioral abnormalities and neurodegeneration in vivo despite widespread neuronal Huntingtin inclusions. Proc Natl Acad Sci U S A. 2005 Aug 9;102(32):11402-7.

Smith R, Brundin P, Li JY. Synaptic dysfunction in Huntington's disease: a new perspective. Cell Mol Life Sci. 2005 Sep;62(17):1901-12.

Squitieri F, Cannella M, Simonelli M. CAG mutation effect on rate of progression in Huntington's disease. Neurol Sci. 2002 Sep;23 Suppl 2:S107-8.

Squitieri F, Gellera C, Cannella M, Mariotti C, Cislaghi G, Rubinsztein DC, Almqvist EW, Turner D, Bachoud-Lévi AC, Simpson SA, Delatycki M, Maglione V, Hayden MR, Donato SD. Homozygosity for CAG mutation in Huntington disease is associated with a more severe clinical course. Brain. 2003 Apr;126(Pt 4):946-55.

Stack EC, Del Signore SJ, Luthi-Carter R, Soh BY, Goldstein DR, Matson S, Goodrich S, Markey AL, Cormier K, Hagerty SW, Smith K, Ryu H, Ferrante RJ. Modulation of nucleosome dynamics in Huntington's disease. Hum Mol Genet. 2007 May $15 ; 16(10): 1164-75$.

Steffan JS. Does Huntingtin play a role in selective macroautophagy? Cell Cycle. 2010 Sep 1;9(17):3401-13.

Steffan JS, Agrawal N, Pallos J, Rockabrand E, Trotman LC, Slepko N, Illes K, Lukacsovich T, Zhu YZ, Cattaneo E, Pandolfi PP, Thompson LM, Marsh JL. SUMO modification of Huntingtin and Huntington's disease pathology. Science. 2004 Apr 2;304(5667):100-4.

Steffan JS, Bodai L, Pallos J, Poelman M, McCampbell A, Apostol BL, Kazantsev A, Schmidt E, Zhu YZ, Greenwald M, Kurokawa R, Housman DE, Jackson GR, Marsh JL, Thompson LM. Histone deacetylase inhibitors arrest polyglutamine-dependent neurodegeneration in Drosophila. Nature. 2001 Oct 18;413(6857):739-43.

Steffan JS, Kazantsev A, Spasic-Boskovic O, Greenwald M, Zhu YZ, Gohler H, Wanker EE, Bates GP, Housman DE, Thompson LM. The Huntington's disease protein interacts with p53 and CREB-binding protein and represses transcription. Proc Natl Acad Sci U S A. 2000 Jun 6;97(12):6763-8. 
Stine OC, Pleasant N, Franz ML, Abbott MH, Folstein SE, Ross CA. Correlation between the onset age of Huntington's disease and length of the trinucleotide repeat in IT-15. Hum Mol Genet. 1993 Oct;2(10):1547-9.

Sugars KL, Brown R, Cook LJ, Swartz J, Rubinsztein DC. Decreased cAMP response element-mediated transcription: an early event in exon 1 and full-length cell models of Huntington's disease that contributes to polyglutamine pathogenesis. J Biol Chem. 2004 Feb 6;279(6):4988-99.

Suhr ST, Senut MC, Whitelegge JP, Faull KF, Cuizon DB, Gage FH. Identities of sequestered proteins in aggregates from cells with induced polyglutamine expression. $\mathrm{J}$ Cell Biol. 2001 Apr 16;153(2):283-94.

Sun AY, Wang Q, Simonyi A, Sun GY. Resveratrol as a therapeutic agent for neurodegenerative diseases. Mol Neurobiol. 2010 Jun;41(2-3):375-83.

Sun XJ, Wei J, Wu XY, Hu M, Wang L, Wang HH, Zhang QH, Chen SJ, Huang QH, Chen Z. Identification and characterization of a novel human histone H3 lysine 36-specific methyltransferase. J Biol Chem. 2005 Oct 21;280(42):35261-71.

Sun Y, Savanenin A, Reddy PH, Liu YF. Polyglutamine-expanded Huntingtin promotes sensitization of N-methyl-D-aspartate receptors via post-synaptic density 95. J Biol Chem. $2001 \mathrm{Jul}$ 6;276(27):24713-8.

Takahashi T, Katada S, Onodera O. Polyglutamine diseases: where does toxicity come from? what is toxicity? where are we going? J Mol Cell Biol. 2010 Aug;2(4):180-91.

Takahashi T, Kikuchi S, Katada S, Nagai Y, Nishizawa M, Onodera O. Soluble polyglutamine oligomers formed prior to inclusion body formation are cytotoxic. Hum Mol Genet. 2008 Feb 1;17(3):345-56.

Takano H, Gusella JF. The predominantly HEAT-like motif structure of Huntingtin and its association and coincident nuclear entry with dorsal, an NF-kB/Rel/dorsal family transcription factor. BMC Neurosci. 2002 Oct 14;3:15.

Tang BL. Resveratrol is neuroprotective because it is not a direct activator of Sirt1-A hypothesis. Brain Res Bull. 2010 Mar 16;81(4-5):359-61.

Taylor JP, Taye AA, Campbell C, Kazemi-Esfarjani P, Fischbeck KH, Min KT. Aberrant histone acetylation, altered transcription, and retinal degeneration in a Drosophila model of polyglutamine disease are rescued by CREB-binding protein. Genes Dev. 2003 Jun $15 ; 17(12): 1463-8$.

Taylor N, Bramble D. Sleep disturbance and Huntingdon's disease. Br J Psychiatry. 1997 Oct; 171:393.

Thakur AK, Jayaraman M, Mishra R, Thakur M, Chellgren VM, Byeon IJ, Anjum DH, Kodali R, Creamer TP, Conway JF, Gronenborn AM, Wetzel R. Polyglutamine disruption of the Huntingtin exon $1 \mathrm{~N}$ terminus triggers a complex aggregation mechanism. Nat Struct Mol Biol. 2009 Apr;16(4):380-9. 
Thomas EA, Coppola G, Desplats PA, Tang B, Soragni E, Burnett R, Gao F, Fitzgerald KM, Borok JF, Herman D, Geschwind DH, Gottesfeld JM. The HDAC inhibitor 4b ameliorates the disease phenotype and transcriptional abnormalities in Huntington's disease transgenic mice. Proc Natl Acad Sci U S A. 2008 Oct 7;105(40):15564-9.

Thompson LM, Aiken CT, Kaltenbach LS, Agrawal N, Illes K, Khoshnan A, MartinezVincente M, Arrasate M, O'Rourke JG, Khashwji H, Lukacsovich T, Zhu YZ, Lau AL, Massey A, Hayden MR, Zeitlin SO, Finkbeiner S, Green KN, LaFerla FM, Bates G, Huang L, Patterson PH, Lo DC, Cuervo AM, Marsh JL, Steffan JS. IKK phosphorylates Huntingtin and targets it for degradation by the proteasome and lysosome. J Cell Biol. 2009 Dec 28;187(7):1083-99.

Thu DC, Oorschot DE, Tippett LJ, Nana AL, Hogg VM, Synek BJ, Luthi-Carter R, Waldvogel HJ, Faull RL. Cell loss in the motor and cingulate cortex correlates with symptomatology in Huntington's disease. Brain. 2010 Apr;133(Pt 4):1094-110.

Tie F, Banerjee R, Stratton CA, Prasad-Sinha J, Stepanik V, Zlobin A, Diaz MO, Scacheri PC, Harte PJ. CBP-mediated acetylation of histone H3 lysine 27 antagonizes Drosophila Polycomb silencing. Development. 2009 Sep;136(18):3131-41.

Todd PK, Oh SY, Krans A, Pandey UB, Di Prospero NA, Min KT, Taylor JP, Paulson HL. Histone deacetylases suppress CGG repeat-induced neurodegeneration via transcriptional silencing in models of fragile $\mathrm{X}$ tremor ataxia syndrome. PLoS Genet. 2010 Dec 9;6(12):e1001240.

Toma DP, White KP, Hirsch J, Greenspan RJ. Identification of genes involved in Drosophila melanogaster geotaxis, a complex behavioral trait. Nat Genet. 2002 Aug;31(4):349-53.

Turek FW, Gillette MU. Melatonin, sleep, and circadian rhythms: rationale for development of specific melatonin agonists. Sleep Med. 2004 Nov;5(6):523-32.

Valenza M, Rigamonti D, Goffredo D, Zuccato C, Fenu S, Jamot L, Strand A, Tarditi A, Woodman B, Racchi M, Mariotti C, Di Donato S, Corsini A, Bates G, Pruss R, Olson JM, Sipione S, Tartari M, Cattaneo E. Dysfunction of the cholesterol biosynthetic pathway in Huntington's disease. J Neurosci. 2005 Oct 26;25(43):9932-9.

Velier J, Kim M, Schwarz C, Kim TW, Sapp E, Chase K, Aronin N, DiFiglia M. Wildtype and mutant Huntingtins function in vesicle trafficking in the secretory and endocytic pathways. Exp Neurol. 1998 Jul;152(1):34-40.

Venkatraman P, Wetzel R, Tanaka M, Nukina N, Goldberg AL. Eukaryotic proteasomes cannot digest polyglutamine sequences and release them during degradation of polyglutamine-containing proteins. Mol Cell. 2004 Apr 9;14(1):95-104.

Videnovic A, Leurgans S, Fan W, Jaglin J, Shannon KM. Daytime somnolence and nocturnal sleep disturbances in Huntington disease. Parkinsonism Relat Disord. 2009 Jul;15(6):471-4. 
Von Horsten S, Schmitt I, Nguyen HP, Holzmann C, Schmidt T, Walther T, Bader M, Pabst R, Kobbe P, Krotova J, Stiller D, Kask A, Vaarmann A, Rathke-Hartlieb S, Schulz JB, Grasshoff U, Bauer I, Vieira-Saecker AM, Paul M, Jones L, Lindenberg KS, Landwehrmeyer B, Bauer A, Li XJ, Riess O. Transgenic rat model of Huntington's disease. Hum Mol Genet. 2003 Mar 15;12(6):617-24.

Vonsattel JP, DiFiglia M. Huntington disease. J Neuropathol Exp Neurol. 1998 May;57(5):369-84.

Vonsattel JP, Myers RH, Stevens TJ, Ferrante RJ, Bird ED, Richardson EP Jr. Neuropathological classification of Huntington's disease. J Neuropathol Exp Neurol. 1985 Nov;44(6):559-77.

Wacker JL, Zareie MH, Fong H, Sarikaya M, Muchowski PJ. Hsp70 and Hsp40 attenuate formation of spherical and annular polyglutamine oligomers by partitioning monomer. Nat Struct Mol Biol. 2004 Dec;11(12):1215-22.

Wang J, Chen J. SIRT1 regulates autoacetylation and histone acetyltransferase activity of TIP60. J Biol Chem. 2010 Apr 9;285(15):11458-64.

Wang J, Wang CE, Orr A, Tydlacka S, Li SH, Li XJ. Impaired ubiquitin-proteasome system activity in the synapses of Huntington's disease mice. J Cell Biol. 2008 Mar 24;180(6): 1177-89.

Wanker EE, Rovira C, Scherzinger E, Hasenbank R, Wälter S, Tait D, Colicelli J, Lehrach H. HIP-I: a Huntingtin interacting protein isolated by the yeast two-hybrid system. Hum Mol Genet. 1997 Mar;6(3):487-95.

Warrick JM, Paulson HL, Gray-Board GL, Bui QT, Fischbeck KH, Pittman RN, Bonini NM. Expanded polyglutamine protein forms nuclear inclusions and causes neural degeneration in Drosophila. Cell. 1998 Jun 12;93(6):939-49.

Wellington CL, Ellerby LM, Gutekunst CA, Rogers D, Warby S, Graham RK, Loubser O, van Raamsdonk J, Singaraja R, Yang YZ, Gafni J, Bredesen D, Hersch SM, Leavitt BR, Roy S, Nicholson DW, Hayden MR. Caspase cleavage of mutant Huntingtin precedes neurodegeneration in Huntington's disease. J Neurosci. 2002 Sep 15;22(18):7862-72.

Wellington CL, Ellerby LM, Hackam AS, Margolis RL, Trifiro MA, Singaraja R, McCutcheon K, Salvesen GS, Propp SS, Bromm M, Rowland KJ, Zhang T, Rasper D, Roy S, Thornberry N, Pinsky L, Kakizuka A, Ross CA, Nicholson DW, Bredesen DE, Hayden MR. Caspase cleavage of gene products associated with triplet expansion disorders generates truncated fragments containing the polyglutamine tract. J Biol Chem. 1998 Apr 10;273(15):9158-67.

Wellington CL, Hayden MR. Of molecular interactions, mice and mechanisms: new insights into Huntington's disease. Curr Opin Neurol. 1997 Aug;10(4):291-8.

Wellington CL, Singaraja R, Ellerby L, Savill J, Roy S, Leavitt B, Cattaneo E, Hackam A, Sharp A, Thornberry N, Nicholson DW, Bredesen DE, Hayden MR. Inhibiting caspase 
cleavage of Huntingtin reduces toxicity and aggregate formation in neuronal and nonneuronal cells. J Biol Chem. 2000 Jun 30;275(26):19831-8.

Wood JG, Rogina B, Lavu S, Howitz K, Helfand SL, Tatar M, Sinclair D. Sirtuin activators mimic caloric restriction and delay ageing in metazoans. Nature. 2004 Aug 5;430(7000):686-9.

Wyttenbach A. Role of heat shock proteins during polyglutamine neurodegeneration: mechanisms and hypothesis. J Mol Neurosci. 2004;23(1-2):69-96.

Wyttenbach A, Swartz J, Kita H, Thykjaer T, Carmichael J, Bradley J, Brown R, Maxwell M, Schapira A, Orntoft TF, Kato K, Rubinsztein DC. Polyglutamine expansions cause decreased CRE-mediated transcription and early gene expression changes prior to cell death in an inducible cell model of Huntington's disease. Hum Mol Genet. 2001 Aug 15;10(17):1829-45.

Yamamoto A, Lucas JJ, Hen R. Reversal of neuropathology and motor dysfunction in a conditional model of Huntington's disease. Cell. 2000 Mar 31;101(1):57-66.

Yanai A, Huang K, Kang R, Singaraja RR, Arstikaitis P, Gan L, Orban PC, Mullard A, Cowan CM, Raymond LA, Drisdel RC, Green WN, Ravikumar B, Rubinsztein DC, ElHusseini A, Hayden MR. Palmitoylation of Huntingtin by HIP14 is essential for its trafficking and function. Nat Neurosci. 2006 Jun;9(6):824-31.

Yang D, Wang CE, Zhao B, Li W, Ouyang Z, Liu Z, Yang H, Fan P, O'Neill A, Gu W, Yi $\mathrm{H}$, Li S, Lai L, Li XJ. Expression of Huntington's disease protein results in apoptotic neurons in the brains of cloned transgenic pigs. Hum Mol Genet. 2010 Oct 15;19(20):3983-94.

Yang SH, Cheng PH, Banta H, Piotrowska-Nitsche K, Yang JJ, Cheng EC, Snyder B, Larkin K, Liu J, Orkin J, Fang ZH, Smith Y, Bachevalier J, Zola SM, Li SH, Li XJ, Chan AW. Towards a transgenic model of Huntington's disease in a non-human primate. Nature. 2008 Jun 12;453(7197):921-4.

Yu ZX, Li SH, Nguyen HP, Li XJ. Huntingtin inclusions do not deplete polyglutaminecontaining transcription factors in HD mice. Hum Mol Genet. 2002 Apr 15;11(8):905-14.

Zeitlin S, Liu JP, Chapman DL, Papaioannou VE, Efstratiadis A. Increased apoptosis and early embryonic lethality in mice nullizygous for the Huntington's disease gene homologue. Nat Genet. 1995 Oct;11(2):155-63.

Zhang J. Resveratrol inhibits insulin responses in a SirT1-independent pathway. Biochem J. 2006 Aug 1;397(3):519-27.

Zhang S, Feany MB, Saraswati S, Littleton JT, Perrimon N. Inactivation of Drosophila Huntingtin affects long-term adult functioning and the pathogenesis of a Huntington's disease model. Dis Model Mech. 2009 May-Jun;2(5-6):247-66.

Zhang X, Smith DL, Meriin AB, Engemann S, Russel DE, Roark M, Washington SL, Maxwell MM, Marsh JL, Thompson LM, Wanker EE, Young AB, Housman DE, Bates 
GP, Sherman MY, Kazantsev AG. A potent small molecule inhibits polyglutamine aggregation in Huntington's disease neurons and suppresses neurodegeneration in vivo. Proc Natl Acad Sci U S A. 2005 Jan 18;102(3):892-7.

Zhang Y, Leavitt BR, van Raamsdonk JM, Dragatsis I, Goldowitz D, MacDonald ME, Hayden MR, Friedlander RM. Huntingtin inhibits caspase-3 activation. EMBO J. 2006 Dec 13;25(24):5896-906.

Zsindely N, Pankotai T, Ujfaludi Z, Lakatos D, Komonyi O, Bodai L, Tora L, Boros IM. The loss of histone $\mathrm{H} 3$ lysine 9 acetylation due to dSAGA-specific dAda2b mutation influences the expression of only a small subset of genes. Nucleic Acids Res. 2009 Nov;37(20):6665-80.

Zuccato C, Ciammola A, Rigamonti D, Leavitt BR, Goffredo D, Conti L, MacDonald ME, Friedlander RM, Silani V, Hayden MR, Timmusk T, Sipione S, Cattaneo E. Loss of Huntingtin-mediated BDNF gene transcription in Huntington's disease. Science. $2001 \mathrm{Jul}$ 20;293(5529):493-8.

Zuccato C, Tartari M, Crotti A, Goffredo D, Valenza M, Conti L, Cataudella T, Leavitt BR, Hayden MR, Timmusk T, Rigamonti D, Cattaneo E. Huntingtin interacts with REST/NRSF to modulate the transcription of NRSE-controlled neuronal genes. Nat Genet. 2003 Sep;35(1):76-83.

Zuccato C, Valenza M, Cattaneo E. Molecular mechanisms and potential therapeutical targets in Huntington's disease. Physiol Rev. 2010 Jul;90(3):905-81.

Zühlke C, Riess O, Bockel B, Lange H, Thies U. Mitotic stability and meiotic variability of the (CAG)n repeat in the Huntington disease gene. Hum Mol Genet. 1993 Dec;2(12):2063-7. 